Aus der Abteilung Pathologie

(Prof. Dr. med H-J. Radzun)

im Zentrum Pathologie und Rechtsmedizin

der Medizinischen Fakultät der Universität Göttingen

\title{
Expression und Funktion des Vitamin-D-Rezeptors in malignen Keimzelltumoren des Hodens
}

\author{
INAUGURAL-DISSERTATION \\ zur Erlangung des Doktorgrades \\ der Medizinischen Fakultät \\ der Georg-August-Universität zu Göttingen
}

vorgelegt von

Felix Bremmer

aus

Ludwigshafen am Rhein

Göttingen 2010 
Dekan:

1. Berichterstatter:

2. Berichterstatter/in:

3. Berichterstatter/in:
Prof. Dr. med. C. Frömmel

Priv.-Doz. Dr. med. S. Schweyer Juniorprofessor Dr. Johnsen

Priv.-Doz. Dr. med. Loertzer

Tag der mündlichen Prüfung: 02.03.2011 


\section{Inhaltsverzeichnis}

1 Einleitung................................................................................................................................... 1

1.1 Maligne Keimzelltumoren des Hodens ............................................................. 1

1.2 Vitamin-D3-Stoffwechsel und Vitamin-D-Rezeptor........................................ 4

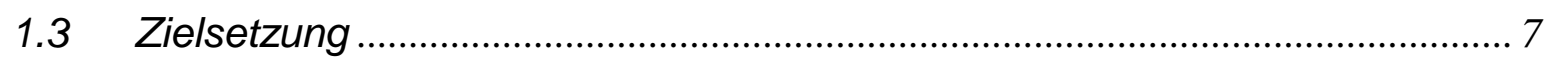

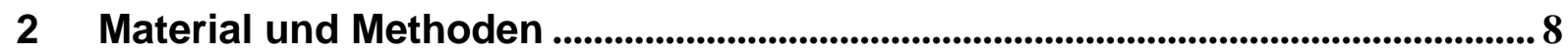

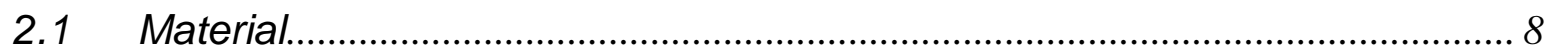

2.1.1 Molekularbiologische Agenzien ............................................................... 8

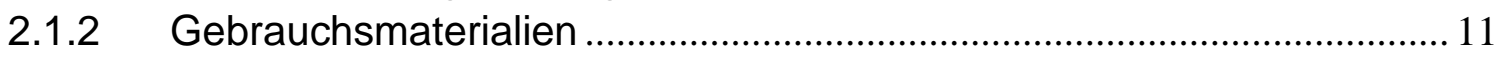

2.1.3 Technische Geräte .......................................................................... 12

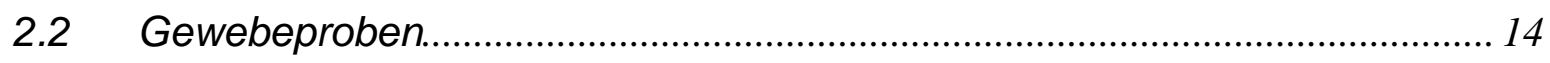

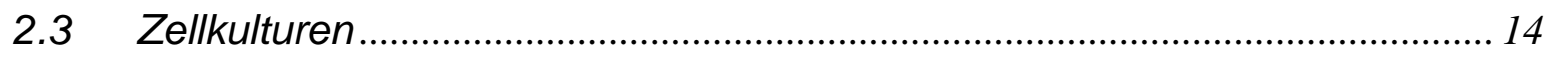

2.3.1 Tumorzelllinien NCCIT- und NTERA-2-Zelllinie ......................................... 14

2.3.2 Stimulation der Tumorzelllinien NTERA-2 und NCCIT mit Vitamin D3 . 15

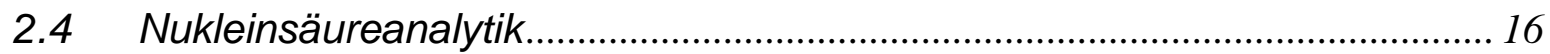

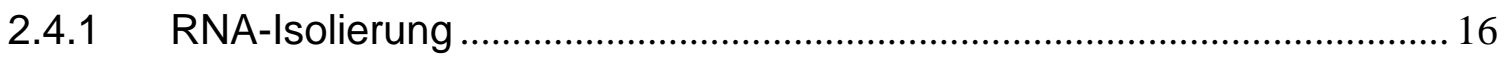

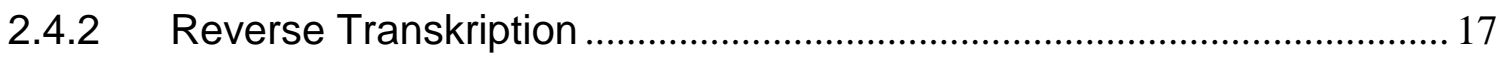

2.4.3 Quantitative Real-Time Polymerase Kettenreaktion (qRT-PCR) ........... 18

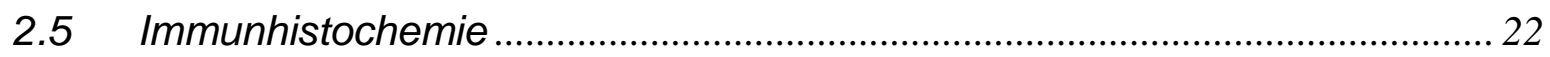

2.5.1 Herstellung von Parraffinschnitten .......................................................... 22

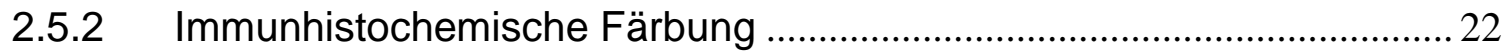

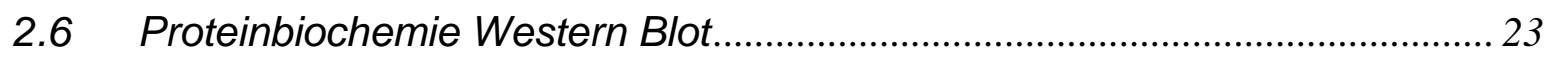

2.6.1 Homogenisierung und Zellaufschluss................................................... 23

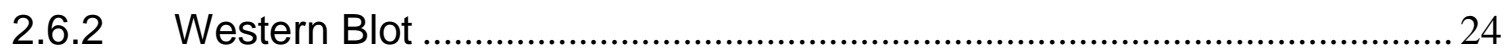

2.6.3 Wiederaufbereitung der Membran .............................................................. 25

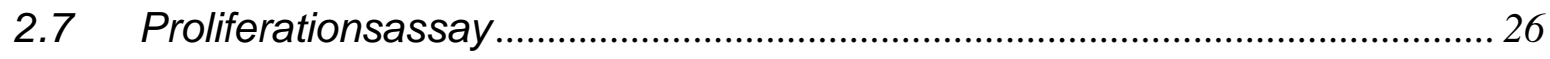

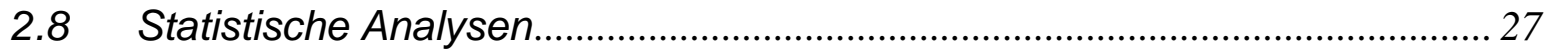

2.8.1 Auswertung der immunhistochemischen Versuche ................................2 27

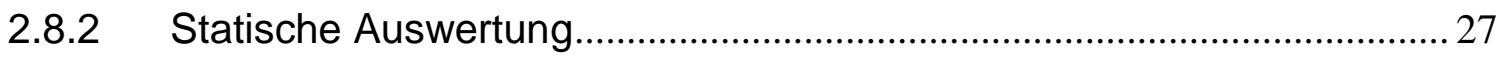

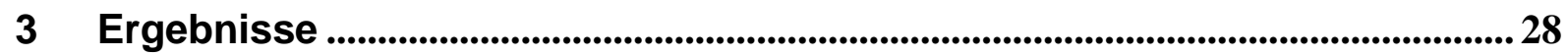

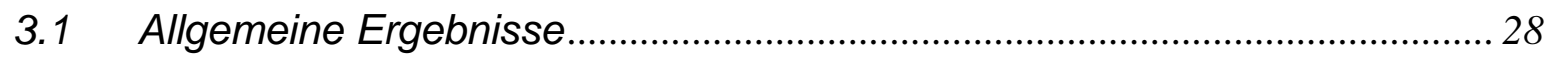

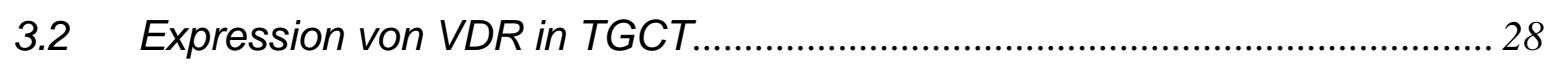

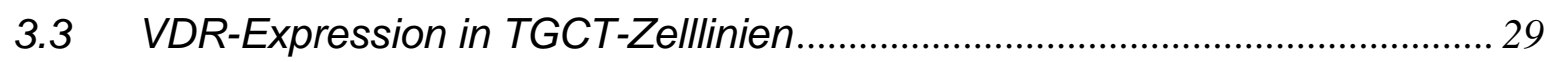

3.4 Vitamin-D3-vermitteltes Expressionsprofil von VDR und Koregulatoren in

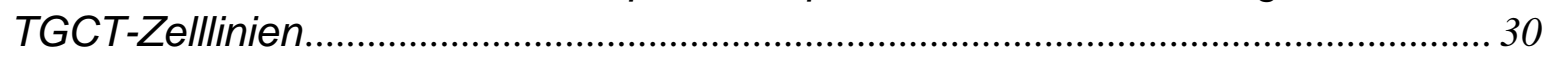


3.5 Proliferation der TGCT-Zelllinien NCCIT und NTERA-2 nach Stimulation mit Vitamin D3

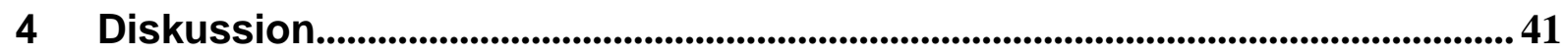

4.1 Expression von VDR in Malignomen und TGCT ....................................... 41

4.2 Regulation des Vitamin-D3-Polymorphismus in TGCT ................................ 44

4.3 Proliferationsverhalten von TGCT-Zelllinien nach Vitamin-D3-Stimulation.. 48

4.4 Therapeutische Aspekte von Vitamin D3 ........................................................ 49

5 Zusammenfassung ..................................................................................................................5 51

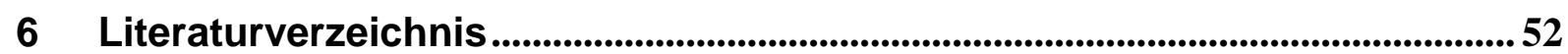

$7 \quad$ Abbildungsverzeichnis .........................................................................................................60

8 Tabellenverzeichnis .............................................................................................60 


\section{Abkürzungsverzeichnis}

$\%$

A

$A b b$

AFP

ARP

ATP

$\beta$-HCG

$\beta$-ME

bp

BrdU

BSA

$C$

${ }^{\circ} \mathrm{C}$

$\mathrm{Ca}^{2+}$

cDNA

$\mathrm{cm}$

$\mathrm{cm}^{2}$

CpG

$\mathrm{Ct}$

CTP

CYP24A1

CYP27B1

$\mathrm{DAB}$

$\triangle$

DEPC

DMEM

DNA

dNTPs

DTT

EDTA

ELISA
Prozent

Ampere

Abbildung

Alpha-Fetoprotein

Actin related Protein

Adenosin-5'-Triphosphat

$\beta$-humanes Choriongonadotropin

2-Mercaptoethanol

Basenpaare

Bromdesoxyuridin

Rinderserumalbumin

centi $\left(10^{-2}\right)$

Grad Celsius

Calcium

komplementäre DNA

Zentimeter

Quadratzentimeter

Cytosin-Phosphat-Guanin

Threshold Cycle

Cytidin-5'-Triphosphat

Cytochrome p450, family 24, subfamily A, polypeptide 1

Cytochrome p450, family 27 , subfamily $B$, polypeptide 1

3`,3`-Diaminobenzidin

delta

Diethylpyrocarbonat

Dulbecco's Modified Eagle's Medium

Desoxyribonukleinsäure

Desoxyribonukleosidtriphosphate

Dithiothreitol

Ethylendiamintetraacetat (Dinatriumsalz)

Enzyme Linked Immunosorbent Assay 


\begin{tabular}{|c|c|}
\hline FCS & Fötales Kälberserum \\
\hline g & Gramm \\
\hline GADD45 & Growth arrest and DNA-damage-inducible 45 \\
\hline GTP & Guanosin-5'-Triphosphat \\
\hline HEPES & 2-(4-(2-Hydroxyethyl)-1-piperazinyl)-ethansulfonsäure \\
\hline $\mathrm{H}_{2} \mathrm{O}$ & Wasser \\
\hline IGCNU & intratubular germ cell neoplasia unclassified type \\
\hline IU & International Unit = internationale Einheit \\
\hline JAA & Jodacetamid \\
\hline $\mathrm{m}$ & Meter \\
\hline M & Molarität \\
\hline $\mathrm{mA}$ & Milliampere \\
\hline mAK & Monoklonaler Antikörper \\
\hline MAPKAPK2 & Mitogen-activated protein kinase-activated protein kinase 2 \\
\hline$\mu g$ & Mikrogramm \\
\hline$\mu \mathrm{l}$ & Mikroliter \\
\hline$\mu \mathrm{m}$ & Mikrometer \\
\hline $\mathrm{ml}$ & Milliliter \\
\hline $\mathrm{mm}$ & Millimeter \\
\hline $\min$ & Minuten \\
\hline $\mathrm{n}$ & nano $\left(10^{-9}\right)$ \\
\hline NCOR1 & Nuclear receptor co-repressor 1 \\
\hline NCOR2 & Nuclear receptor co-repressor 2 \\
\hline $\mathrm{ng}$ & Nanogramm \\
\hline $\mathrm{nm}$ & Nanometer \\
\hline $\mathrm{nM}$ & Nano Molar \\
\hline PBS & Phosphat Buffered Saline \\
\hline PCR & Polymerase-Kettenreaktion \\
\hline PMSF & Phenylmethylsulfonylfluorid \\
\hline qRT-PCR & Quantitative Real-Time Polymerase Kettenreaktion \\
\hline RLT-Buffer & RNeasy Lysis-Puffer \\
\hline RNA & Ribonucleic acid \\
\hline RNAse & Ribonuklease \\
\hline RT & Reverse Transkription \\
\hline
\end{tabular}




$\begin{array}{ll}\text { RXR } & \text { Retinoidsäurerezeptor } \\ \text { SDS } & \text { Sodiumdodecylsulfat } \\ \text { TDS } & \text { testikuläres Dysgenesie-Syndrom } \\ \text { TGCT } & \text { testicular germ cell tumor(s) } \\ \text { TRIS } & \text { Tris-(Hydroxymethyl)-Aminomethan } \\ \text { TTP } & \text { Thymidin-5'-Trisphosphat } \\ \text { Upm } & \text { Umdrehungen pro Minute } \\ \text { UV } & \text { Ultraviolett } \\ \text { V } & \text { Volt } \\ \text { VDR } & \text { Vitamin-D-Rezeptor } \\ \text { VDREs } & \text { Vitamin-D-Rezeptor response elements }\end{array}$




\section{$1 \quad$ Einleitung}

\subsection{Maligne Keimzelltumoren des Hodens}

Die malignen Keimzelltumoren des Hodens (testicular germ cell tumors, TGCT) sind die häufigsten soliden malignen Tumoren des Mannes zwischen dem 20.-40. Lebensjahr und repräsentieren etwa 90\% aller Neubildungen des Hodens (Ekbom und Akre 1998, Haag P et al. 2007/08). Mit lediglich 1-2\% aller Tumorerkrankungen stellt diese Tumorgruppe jedoch eine seltene Tumorentität dar. Die Inzidenz der TGCT zeigt interessanterweise eine hohe geographische Streuung, wobei Deutschland neben Dänemark und der Schweiz das Land mit der höchsten Inzidenzrate ist. Die Inzidenzrate der TGCT beträgt in Deutschland etwa 9 Neuerkrankungsfällle auf 100.000 Einwohner und verzeichnete in den letzten 50 Jahren sowohl in Europa als auch den USA aus noch unbekannten Ursachen einen konstanten Anstieg (Bokemeyer et al. 1992, Krege et al. 2008a, Krege et al. 2008b). Die Suche nach Ursache(n) der TGCT ist von der Vorstellung geleitet, dass der Erkrankungsbeginn bereits in der Fötalperiode liegt und hierbei eine abnorme Differenzierung der primordialen Keimzellen stattfindet. Diese Vorstellung der fötalen Differenzierungsstörung von Keimzellen wird gestützt durch die bekannten Risikofaktoren der TGCT. So besitzen Männer mit einem Maldescencus testis (Kryptorchismus), einer gonadelen Dysgenesie, einer Hypospadie oder familiären Prädisposition ein deutlich erhöhtes Risiko für die Entstehung eines TGCT. Des Weiteren wird die Hypothese der fötalen Differenzierungsstörung der Keimzellen durch die Beobachtung gestützt, dass die männliche Infertilität mit einem erhöhten Risiko für TGCT einhergeht (Jacobsen et al. 2000). Da zwischen mangelhafter Funktion und fehlerhafter Entwicklung des männlichen Reproduktionssystems einerseits und malignen Keimzellneoplasien des Hodens andererseits eine Korrelation besteht, entwickelte sich in den letzten Jahren die Hypothese des testikulären Dysgenesie-Syndroms (TDS) (Pike et al. 1986, Hoei-Hansen et al. 2003). Das TDS kann als eine Art testikuläre Grunderkrankung angesehen werden, die funktionelle Läsionen wie fehlerhafte Spermatogenese und Infertilität, neoplastische Läsionen wie Mikrolithiasis und Keimzellneoplasien und ontogenetische Läsionen wie Kryptorchismus und Hypospadie zusammenfasst (Skakkebaek et al. 
2001, Hoei-Hansen et al. 2003). Abgesehen von den möglichen Ursachen der TGCT herrscht Klarheit darüber, dass die testikuläre intratubuläre Keimzellneoplasie (Intratubular germ cell neoplasia unclassified type, IGCNU) die nicht-invasive Vorläuferläsion invasiver TGCT darstellt (Herbst et al. 1996, Gray et al. 1998, Roelofs et al. 2000). Beim Übergang der nicht-invasiven IGCNU in invasive TGCT kommt es in über $90 \%$ der Fälle zu einer strukturellen Chromosenveränderung von Chromosom 12. Dabei lässt sich in etwa $80 \%$ ein Isochromosom 12, i(12p), beobachten, wobei die Verdopplung des kurzen Armes von Chromosom 12 uniparenteral ist. Die übrigen Fälle der TGCT zeigen ebenfalls strukturelle Veränderungen von Chromosom 12, so dass diesem eine zentrale Rolle bei der Invasivität der TGCT zukommt (Delozier-Blanchet et al. 1985, Samaniego et al. 1990, Rodriguez et al. 1992).

Die TCGT lassen sich klinisch-therapeutisch als auch histologisch in die zwei großen Gruppen der Seminome (55\%) und Nicht-Seminome (35\%) unterteilen. Die NichtSeminome werden entsprechend ihrer histologischen Differenzierung weiter in embryonale Karzinome, Teratome, Dottersacktumore und Chorionkarzinome unterschieden. Seminome sind die häufigsten TGCT und lassen sich histologisch in drei Gruppen einteilen: Das klassische Seminom, das Seminom mit synzytiotrophoblastären Riesenzellen und das spermatozytische Seminom. Die Tumorzellen des klassischen Seminoms sind groß, rund und weisen ein glykogenreiches, helles Plasma auf, in dem hyperchromatische Zellkerne mit deutlichen Nukleolen liegen, die charakteristischerweise in Gruppen angeordnet und von Bindegewebssepten umgeben sind. Seminome mit trophoblastären Riesenzellen besitzen typischerweise $\beta-H C G$ produzierende synzytiotrophoblastäre Riesenzellen, die zu einer Erhöhung von $\beta$-HCG im Serum auch bei Seminomen führen können. Nicht-seminomatöse Keimzelltumoren zeigen ein bunteres mikroskopisches Erscheinungsbild. Das embryonale Karzinom ist der zweithäufigste TGCT, wobei die Tumorzellen entdifferenzierte Epithelien nachahmen. Die deutlich seltener vorkommenden Teratome zeigen mikroskopisch Gewebsabkömmlinge aller drei Keimblätter, wobei typischerweise epitheliale Zysten, Hautanhangsgebilde, Muskeln, Knorpel und Knochen sowie Darm und Bronchialschleimhaut zu beobachten sind. Der Dottersacktumor tritt zu 75\% bei Kleinkindern auf und macht nur $2 \%$ aller Keimzelltumoren aus. Mikroskopisch zeigen die Tumorzellformationen in der Regel 
mikrozystische Areale unter Ausbildung so genannter Schiller-Duval-Körperchen. Die Dottersacktumoren weisen immunhistochemisch eine Expression von $\alpha$-Fetoprotein (AFP) auf. AFP wird von den Tumorzellen sezerniert und lässt sich als Tumormarker im Serum bei TGCT mit Dottersacktumoranteilen bestimmen (Riede et al. 2004, Mikuz 2008). Das Chorionkarzinom ist der seltenste TGCT, der Plazentagewebe nachahmt und aus trophoblastären und synzytiotrophoblastären Tumorzellen besteht. Die Tumorzellen besitzen immunhistochemisch eine Expression des $\beta$-HCG, welches sezerniert wird und dann im Blut als Tumormarker bei TGCT zur Verfügung steht.

Bei der Symptomatik der Hodentumoren steht meist eine schmerzlose Vergrößerung des Hodens im Vordergrund. Klinisch teilt man maligne Keimzelltumoren des Mannes nach Lugano in 3 Stadien ein, bei der die Ausbreitung des Tumors berücksichtigt wird. Die Diagnostik der malignen Hodentumoren umfasst neben bildgebenden Verfahren (unter anderem Sonographie, Computertomographie und Magnetresonanztomographie) auch die Bestimmung der Tumormarker AFP, $\beta$-HCG und Laktatdehydrogenase. Als therapeutische Maßnahmen stehen Kombinationen aus Operation und Radio/Chemotherapie zur Verfügung (Krege et al. 2008a, Krege et al. 2008b). 


\subsection{Vitamin-D3-Stoffwechsel und Vitamin-D-Rezeptor}

Vitamin D3 gehört in die Gruppe der fettlöslichen Vitamine und entfaltet über seinen aktiven Metaboliten 1,25-Dihydroxycholecalciferol in Darm, Knochen, Nieren und Nebenschilddrüsen seine spezifischen Wirkungen. Wird der Tagesbedarf von $5 \mu \mathrm{g}$ nicht erreicht, können Vitamin-D3-Mangelerscheinungen wie Rachitis und Osteomalazie entstehen (Richter und Eckardstein 2006). Die Synthese des Vitamin D3 läuft im Körper in verschiedenen Organen ab und ist abhängig von unterschiedlichen Faktoren. Vitamin D3 kann zum einen über die Nahrung aufgenommen werden oder aus 7-Dehydrocholesterol in der Haut unter Einfluss von UV-Licht synthetisiert werden (Hollis 2005). In der Leber wird das in der Haut synthetisierte Prävitamin D3 an dem 25-C-Atom durch eine mitochondrial und mikrosomal gelegene 25-Hydroxylase hydroxyliert. Die $1 \alpha$-Hydroxylase hydroxyliert in der Niere den Hauptmetabolit von Vitamin D3, das 25-Hydroxycholecalciferol, an der C1-Position.

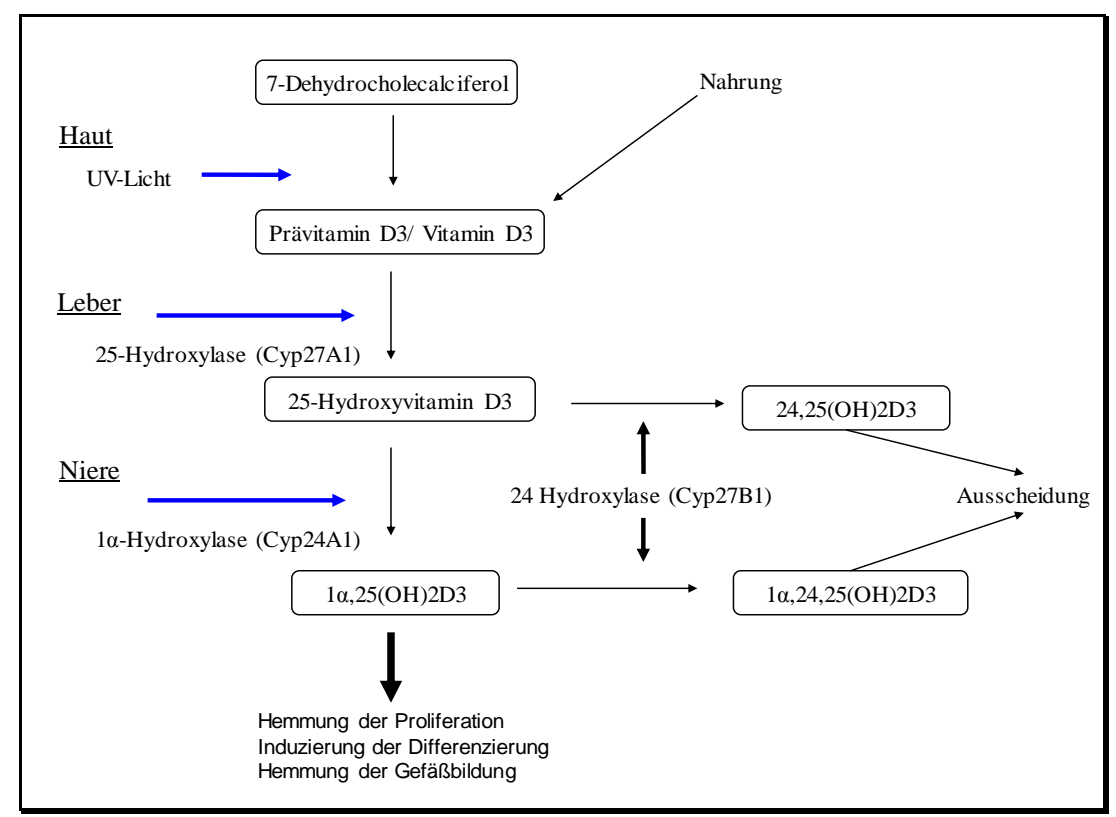

Abbildung 1: Vitamin-D3-Stoffwechsel und Metabolismus; modifiziert nach Deeb et al. (2007), S.688 
Die 24-Hydroxylase hydroxyliert sowohl $1 \alpha, 25(\mathrm{OH})_{2} \mathrm{D}_{3}$ als auch $25(\mathrm{OH}) \mathrm{D}_{3}$ an dem 24-C-Atom und ist der limitierende Schritt im Katabolismus von $25(\mathrm{OH}) \mathrm{D}_{3}$ und $1 \alpha, 25(\mathrm{OH})_{2} \mathrm{D}_{3}$. Die entstandenen Metabolite $24,25(\mathrm{OH})_{2} \mathrm{D}_{3}$ und $1 \alpha, 24,25(\mathrm{OH})_{2} \mathrm{D}_{3}$ werden ausgeschieden oder haben regulatorischen Einfluss auf den Vitamin D3 Stoffwechsel. Die Serumkonzentrationen von $1 \alpha, 25(\mathrm{OH})_{2} \mathrm{D}_{3}$ sind streng von einem Rückkopplungsmechanismus reguliert, der zum einen die Metaboliten direkt und zum anderen die Synthese auf genetischer Ebene beeinflusst. Bei der direkten Regulation induziert $24,25(\mathrm{OH})_{2} \mathrm{D}_{3}$ die Synthese von $1 \alpha, 25(\mathrm{OH})_{2} \mathrm{D}_{3}$, während $\mathrm{Ca}^{2+}$, Phosphat und $1 \alpha, 25(\mathrm{OH})_{2} \mathrm{D}_{3}$ selbst die Synthese unterdrücken (Takeyama et al. 1997, Haussler et al. 1998, Brenza und Deluca 2000, Hewison et al. 2000). Der entstandene Metabolit $1 \alpha, 25(\mathrm{OH})_{2} \mathrm{D}_{3}$ führt im Darm zu einer vermehrten Resorption von $\mathrm{Ca}^{2+}$ und Phosphat, im Knochen fördert es die Mineralisation und bei Zellen des Immunsystems (Makrophagen) hat es Einfluss auf deren Differenzierung. Die $1 \alpha-$ Hydroxylase wird aber auch in extrarenalen Zellen von Kolon, Gehirn, Plazenta, Pankreas, Lymphknoten und der Haut exprimiert, um hier eine lokale Umwandlung von $25(\mathrm{OH})_{2} \mathrm{D}_{3} \mathrm{zu} \quad 1 \alpha, 25(\mathrm{OH})_{2} \mathrm{D}_{3}$ zu ermöglichen (Zehnder et al. 2001). Das entstandene 1,25-Dihydroxycholecalciferol ist das aktive Hormon und entfaltet seine Wirkung über den Vitamin-D-Rezeptor (VDR) (Haussler et al. 1998).

Der VDR gehört wie die Retinoid-, Thyroid- und Östrogen-Hormon-Rezeptoren zu der Familie der Steroidhormonrezeptoren. $\mathrm{Er}$ ist ein Liganden-aktivierter Transkriptionsfaktor und wird auf Chromosom 12 kodiert (Hsieh et al. 1998, Michigami et al. 1999, Yasmin et al. 2005). Nach intrazellulärer Bindung von $1 \alpha, 25(\mathrm{OH})_{2} \mathrm{D}_{3}$ an den VDR kommt es im Zellkern zu einer Heterodimerisation mit dem Retinoidsäurerezeptor (RXR). Das VDR/RXR-Heterodimer bindet an VDR response elements (VDREs) der DNA. Mit der Bindung des VDR/RXR-Komplexes an die VDREs können die Expression und Repression von Zielgenen des $1 \alpha, 25(\mathrm{OH})_{2} \mathrm{D}_{3}$ beeinflusst werden (Haussler et al. 1998). 


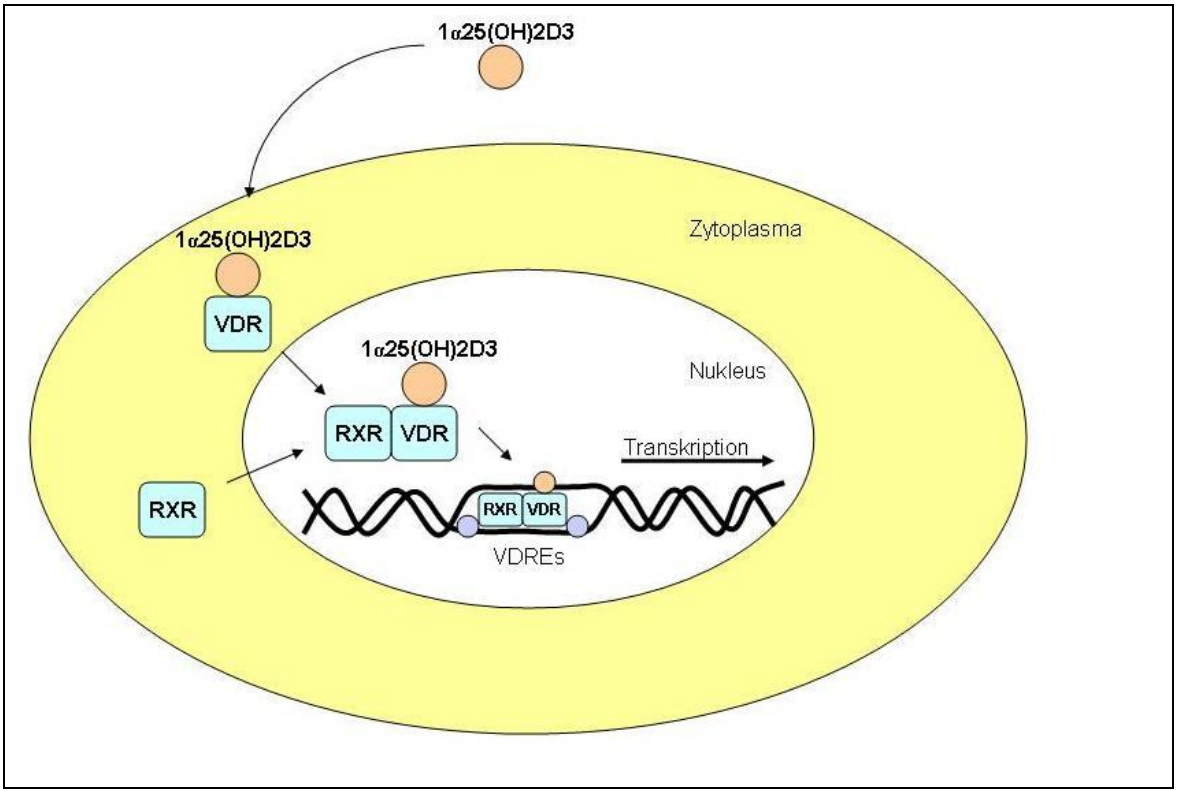

Abbildung 2: Zelluläre Wirkung von Vitamin D3; modifiziert nach Haussler et al. (1998), S.339

Neben den bekannten physiologischen Wirkungen von 1,25-Hydroxycholecalciferol auf Niere, Knochen, Darm und Nebenschilddrüse wurde in den letzten zwei Jahrzehnten zunehmend der Einfluss des Vitamin-D3-Stoffwechsels in Tumoren des Menschen untersucht. So konnten mehrere Arbeitsgruppen in verschiedenen Malignomen wie der Prostata, Mamma, Niere und des Kolons eine Erhöhung der VDR-Expression aufzeigen. Des Weiteren wurde in diesen Tumoren neben einem Vitamin-D3-induzierten Effekt auf die Proliferation auch die Auswirkung auf die Differenzierung der Tumorzellen untersucht und dargestellt (Skowronski et al. 1993, Friedrich et al. 1998, Conde et al. 2004).

An der Regulation des Zellzyklus, der Signaltransduktion und Interaktion mit Thyroidhormonrezeptoren sind neben dem VDR unterschiedliche Gene beteiligt. CYP27B1 und CYP24A1 sind zwei entscheidende Enzyme der Vitamin-D3-Synthese und greifen an verschiedenen Stellen regulierend in den Stoffwechsel des Vitamins D3 ein (Haussler et al. 1998). NCOR1 ist ein essentielles Protein bei der Interaktion mit Thyroidhormon- und Retinsäure-Rezeptoren. Es vermittelt eine Unterdrückung der Transkription von Thyroidhormon- sowie Retinsäure-Rezeptoren und sorgt durch eine Chromatin-Kondensation für eine Unterdrückung bestimmter Transkriptionsfaktoren (Horlein et al. 1995). NCOR2 spielt in der transkriptionellen Regulation nukleärer Hormonrezeptoren eine wichtige Rolle. Es führt durch Demethylierung von Histonproteinen zu einer Repression der Transkription. Nukleäre Hormonrezeptoren 
werden so in der Inhibition von Zielgenen unterstützt (Chen und Evans 1995, Sande und Privalsky 1996, Nagy et al. 1997). Das Protein TRIP 15, auch CSN2 genannt, ist als Bestandteil des COP9/Signalosome Komplexes an der Regulation unterschiedlicher Zell-Signalwege sowie des Zellzyklus beteiligt. Es hat nach Ligandenbindung Einfluss auf Thyroidhormon- und Retinsäure-X-Rezeptoren (RXR) (Lee et al. 1995, Seeger et al. 1998, Schaefer et al. 1999). MAPKAPK2 kodiert für das gleichnamige Protein, ist im p38 MAPK Signaltransduktionsweg beteiligt und hat Einfluss auf den Zellzyklus (Stokoe et al. 1992, Stokoe et al. 1993, Rouse et al. 1994). GADD45 ist an der Replikation der DNA, des G1-Zellzyklusarrest und durch die Unterdrückung von Protoonkogenen an antiproliferativen Effekten in Tumorzellen beteiligt. Es wirkt direkt proapototisch und hat Einfluss auf die DNA Reperatur (Fornace et al. 1992, Liebermann und Hoffman 1998, Takekawa und Saito 1998, Mita et al. 2002).

\subsection{Zielsetzung}

In mehreren Studien konnte bisher in malignen Tumoren wie dem Prostata- oder Mammakarzinom eine Expression des VDR gezeigt werden (Skowronski et al. 1993, Conde et al. 2004, W. Liu et al. 2006). Interessanterweise zeigte die VDR-vermittelte Wirkung des Vitamin D3 in den Tumorzellen eine antiproliferative als auch tumorfördernde Wirkung.

Die Ziele der vorliegenden Arbeit waren (I) die Expressionsanalyse von VDR und von Vitamin-D3-regulierten Genen in primären TGCT und TGCT-Zelllinien mittels qRTPCR, Immunhistochemie und Western Blot und (II) die Funktionsanalyse von Vitamin D3 in TGCT-Zelllinien. 


\section{Material und Methoden}

\subsection{Material}

\subsubsection{Molekularbiologische Agenzien}

\begin{tabular}{|l|l|}
\hline Agens & Hersteller \\
\hline$\beta$-ME & Sigma, München, Deutschland \\
\hline Aceton & Merck, Darmstadt, Deutschland \\
\hline Agarose & Sat Lab, Ahrensburg, Deutschland \\
\hline Agilent RNA 6000 Nano-Kit & $\begin{array}{l}\text { Agilent Technologies, } \\
\text { Deutschland }\end{array}$ \\
\hline Anti-BrdU-Block & Roche, Basel, Schweiz \\
\hline Aqua bidest & Roth, Karlsruhe, Deutschland \\
\hline Aqua dest & Universitätsmedizin, Göttingen, Deutschland \\
\hline Aquamount Aquatex & Merck, Darmstadt, Deutschland \\
\hline BrdU & Roche, Basel, Schweiz \\
\hline BSA V & Paesel \& Lorei, Hanau, Deutschland \\
\hline Chloralhydrat & Merck, Darmstadt, Deutschland \\
\hline Citronensäure-Monohydrat & Merck, Darmstadt, Deutschland \\
\hline DAB-Chromogen & Dako, Hamburg, Deutschland \\
\hline DEPC & Sigma, München, Deutschland \\
\hline DMEM & Sigma, München, Deutschland \\
\hline dNTPs-Mix, 5mM & Qiagen, Hilden, Deutschland \\
\hline DTT & Sigma, München, Deutschland \\
\hline
\end{tabular}




\begin{tabular}{|l|l|}
\hline LDS Samplepuffer + 4x Bromphenolblau & Invitrogen, Karlsruhe, Deutschland \\
\hline ECL-Western-Blot-Analysis-System & $\begin{array}{l}\text { Amersham Buchler, } \\
\text { Deutschland }\end{array}$ \\
\hline EDTA & Sigma, München, Deutschland \\
\hline ELISA Reader & BioRad, München, Deutschland \\
\hline Essigsäure & Merck, Darmstadt, Deutschland \\
\hline FCS & Paa Laboratories, Linz, Österreich \\
\hline Glycerin & Sigma, München, Deutschland \\
\hline Glycin & Roth, Karlsruhe, Deutschland \\
\hline Hämatoxylin & Merck, Darmstadt, Deutschland \\
\hline HEPES-Puffer, Buffer-Solution, 1M & Paa Laboratories, Linz, Österreich \\
\hline HOPE-I- und -II-Lösung & DCS, Hamburg, Deutschland \\
\hline HotStar Taq Master Mix & Qiagen, Hilden, Deutschland \\
\hline Isopropanol & Merck, Darmstadt, Deutschland \\
\hline JAA & Sigma, München, Deutschland \\
\hline Kaliumaluminiumsulfat-Dodecahydrat & Merck, Darmstadt, Deutschland \\
\hline L-Glutamin, 200mM & Biochrom, Berlin, Deutschland \\
\hline LINK/LABEL-Detektionssystem & Dako, Hamburg, Deutschland \\
\hline Magermilchpulver & Merck, Darmstadt, Deutschland \\
\hline mAK gegen VDR & $\begin{array}{l}\text { Santa Cruz Biotechnology, Heidelberg, } \\
\text { Deutschland }\end{array}$ \\
\hline Methanol & Merck, Darmstadt, Deutschland \\
\hline Natriumchlorid & Merck, Darmstadt, Deutschland \\
\hline Natriumjodat & Merck, Darmstadt, Deutschland \\
\hline NCCIT-Zelllinie & American Type Culture Collection, Manassas, \\
\hline
\end{tabular}




\begin{tabular}{|l|l|}
\hline NTERA-2-Zellinie & $\begin{array}{l}\text { American Type Culture Collection, Manassas, } \\
\text { USA }\end{array}$ \\
\hline Omniscript Reverse Transkriptase & Qiagen, Hilden, Deutschland \\
\hline Omniscript RT-PCR Kit & Qiagen, Hilden, Deutschland \\
\hline PBS-Puffer & Biochrom, Berlin, Deutschland \\
\hline Penicillin-Streptomycin & Invitrogen, Karlsruhe, Deutschland \\
\hline PMSF & Sigma, München, Deutschland \\
\hline PCR-Primer & MWG, München, Deutschland \\
\hline Random Hexamer Primer & Invitrogen, Karlsruhe, Deutschland \\
\hline Ribonuclease-Inhibitor & Fermentas, St. Leon-Rot, Deutschland \\
\hline RLT-Puffer & Qiagen, Hilden, Deutschland \\
\hline RNAse freies Wasser & Fermentas, St. Leon-Rot, Deutschland \\
\hline RPE-Wash-Puffer & Qiagen, Hilden, Deutschland \\
\hline RPMI 1640, Amino-Acids-Solution & Sigma, München, Deutschland \\
\hline RT-Puffer & Qiagen, Hilden, Deutschland \\
\hline RW1-Wasch-Puffer & Qiagen, Hilden, Deutschland \\
\hline Salzsäure & Merck, Darmstadt, Deutschland \\
\hline Schwefelsäure & Merck, Darmstadt, Deutschland \\
\hline SDS-Running-Puffer & Invitrogen, Karlsruhe, Deutschland \\
\hline Sodiumdodecylsulfat & Sigma, München, Deutschland \\
\hline Streptomycin & Sigma, München, Deutschland \\
\hline SYBR-Green & BioRad, München, Deutschland \\
\hline Taq-DNA-Polymerase (1000U) & Amersham Pharmacia Biotech, Freiburg, \\
\hline Taq-Puffer (10×) & Deutschland \\
\hline
\end{tabular}




\begin{tabular}{|l|l|}
\hline TRIS & Roth, Karlsruhe, Deutschland \\
\hline Trypsin/ EDTA Solution 10x & Biochrom, Berlin, Deutschland \\
\hline Vitamin D3 & Sigma, München, Deutschland \\
\hline Wasserstoffperoxid & Merck, Darmstadt, Deutschland \\
\hline
\end{tabular}

\subsubsection{Gebrauchsmaterialien}

\begin{tabular}{|c|c|}
\hline Material & Hersteller \\
\hline 96-well Platte & Nunc, Langenselbold, Deutschland \\
\hline Auslaufpipette (5ml, $10 \mathrm{ml}, 15 \mathrm{ml})$ & Sarstedt, Nümbrecht, Deutschland \\
\hline Deckgläser & Menzel-Gläser, Braunschweig, Deutschland \\
\hline Falcon-Tubes, $50 \mathrm{ml}$ & Sarstedt, Nümbrecht, Deutschland \\
\hline Gießkammer für horizontale Gele & Biometra, Göttingen, Deutschland \\
\hline Gießkammer für vertikale Gele & Biometra, Göttingen, Deutschland \\
\hline Kanüle, $\varnothing 50 \mu \mathrm{m}$ & Braun, Melsungen, Deutschland \\
\hline $\begin{array}{l}\text { Klebefolie I-Cycler IQ Optical Quality } \\
\text { Sealing tape }\end{array}$ & $\begin{array}{l}\text { BioRad Laboratories, München, } \\
\text { Deutschland }\end{array}$ \\
\hline $\begin{array}{l}\text { Kolbenhub-Pipetten }(0,1-2,5 \mu \mathrm{l}, 0,5-10 \mu \mathrm{l} \text {, } \\
10-100 \mu \mathrm{l}, 100-1000 \mu \mathrm{l})\end{array}$ & Eppendorf, Hamburg, Deutschland \\
\hline Mini-Cell-Kammer, XCellSureLock & Invitrogen, Karlsruhe, Deutschland \\
\hline PCR-Multiplates & $\begin{array}{l}\text { BioRad Laboratories, München, } \\
\text { Deutschland }\end{array}$ \\
\hline Pipettenspitzen $(10 \mu \mathrm{l}, 100 \mu \mathrm{l}, 1000 \mu \mathrm{l})$ & Sarstedt, Nümbrecht, Deutschland \\
\hline Pipettenspitzen $(2,5 \mu \mathrm{l})$ & $\begin{array}{l}\text { Biozym Diagnostik, Hess. Oldendorf, } \\
\text { Deutschland }\end{array}$ \\
\hline Polymermembran für Western Blot & Schleicher \& Schüll, Dassel, Deutschland \\
\hline
\end{tabular}




\begin{tabular}{|l|l|}
\hline Polystyrol Röhrchen, konisch (15ml, 50 ml) & $\begin{array}{l}\text { Greiner Bio-One, Frickenhausen, } \\
\text { Deutschland }\end{array}$ \\
\hline Rneasy Mini Kit & Qiagen, Hilden, Deutschland \\
\hline Röntgenkassette Hyperfilm ECL & $\begin{array}{l}\text { Amersham Buchler, Braunschweig, } \\
\text { Deutschland }\end{array}$ \\
\hline NuPAGE-Gele (10 Well) & Invitrogen, Karlsruhe, Deutschland \\
\hline Standard-Reaktionsgefäße $(0,5 \mathrm{ml}, 1.5 \mathrm{ml})$ & Eppendorf, Hamburg, Deutschland \\
\hline Triton $\mathrm{X}_{100}$ & Sigma, München, Deutschland \\
\hline Whatman-Paper & Roth, Karlsruhe, Deutschland \\
\hline Zählkammer Neubauer & Brand, Wertheim, Deutschland \\
\hline Zellkulturflaschen $\left(25 \mathrm{~cm}^{2}, 75 \mathrm{~cm}^{2}\right)$ & Sarstedt, Nümbrecht, Deutschland \\
\hline Zellschaber & Sarstedt, Nümbrecht, Deutschland \\
\hline
\end{tabular}

\subsubsection{Technische Geräte}

\begin{tabular}{|l|l|}
\hline Gerät & Hersteller \\
\hline Agilent 2100 BioAnalyzer & $\begin{array}{l}\text { Agilent Technologies, Waldbronn, } \\
\text { Deutschland }\end{array}$ \\
\hline Brutschrank $\left(+40^{\circ} \mathrm{C}\right)$ & Heraeus, Düsseldorf, Deutschland \\
\hline Eismaschine, Scotsman AF 80 & Scotsman Ice Systems, Mailand, Italien \\
\hline Feinwaage & Sartorius, Göttingen, Deutschland \\
\hline Gefrierschrank $\left(-20^{\circ} \mathrm{C}\right)$ & Liebherr, Biberach, Deutschland \\
\hline Gefrierschrank $\left(-80^{\circ} \mathrm{C}\right)$ & GFL, Burgwedel, Deutschland \\
\hline Gel-Elektrophorese-Kammer & Biometra, Göttingen, Deutschland \\
\hline
\end{tabular}




\begin{tabular}{|l|l|}
\hline $\begin{array}{l}\text { Horizontale Elektrophoresekammer- } \\
\text { Agargel-Standard, 10x10cm }\end{array}$ & Biometra, Göttingen, Deutschland \\
\hline $\begin{array}{l}\text { Icycler Real-Time PCR } \\
\text { Detektionssystem }\end{array}$ & $\begin{array}{l}\text { BioRad Laboratories, München, } \\
\text { Deutschland }\end{array}$ \\
\hline Ikamag RH (Magnetrührer) & $\begin{array}{l}\text { IKA Werke GmbH \& Co. KG, Staufen, } \\
\text { Deutschland }\end{array}$ \\
\hline Inkubator, OV 5 & Biometra, Göttingen, Deutschland \\
\hline Kühlschrank, Silkafrost comfort & Siemens, München, Deutschland \\
\hline Kulturbank, Hera Safe & Heraeus, Düsseldorf, Deutschland \\
\hline Mikroskop ID 03 & Zeiss, Jena, Deutschland \\
\hline Objektträger 67x26 mm & Knittel- Gläser, Bielefeld, Deutschland \\
\hline pH-Meter InoLab ph 720 & WTW, Weilheim, Deutschland \\
\hline Präzitherm Typ PZ 28-2 (Heizplatte) & Gestigkeit, Düsseldorf, Deutschland \\
\hline Schlittenmikrotom Hn 40 & Reichert \& Jung, Heidelberg, Deutschland \\
\hline Schüttler, Modell 3016 & GFL, Burgwedel, Deutschland \\
\hline Spannungsgerät LKB GPS 200/400 & $\begin{array}{l}\text { Amersham Pharmacia Biotech, Freiburg, } \\
\text { Deutschland }\end{array}$ \\
\hline Thermocycler, T Personal & Biometra, Göttingen, Deutschland \\
\hline Thermomixer 5436 & Eppendorf, Hamburg, Deutschland \\
\hline Trockenschrank (+80C) & Memmert, Schwabach, Deutschland \\
\hline Ultraviolett-Bestrahlungs-Lampe & Schütt, Göttingen, Deutschland \\
\hline Vortex Genie 2 & Bänder u. Hobein AG, Zürich, Schweiz \\
\hline Wärmeschrank OV 5 & Biometra, Göttingen, Deutschland \\
\hline Wasserbad Modell 1002-1013 & GFL, Burgwedel, Deutschland \\
\hline Zentrifuge, Biofuge Stratos & Heraeus, Düsseldorf, Deutschland \\
\hline
\end{tabular}




\subsection{Gewebeproben}

Für die immunhistochemischen Färbungen und qRT-PCR-Messungen wurden Proben eines Patientenkollektivs des Bundeswehrkrankenhauses Hamburg verwendet. Die Patienten stimmten im Rahmen ihres Behandlungsvertrages für die Freigabe inrer Gewebeproben für Forschungszwecke zu. Das Kollektiv umfasste insgesamt 80 männliche Patienten. Die Gewebeproben wurden mittels HOPETechnik ( fixiert. Dabei handelt es sich um eine spezielle Gewebsfixierung, bei welcher Strukturproteine, Enzyme und Nukleinsäuren im Gegensatz zu anderen Fixierungstechniken weitgehend erhalten bleiben.

\subsection{Zellkulturen}

\subsubsection{Tumorzelllinien NCCIT- und NTERA-2-Zelllinie}

Die pluripotente Stammzelle der NCCIT-Zelllinie stammte von einem Teratokarzinom ab und glich in ihrer Morphologie Epithelien. Wohingegen die NTERA-2-Zellen Abkömmlinge einer pluripotenten Stammzelle eines embryonalen Karzinoms waren und morphologisch Fibroblasten ähnelten. Beide Zelllinien zeigten ein einschichtiges Wachstumsverhalten. Alle Arbeitsabläufe wurden unter sterilen Bedingungen an einer Kulturbank vorgenommen.

Die Tumorzelllinien wurden in Kulturflaschen mit einer Grundfläche von $75 \mathrm{~cm}^{2}$ kultiviert. Um den Zellen ein optimales Wachstum zu ermöglichen, wurde vor der Inkubation bei $37^{\circ} \mathrm{C}$ und $5 \% \mathrm{CO}_{2}$ ein Kulturmedium bestehend aus $85 \%$ RPMI-1640, $100 \mathrm{IU} / \mathrm{ml}$ Penicillin, $100 \mathrm{\mu g} / \mathrm{ml}$ Streptomycin, $2 \mathrm{mM} \mathrm{L-Glutamin,} \mathrm{10 \%} \mathrm{FCS} \mathrm{und} \mathrm{2,5 \%}$ $1 \mathrm{M}$ HEPES in die Kulturflasche transferiert. Innerhalb von zwei bis drei Tagen (NCCIT) bzw. drei bis vier Tagen (NTERA-2) bildete sich eine Zellschicht, welche den Boden der Kulturflasche komplett bedeckte. Während dieser Tage musste das Kulturmedium erneuert werden, dabei konnte anhand der Farbveränderung des Mediums ( $r o t=$ frisch, gelb = verbraucht) die Notwendigkeit für ein Erneuern des Mediums abgelesen werden.

Das Kultivieren und Passagieren der NCCIT- und NTERA-2- Zelllinien war bis auf das Herauslösen des vollgewachsenen Zellrasens identisch. Zum Ablösen der 
NCCIT-Zelllinien folgte ein Absaugen des verbrauchten und gelb verfärbten Mediums. Zusätzlich schloss sich ein zweiminütiger Spülvorgang mit $10 \mathrm{ml}$ PBS und die Applikation von $5 \mathrm{ml}$ frischem Trypsin (Trypsin/EDTA Solution 10× im Verhältnis 1:10 mit Aqua bidest. verdünnt) an. Nach 3 bis 5 Minuten Inkubation bei $37^{\circ} \mathrm{C}$ waren die Zellen abgelöst und konnten mit einer sterilen Pipette abgesaugt werden.

Die NTERA-2-Zellen wurden drei bis vier Tage, nachdem das verbrauchte Medium abgesaugt wurde, mit einem sterilen Zellschaber abgetragen und in eine $50 \mathrm{ml}$ Falcon-Tube überführt. Nach einer 7 minütigen Zentrifugation bei 1500 Upm wurde das überschüssige Kulturmedium abgesaugt und mit $10 \mathrm{ml}$ Kulturmedium versetzt, um ein Auszählen in einer Neubauer Zählkammer zu ermöglichen. Für spätere Versuche wurden $5 \times 10^{6}$ Zellen in eine neue Zellkulturflasche überführt und neues Kulturmedium hinzugefügt.

\begin{tabular}{|lr|}
\hline Phosphat Buffered Saline (PBS) \\
\hline $\mathrm{Na}_{2} \mathrm{HPO}_{4}$ & $5,75 \mathrm{~g}$ \\
$\mathrm{KH}_{2} \mathrm{PO}_{4}$ & $1 \mathrm{~g}$ \\
$\mathrm{NaCl}$ & $40 \mathrm{~g}$ \\
$\mathrm{KCl}$ & $1 \mathrm{~g}$ \\
Aqua dest. (DEPC) & $500 \mathrm{ml}$ \\
\hline
\end{tabular}

\subsubsection{Stimulation der Tumorzelllinien NTERA-2 und NCCIT mit Vitamin D3}

Das Anzüchten der Zellen erfolgte wie unter Punkt 2.3.1. beschrieben. Um eine gleiche Zellzahl bei den Stimulationsversuchen und der späteren Auswertung gewährleisten zu können, wurde die Anzahl der Zellen bestimmt. Hierzu wurde aus der mit PBS verdünnten Zellsuspension $12 \mu$ entnommen und in eine NeubauerZählkammer gegeben. Nach Auszählen der Zellen wurde mit der folgenden Formel ein Wert ermittelt und auf $4 \times 10^{6}$ umgerechnet:

Mittelwert der ausgezählten Zellen x 10.000 x ml der Zellsuspension

Das Ergebnis war die Anzahl an Zellen, welche der Zellsuspension entnommen und in die vorbereiteten Pallets für den Stimulationsversuch übertragen wurde. 
Zusätzlich wurde zu den Zellen 10ml RPMI gegeben. Nachdem die Zellen adhäriert waren, erfolgte nach Wechsel des Kulturmediums die Stimulation mit Vitamin D3.

\begin{tabular}{|l|l|l|}
\hline Tumorzelllinie & $\begin{array}{l}\text { Vitamin D3 } \\
\text { Konzentration in } \mathbf{n M}\end{array}$ & Zeit in Stunden \\
\hline NCCIT und NTERA-2 & 50 & 24 und 48 \\
\cline { 2 - 3 } & 100 & 24 und 48 \\
\cline { 2 - 3 } & 200 & 24 und 48 \\
\hline
\end{tabular}

\subsection{Nukleinsäureanalytik}

\subsubsection{RNA-Isolierung}

Die Gesamt-RNA wurde aus den beiden Tumorzelllinien NCCIT und NTERA-2 mit Hilfe des Mini-Kits der Firma Quiagen extrahiert. Die komplette RNA der Proben bindet sich in diesem Verfahren an eine spezielle Silikatmatrix im RNA-Filter, nachdem die DNA und Proteine durch die Bindung an mineralische Trägersubstanzen entfernt wurden. Dazu wurden die zu untersuchenden Zellen mit $600 \mu \mathrm{l} \mathrm{RLT} / \beta-M E$ in einem Reaktionsgefäß $(1,5 \mathrm{ml})$ gesammelt und durch kräftiges Vortexen sowie Schreddern zerkleinert. Es folgten unter mehrmaligem Abzentrifugieren bei 10.000 Upm Spülvorgänge mit $350 \mu \mathrm{l}$ RW 1 sowie $500 \mu \mathrm{l}$ RPE. Die so gebundene RNA wurde mit einer Zentrifuge bei 13.000 Upm aus dem Filter gelöst. Die Qualität und Quantität der RNA wurde mittels Kapillarelektrophorese des Agilent 2100 Bioanalyzer bestimmt. Dabei erfolgte eine photometrische Messung bei 260 nm, zur Ermittlung des RNA-Gehalts. Die Extinktion $E_{260}$ von 1 entsprach einer Konzentration von $40 \mu \mathrm{g} R \mathrm{RA} / \mathrm{ml}$. Die hergestellte RNA konnte sofort weiter verwendet oder bei $-80^{\circ} \mathrm{C}$ kryokonserviert werden. 


\subsubsection{Reverse Transkription}

Vor der quantitativen RT-PCR wurde eine Reverse Transkription durchgeführt, da die Taq-Polymerase der PCR nicht in der Lage ist, die Ausgangs-RNA des zu untersuchenden Gewebes als Matrize zu benutzen. Dazu wurde die zuvor isolierte RNA mit Hilfe des Omniscript RT-PCR Kit in komplementäre DNA (cDNA) umgeschrieben. Der ganze Vorgang umfasste zuvor zwei Versuchsabläufe. Zum einen wurde ein Arbeitsansatz mit Reverse Transkriptase hergestellt, welcher später mit der RNA zusammengefügt wurde. Zum anderen wurde die einzusetzende RNAMenge, deren Gehalt zuvor im Agilent 2100 BioAnalyzer gemessen wurde, mit nukleotid-freiem Wasser vorverdünnt. Der $500 \mathrm{ng}$ RNA-haltige Ansatz fasste insgesamt $13 \mu \mathrm{l}$ und wurde für fünf Minuten bei $70^{\circ} \mathrm{C}$ im Thermocycler denaturiert, um eine bessere Anlagerung der Random Hexamer-Primer gewährleisten zu können. Es folgte eine kurze Abkühlung auf Eis. Nach Fertigstellung wurden beide Ansätze zusammengeführt und für eine Stunde bei $37^{\circ} \mathrm{C}$ sowie 5 Minuten bei $95^{\circ} \mathrm{C}$ inkubiert. Die hergestellten $20 \mu \mathrm{l}$ cDNA wurden mit $80 \mu \mathrm{l} \mathrm{H}_{2} \mathrm{O}$ verdünnt und damit auf $5 \mathrm{ng} / \mathrm{ml}$ eingestellt. Die cDNA konnte jetzt für die PCR eingesetzt oder kryokonserviert werden.

\begin{tabular}{|ll|}
\hline Reverse Transkriptase Kit \\
\hline RT-Puffer & $2 \mu \mathrm{l}$ \\
dNTPs & $2 \mu \mathrm{l}$ \\
Random Hexa Primer & $1 \mu \mathrm{l}$ \\
RNAase-Inhibitor & $1 \mu \mathrm{l}$ \\
Reverse Transkriptase & $1 \mu \mathrm{l}$ \\
\hline
\end{tabular}

\begin{tabular}{|lr|}
\hline Reagenz & \\
\hline cDNA & $5 \mu \mathrm{l}$ \\
Aqua dest. & $4 \mu \mathrm{l}$ \\
Primer forward $[20 \mu \mathrm{mol} / \mathrm{l}]$ & $0,5 \mu \mathrm{l}$ \\
Primer reverse $[20 \mu \mathrm{mol} / \mathrm{l}]$ & $0,5 \mu \mathrm{l}$ \\
Taq-DNA-Polymerase & $10 \mu \mathrm{l}$ \\
\hline
\end{tabular}




\begin{tabular}{|c|l|c|c|}
\hline Zyklen & Reaktionsphase & Temperatur ${ }^{\circ} \mathbf{C}$ ] & Zeit [Sek.] \\
\hline \multirow{2}{*}{$1 \mathrm{x}$} & Denaturierungsphase & 95 & 900 \\
\hline \multirow{3}{*}{$35 \mathrm{x}$} & Denaturierungsphase & 95 & 20 \\
\cline { 2 - 4 } & Annealingphase & Primer abhängig & 20 \\
\cline { 2 - 4 } & Elongationsphase & 72 & 20 \\
\hline $1 \mathrm{x}$ & Elongationsphase & 72 & 420 \\
\hline
\end{tabular}

\subsubsection{Quantitative Real-Time Polymerase Kettenreaktion (qRT-PCR)}

Die quantitative Real-time-Polymerase-Kettenreaktion ist eine spezielle PCRTechnik, die die gewöhnliche PCR mit einer Quantifizierung amplifizierter Nukleinsäuren verbindet. Die Quantifizierung erfolgt mit Hilfe von FluoreszenzMessungen. Während den einzelnen PCR-Zyklen wird ein Fluoreszenzfarbstoff (SYBRGreen) proportional zu der Menge des des PCR-Produktes eingebaut und die Fluoreszenz nimmt dementsprechend zu. Am Ende einer PCR-Reaktion wird die gemessene Fluoreszenz in der exponentiellen Phase der PCR quantifiziert. Nur während der exponentiellen Phase der PCR ist eine Quantifizierung möglich, da nur in dieser Phase der PCR optimale Reaktionsbedingen vorherrschen. Die untersuchte cDNA stammte aus Gewebe maligner Keimzelltumoren sowie aus den beiden Tumorzellinien NCCIT- und NTERA-2. Die PCR-Reaktionen wurden im iCycler (Biorad) eingesetzt und analysiert. Der Ansatz der PCR setzt sich wie folgt zusammen:

\begin{tabular}{|lr|}
\hline Reagenz \\
\hline SYBRGreen Mix & $10 \mu \mathrm{l}$ \\
RNAse freies Wasser & $4,7 \mu \mathrm{l}$ \\
Primer forward & $0,15 \mu \mathrm{l}$ \\
Primer reverse & $0,15 \mu \mathrm{l}$ \\
cDNA & $5 \mu \mathrm{l}$ \\
\hline
\end{tabular}


Die Quantifizierung der PCR-Reaktionen erfolgte mit der $\Delta \Delta$ Ct-Methode (Livak und Schmittgen 2001). Der Ct-Wert (engl. Cycle threshold) ist der Schwellenwertzyklus einer PCR-Reaktion, bei dem die eingebaute Fluoreszenz erstmalig signifikant über der Hintergrund-Fluoreszenz liegt. Zur Quantifizierung werden dann die Ct-Werte der unterschiedlich zu vergleichenden Gruppen (stimuliert versus unstimuliert, Tumor versus Normalgewebe) voneinander abgezogen und in die Gleichung $2^{-\Delta \Delta C t}$ eingesetzt. In der Regel reichte eine Zyklenzahl von 35, um ein Gen sichtbar zu machen. Wurde nach 35 Zyklen kein Ergebnis erzielt, wurde der Versuchsablauf mit 60 Zyklen durchgeführt. Nach der letzten Elongationspahse erfolgte zur Genquantifizierung eine Schmelzkurvanalyse. Als Referenzgen der $\Delta \Delta \mathrm{Ct}$-Methode diente das nicht-regulierte Housekeeping-Gen ARP. Die zu untersuchenden Primersequenzen wurden mit Hilfe des primer-3-Programms (http://frodo.wi.mit.edu/primer3/) ausgewählt bei http://www.ncbi.nlm.nih.gov/pubmed/ in der BLAST-Funktion kontrolliert (http://www.ncbi.nlm.nih.gov/tools/primer-blast/index.cgi?LINK LOC=BlastHome).

\begin{tabular}{|c|l|c|c|}
\hline Zyklen & Reaktionsphase & Temperatur [ $\left.{ }^{\circ} \mathbf{C}\right]$ & Zeit [Sek.] \\
\hline $1 \mathrm{x}$ & Initiale Denaturierungsphase & 95 & 900 \\
\hline \multirow{3}{*}{$60 \mathrm{x}$} & Denaturierungsphase & 95 & 30 \\
\cline { 2 - 4 } & Annealingphase & Primer abhängig & 30 \\
\cline { 2 - 4 } & Elongationsphase & 72 & 30 \\
\hline $1 \mathrm{x}$ & Finale Elongationsphase & 72 & 420 \\
\hline
\end{tabular}


Tabelle 1: Primer für die Polymerase-Kettenreaktion

\begin{tabular}{|c|c|c|c|c|}
\hline Produkt & Sequenz & Annealingtemperatur in $\left[{ }^{\circ} \mathrm{C}\right]$ & Produktgröße & Basenpaare \\
\hline CYP24 A1 forward & $\begin{array}{l}\text { 5'-GAG ACT GGT GAC } \\
\text { ATC TAC GGC GTA CA-3` }\end{array}$ & 65 & 488 & 26 \\
\hline CYP24 A1 reverse & $\begin{array}{l}5^{`}-\mathrm{CCA} \text { TAA AAT CGG } \\
\text { CCA AGA CCT CAT TG-3` }\end{array}$ & & & 26 \\
\hline CYP 27 B1 forward & $\begin{array}{l}\text { 5-CAG AGG CAG CCA } \\
\text { TGA GGA AC-3 }\end{array}$ & 61,5 & 1.132 & 20 \\
\hline CYP 27 B1 reverse & $\begin{array}{l}\text { 5`-GGG TCC CTT GAA } \\
\text { GTG GCA TAG-3` }\end{array}$ & & & 21 \\
\hline VDR forward & $\begin{array}{l}\text { 5'-GCC CAC CAT AAG } \\
\text { ACC TAC GA-3 }\end{array}$ & 58 & 203 & 20 \\
\hline VDR reverse & $\begin{array}{l}\text { 5-AGA TTG GAG AAG } \\
\text { CTG GAC GA-3 }\end{array}$ & & & 20 \\
\hline GADD 45 forward & $\begin{array}{l}\text { 5'-GCC TGT GAG TGA } \\
\text { GTG CAG AA-3 }\end{array}$ & 58 & 159 & 20 \\
\hline GADD 45 reverse & $\begin{array}{l}\text { 5`CCC CAC CTT ATC } \\
\text { САТ CCT TT-3` }\end{array}$ & & & 20 \\
\hline MAPKAPK 2 forward & $\begin{array}{l}\text { 5'-TCA TGA AGA GCA } \\
\text { TCG GTG AG-3`}\end{array}$ & 58 & 165 & 20 \\
\hline MAPKAPK 2 reverse & $\begin{array}{l}\text { 5-TCA AAG AGT TGT } \\
\text { GGC TGG TG-3 }\end{array}$ & & & 20 \\
\hline
\end{tabular}




\begin{tabular}{|c|c|c|c|c|}
\hline Produkt & Sequenz & Annealingtemperatur in $\left[{ }^{\circ} \mathrm{C}\right]$ & Produktgröße & Basenpaare \\
\hline NCoR1 forward & $\begin{array}{l}\text { 5`AAA GTG TGG AGA } \\
\text { CCC AGG TG-3 }\end{array}$ & 58 & 151 & 20 \\
\hline NCoR1 reverse & $\begin{array}{l}\text { 5'-ACC CTC ACT TCA } \\
\text { ACG TCC AC-3 }\end{array}$ & & & 20 \\
\hline NCoR2 forward & $\begin{array}{l}5^{\prime} \text {-AAG TCC ATC CTC } \\
\text { ACG TCC AC-3' }\end{array}$ & 59 & 201 & 20 \\
\hline NCoR2 reverse & $\begin{array}{l}\text { 5-TGA AGC ACA CTG } \\
\text { GGT CTC TG-3` }\end{array}$ & & & 20 \\
\hline TRIP 15 forward & $\begin{array}{l}\text { 5'-AGG GGT GGT GCA } \\
\text { CGA TAT AC-3 }\end{array}$ & 58 & 188 & 20 \\
\hline TRIP 15 reverse & $\begin{array}{l}\text { 5'CAG GAC ACA TCA ACC } \\
\text { GAC AG-3` }\end{array}$ & & & 20 \\
\hline ARP forward & $\begin{array}{l}\text { 5`CGA CCT GGA AGT } \\
\text { CCA ACT AC-3` }\end{array}$ & 55 & 109 & 20 \\
\hline ARP reverse & $\begin{array}{l}\text { 5'-ATC TGC TGC ATC } \\
\text { TGC TTG-3` }\end{array}$ & & & 18 \\
\hline
\end{tabular}




\subsection{Immunhistochemie}

\subsubsection{Herstellung von Parraffinschnitten}

Mit Hilfe eines Schlittenmikrotoms wurde von den zuvor in HOPE fixierten und in Paraffin eingebetteten Gewebeproben 1 bis $2 \mu \mathrm{m}$ dicke Paraffinschnitte hergestellt und auf silanisierte Objektträger aufgetragen. Die Schnitte wurden anschließend im Wärmeschrank bei $40^{\circ}$ getrocknet.

\subsubsection{Immunhistochemische Färbung}

Die in HOPE fixierten und in Paraffin eingebetteten Schnittpräparate wurden bei $60^{\circ} \mathrm{C}$ in Iso-Propanol 2x10 min inkubiert, anschließend für $15 \mathrm{~min}$ in eiskaltem $70 \%$ Aceton fixiert und abschließend $10 \mathrm{~min}$ in Aqua dest. gespült. Nach Blockade der endogenen Peroxidase und unspezifischer Antikörperbindungen erfolgte eine Inkubation für 20 min in $\mathrm{H}_{2} \mathrm{O}_{2}(3 \%)$ sowie für 15 min in einer $10 \% \mathrm{BSA} / 5 \% \mathrm{FCS}$ Lösung. Nach Waschen in TBS-Puffer wurden die Schnitte für $1 \mathrm{~h}$ bei Raumtemperatur mit dem Primärantikörper (Verdünnung 1:200) inkubiert. Anschließend erfolgte die Inkubation mit einem Sekundärantikörper und einer Immunmarkierungssubstanz zur Verstärkung der Antigen-Antikörperbindung des Primärantikörpers. Dazu wurde das REAL Link/Label-System als Detektionssystem benutzt. Bei der Komponente "Link" handelte es sich um einen biotinylierten Sekundär-Antikörper und bei „Label“ um eine Immunmarkierungssubstanz bestehend aus Streptavidin mit (Meerrettich)-Peroxidase. Beide wurden nach kurzem Spülen für jeweils 30 Minuten auf die zu untersuchenden Schnitte aufgetragen. Nach einem kurzen Spülvorgang wurde die Immunmarkierungssubstanz mit DAB Chromogen von Dako (1:50 verdünnt) innerhalb von maximal 20 Minuten angefärbt. Nach Spülen mit entionisiertem Wasser und TBS wurden die Schnittpräparate mit Mayer's Hämalaun gegengefärbt und in Aquamount eingedeckt. 


\begin{tabular}{|l|l|l|l|l|}
\hline Antikörper & Clone & Spezies/Quelle & zelluläre Lokalisation & Firma \\
\hline VDR & polyklonal & Kaninchen & Nukleär & Santa Cruz \\
\hline
\end{tabular}

\begin{tabular}{|lr|}
\hline Hämalaun \\
\hline Hämatoxylin & $1 \mathrm{~g}$ \\
$\mathrm{~K} \mathrm{Al}\left(\mathrm{SO}_{4}\right) 12 \mathrm{H}_{2} \mathrm{O}$ & $50 \mathrm{~g}$ \\
$\mathrm{Na}$-Jodat & $0,2 \mathrm{~g}$ \\
Chloralhydrat & $30 \mathrm{~g}$ \\
Zitronensäure & $1 \mathrm{~g}$ \\
Aqua dest. & $\mathrm{ad} 1 \mathrm{I}$ \\
\hline
\end{tabular}

\section{TBS}

$\begin{array}{ll}\text { Tris- } \mathrm{HCl} ; \mathrm{pH} \mathrm{7,4} & 0,05 \mathrm{M} \\ \mathrm{NaCl} & 0,15 \mathrm{M}\end{array}$

\subsection{Proteinbiochemie Western Blot}

\subsubsection{Homogenisierung und Zellaufschluss}

Wie unter 2.3.1 beschrieben, wurden die NCCIT- und NTERA-2-Zellen für die Durchführung der Proteinanalyse von der vollgewachsenen Kulturschale abgelöst und pelletiert. Mit 500 $\mu$ TBS, welches mit Proteinase-Inhibitoren versetzt war, erfolgte die Resuspendierung. Zusätzlich verwendet wurden 1mM PMSF (Serinproteinase-Inhibitor), 1mM EDTA (Metalloproteinase-Inhibitor) und 5mM JAA. Zur Isolation der intrazellulären Proteine wurden die Zellen mit Hilfe der FrenchPress-Methode aufgebrochen. Dabei wurden die Zellen 50 mal durch eine im Durchschnitt $50 \mu \mathrm{m}$ messende Kanüle gepresst. Alle Schritte erfolgten auf Eis, um die entstandene Reibungswärme abzudämpfen. Nach den 50 French- Press- Hüben und der Einstellung auf $1 \%$ Triton $X_{100}$, wurden die Proben für 30 Minuten auf Eis inkubiert. Es folgten zum Abschluss 10 Hübe French-Press bevor die Proben in $20 \mu \mathrm{l}-$ Portionen alliquotiert und bei $-20^{\circ} \mathrm{C}$ kryokonserviert wurden. 


\subsubsection{Western Blot}

Die Proteine wurden zunächst mit $500 \mu \mathrm{l}$ eiskaltem Aceton gefällt und in $30 \mu \mathrm{l} \mathrm{WB-}$ Probenpuffer bestehend aus Tris/Glycinpuffer aufgenommen. Nach zehnminütigem Abzentrifugieren wurde in jede Probe 10 $\mu$ LDS Samplepuffer 4xBromphenolblau + $4 \mu \mathrm{l}$ Reduktionsreagenz pipettiert. So sollten Proteine angefärbt und Wechselwirkungen innerhalb der molekularen Proteinstruktur vermieden werden. Es folgte die Denaturierung der Proteine für 5 Minuten bei $95^{\circ} \mathrm{C}$. Anschließend wurde die Reaktion auf Eis abgestoppt. Die Auftrennung der Proteine erfolgte mit einem 10 Wel Elektrophoresegel in einer Gelelektrophoresekammer. Zur Anwendung kamen fertige Polyacrylamid-Gele. Die dabei entstandenen zwei Kompartimente ließen sich in ein äußeres und eine inneres Kompartiment unterteilen. Diese wurden mit Laufpuffer (äußeres Kompartiment) und Laufpuffer ergänzt mit Antioxidans (inneres Kompartiment) aufgefüllt. Anschließend wurden die Proben auf das Gel aufgetragen. Die Auftrennung nach Ladung und Molekulargewicht erfolgte bei $200 \mathrm{~V}$ über 45 Minuten. Das Gel wurde in den Transferpuffer gebracht und in der Blotkammer auf eine Nitrocellulosemembran zwischen drei Lagen Filterpapier, getränkt in Transferpuffer, gebettet. Die mit dem Gel beladene Blotkammer wurde mit einer Stromstärke von 0,04A für eine Stunde angeschlossen, anschließend die mit Proteinen beladene Membran für eine Stunde in 5\% Magermilch in TBST inkubiert, um unspezifische Antikörperbindungen gegen freie Proteinbindungsstellen zu vermeiden. Nach einer über Nacht stattfindenden Inkubation bei $4^{\circ} \mathrm{C}$ in einer BSAPrimärantikörperlösung wurde die Membran dreimal mit TBST-Waschpuffer gewaschen. Anschließend wurde die Membran für eine Stunde in $5 \%$ Magermilch TBST-Sekundärantikörperlösung belassen. Dabei bindet der Sekundärantikörper in spezifischer Weise an den Primärantikörper. Es folgte ein dreimaliges Waschen für fünf Minuten in TBST zum Ablösen der ungebundenen Antikörper. Nach Konjugation des sekundären Antikörpers mit HRP (Horseraddish-Peroxidase) wurde das AntigenAntikörper-HRP-Konjugat mittels verstärkter Chemielumineszenz visualisiert. Nach kurzem Kontakt mit der Membran wurde das Signal mittels eines Röntgenfilms in einer Röntgenkassette sichtbar gemacht. 


\begin{tabular}{|lr|}
\hline Transferpuffer \\
\hline Tris & $3,028 \mathrm{~g}$ \\
Glycin & $14,413 \mathrm{~g}$ \\
Methanol & $200 \mathrm{ml}$ \\
Aqua bidest & Auf 11 \\
\hline
\end{tabular}

\begin{tabular}{|lr|}
\hline Laufpuffer \\
\hline MES-Running-Buffer & $50 \mathrm{ml}$ \\
aqua bidest & $950 \mathrm{ml}$ \\
Innere Kammer $+400 \mu \mathrm{l}$ & \\
Antioxidans & \\
\hline
\end{tabular}

\begin{tabular}{|lr|}
\hline TBST Waschpuffer pH 7,4 & \\
\hline Tris & $12,11 \mathrm{~g}$ \\
Tween & $0,1 \%$ \\
$\mathrm{NaCl}$ & $17,53 \mathrm{~g}$ \\
Rauchende Salzsäure $\quad 37 \%$ & \\
zur pH-Einstellung & \\
Aqua bidest & Auf 2I \\
\hline
\end{tabular}

\subsubsection{Wiederaufbereitung der Membran}

Die hergestellte Membran lies sich für weitere Versuche verwenden. Um die PrimärSekundärantikörperkomplexe von der Membran zu lösen wurde ein spezieller Lösepuffer (Stripppuffer) verwendet. Nach einer einstündigen Inkubation in diesem Stripppuffer wurde unter mehrfachem Austauschen des Waschpuffers die Membran mit TBST eine Stunde gewaschen. Jetzt konnte die Membran erneut mit 5\% Magermilch/TBST gesättigt und mit einem neuen Antikörper beladen werden. 


\begin{tabular}{|lr|}
\hline Stripppuffer $\mathbf{p H 7 , 4}$ & $10 \mathrm{~g}$ \\
\hline TRIS & $200 \mathrm{ml}$ \\
10\% SDS-Solution & $7 \mathrm{ml}$ \\
B- Mercaptoethanol & \\
Rauchende Salzsäure & $37 \%$ \\
zur pH-Einstellung & \\
\hline
\end{tabular}

\subsection{Proliferationsassay}

Mit dem BrdU-Proliferationsassay wurde die Proliferation der TGCT-Tumorzelllinien unter der Stimulation von Vitamin D3 untersucht. Hierzu wurden 5000 Zellen/well einer jeden Tumorzelllinie (NCCIT und NTERA-2) in eine 96-well-Platte transferiert und in $200 \mu \mathrm{l}$ DMEM+10\% FCS Kultiviermedium für 72 Stunden inkubiert. Die Markierung der Zellen erfolgte nach 72 Stunden mittels 1:1000 verdünnten BrdU. Es folgte eine Inkubation für 14 Stunden bei $37^{\circ} \mathrm{C}$.

Das BrdU ist ein Thyminanalogon und wird in DNA proliferierender Zellen eingebaut. Die Menge des eingebauten BrdU ist proportional zur Proliferationsrate der Zelle und lässt sich mittels Antikörperbindung im ELISA-System messen. Nach 14 stündiger Inkubation erfolgten ein Abklopfen der 96-well-Platte und ein Abtrocknen im Hybridisierungsofen. Die Zellen wurden nach Abtrocknen für 15 Minuten bei

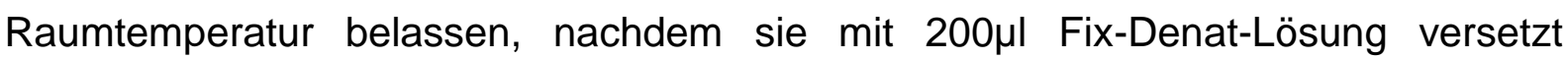
wurden.

Die Fixierungslösung wurde von den Zellen entfernt, anschließend mit 200 $\mu \mathrm{l} 2 \%$ BSA gespült und schließlich 10 Minuten bei RT im Dunkeln belassen. Nach 15 minütiger

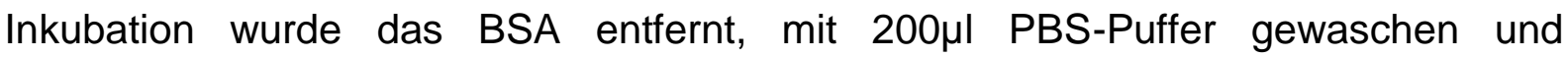
anschließend mit Anti-BrdU-POD (1:100 mit Diluent aus dem Kit) versetzt, mit dem es für 45 min bei RT im Dunkeln inkubiert wurde. Es schlossen sich 3 Waschritte mit $200 \mu \mathrm{l}$ Waschlösung an, bei denen die Zellen auf einen Schüttler gestellt wurden. Vor einer weiteren 10 minütigen, bei RT und im Dunkeln stattfindenden Inkubation wurden $100 \mu$ l Substratlösung auf die Zellen gegeben. Die Reaktion wurde mit $25 \mu \mathrm{l}$ $1 \mathrm{M} \mathrm{H}_{2} \mathrm{SO}_{4}$ abgestoppt. Jetzt konnten die Zellen im ELISA Reader mit einer Wellenlänge von $450 \mathrm{~nm}$ und einer Referenzlänge von $655 \mathrm{~nm}$ gemessen werden. 


\subsection{Statistische Analysen}

\subsubsection{Auswertung der immunhistochemischen Versuche}

Die immunhistochemischen Färbungen wurden in Anlehnung an den RemmeleScore in der Diagnostik von Mamakarzinomen mittels eines immunhistochemischen Multiplikationsscores ausgewertet. Dieser setzt sich aus dem Prozentsatz positiver Tumorzellen und der Färbeintensität zusammen (Tabelle 2).

\begin{tabular}{|c|c|c|c|c|c|}
\hline \multicolumn{2}{|c|}{ Prozentsatz positiver Zellen } & \multicolumn{2}{|l|}{ Färbeintesität } & \multicolumn{2}{|l|}{ Score } \\
\hline Keine positiven Zellen & 0 Punkte & Keine Färbereaktion & 0 Punkte & Gruppe I & 0 Punkte \\
\hline$<10 \%$ positive Zellen & 1 Punkt & Schwache Färbereaktion & 1 Punkt & Gruppe II & 1-6 Punkte \\
\hline $10-50 \%$ positive Zellen & 2 Punkte & Mäßige Färbereaktion & 2 Punkte & Gruppe III & 7-12 Punkte \\
\hline $50-80 \%$ positive Zellen & 3 Punkte & Starke Färbereaktion & 3 Punkte & & \\
\hline$>80 \%$ positive Zellen & 4 Punkte & & & & \\
\hline
\end{tabular}

Tabelle 2: Immunreaktiver Score für die immunhistochemische Auswertung

\subsubsection{Statische Auswertung}

Alle qRT-PCR- und Proliferationsuntersuchungen wurden mit Hilfe von Microsoft Excel ausgewertet. Die Errechnung der p-Werte erfolgte mit dem ungepaarten t-Test und mit Hilfe der GraphPad Prism Software. Die Signifikanzwerte wurden als ${ }^{*} p<0.05 ;{ }^{* *} p<0.01 ;{ }^{* * *} p<0.001$ angegeben. Die Standardabweichung wurde ebenfalls mit Hilfe der GraphPad Prism Software errechnet. Alle qRT-PCRUntersuchungen und Proliferationsassays wurden in dreifachen Ansetzungen in Triplikaten durchgeführt. 


\section{Ergebnisse}

\subsection{Allgemeine Ergebnisse}

Das untersuchte Patientenkollektiv setzte sich aus insgesamt 80 männlichen Patienten zusammen, die in den Jahren 2004 bis 2006 im Bundeswehrkrankenhaus Hamburg aufgrund eines malignen Keimzelltumor des Hodens orchiektomiert wurden. Bei 57 Patienten lag ein Seminom und bei 23 ein Nicht-Seminom (13 embryonale Karzinome, 8 Teratome, 1 Chorionkarzinom, 1 Dottersacktumor) vor. Das Durchschnittsalter der Patienten bei Diagnosestellung war 33,86 Jahren. Bei genauerer Betrachtung zeigte sich bei den Patienten mit einem Seminom ein mittleres Erkrankungsalter von 35,43 Jahren, wohingegen das mittlere Erkrankungsalter bei Patienten mit Nicht-Seminomen mit 28,95 Jahren deutlich niedriger lag.

\begin{tabular}{|c|c|c|}
\hline Tumorentität & Anzahl & $\begin{array}{c}\text { Durchschnittliches } \\
\text { Erkrankungsalter in Jahren }\end{array}$ \\
\hline Gesamt & 80 & $33,86 \pm 9,276$ \\
\hline Seminom & 57 & $35,43 \pm 9,417$ \\
Embryonales Karzinom & 13 & $28,57 \pm 8,446$ \\
Teratom & 8 & $29,63 \pm 7,308$ \\
Chorionkarzinom & 1 & $27 \pm 0$ \\
Dottersacktumor & 1 & $34 \pm 0$ \\
\hline
\end{tabular}

\subsection{Expression von VDR in TGCT}

Zur Expressionsanalyse von VDR in TGCT wurden die in HOPE fixierten und in Paraffin eingebetteten Gewebeproben mittels Immunhistochemie untersucht.

Das tumorfreie normale Hodengewebe zeigte weder eine nukleäre noch eine zytoplasmatische Expression von VDR in den Keimzellen oder Zellen des 
Keimstrangstromas (Leydig-, Sertoli- Zellen) (Abb.3). Die IGCNU als nicht-invasive Vorläuferläsion der TGCT ließ dagegen eine geringe Expression von VDR in den atypischen Keimzellen erkennen, wobei die Expression zytoplasmatisch lokalisiert war (Abb.4). Ein ähnliches Bild zeigte die VDR-Expression in Seminomen. In allen untersuchten Fällen konnte eine geringe zytoplasmatische Expression von VDR in den Tumorzellen nachgewiesen werden (Abb.5).

Bei allen 23 untersuchten nicht-seminomatösen Tumoren konnte eine starke zytoplasmatische und nukleäre VDR-Expression gezeigt werden. Bei den embryonalen Karzinomen zeigten die Tumorzellen eine starke nukleäre und zytoplasmatische Expression (Abb.6). Ebenfalls konnte eine starke Expression von VDR in Teratomen nachgewiesen werden (Abb.7). Bei dem untersuchten Chorionkarzinom und Dottersacktumor zeigte sich ebenfalls eine starke nukleäre und zytoplasmatische VDR-Expression (Abb.8 und Abb. 9).

Eine Zusammenfassung der immunhistochemischen Ergebnisse zeigt Tabelle 3. Die untersuchten tumorfreien Gewebe, Vorläuferläsionen und Seminome zeigen keine oder eine geringe Expression des VDR-Proteins. Alle nicht-seminomatösen Tumoren zeigen eine deutliche Expression von VDR-Protein in den untersuchten Tumorzellen. Um die in der Immunhistochemie erzielten Ergebnisse der VDR-Proteinexpression in TGCT zu erweitern wurde mittels qRT-PCR die Expression von VDR-mRNA in TGCT untersucht. In allen untersuchten seminomatösen und nicht-seminomatösen malignen Keimzelltumoren des Hodens konnte eine Expression von VDR mRNA gezeigt werden (Abb.10 und 11).

\subsection{VDR-Expression in TGCT-Zelllinien}

In Ergänzung zu den Untersuchungen in 80 primären TGCT wurde VDR mRNA mittels qRT-PCR in den TGCT-Zelllinien NCCIT und NTERA-2 untersucht. Die qRTPCR zeigte, dass die TGCT-Zelllinien NCCIT und NTERA-2 VDR mRNA exprimieren (Abb.12). Um die Ergebnisse auf translationaler Ebene zu verifizieren, wurde die VDR-Proteinexpression mittels Western Blot in den TGCT-Zelllinien NCCIT und NTERA-2 untersucht. In den angefertigten Western Blots konnte eine Expression von VDR-Protein in beiden TGCT-Zelllinien gezeigt werden (Abb.13). 


\subsection{Vitamin-D3-vermitteltes Expressionsprofil von VDR und Koregulatoren in TGCT-Zelllinien}

Nach Stimulation mit Vitamin D3 wurden die Tumorzelllinien NCCIT und NTERA-2 mittels qRT-PCR auf die Expression der Vitamin-D3-regulierten Gene VDR, NCOR1, NCOR2, TRIP15, GADD45, MAPKAPK2, CYP24A1 und CYP27B1 untersucht. Die Stimulation erfolgte mit 50, 100 oder 200 nM Vitamin D3 für jeweils 24 Stunden.

Nach Stimulation mit Vitamin D3 (50 und 100 nM) zeigte die Tumorzelllinie NCCIT keine statistisch signifikante Änderung der Expression von VDR-regulierten Genen. Im Gegensatz konnte nach Stimulation mit 200 nM Vitamin D3 eine geringe, jedoch statistisch signifikante Zunahme der Genexpression von VDR nachgewiesen werden $(p<0,05)$. Darüberhinaus zeigte NCOR1 eine deutliche statistisch signifikante Zunahme der Genexpression ( $p<0,01)$, wohingegen NCOR2 interessanterweise eine geringe statistisch signifikante Abnahme der Genexpression aufwies $(p<0,05)$. Nach Stimulation mit 200 nM Vitamin D3 wies MAPKAPK2 eine hoch signifikante Zunahme der Expression auf $(p<0,001)$. Die übrigen untersuchten Gene zeigten nach Stimulation mit 200 nM Vitamin D3 keine Änderung der Genexpression (Abb.14).

Nach Stimulation mit Vitamin D3 (50 und 100 nM) zeigte die Tumorzelllinie NTERA-2 keine statistisch signifikante Änderung der Expression von VDR-regulierten Genen. Nach Stimulation mit 200 nM Vitamin D3 konnte in der NTERA-2-Zelllinie eine geringe, jedoch statistisch signifikante Zunahme der Genexpression von VDR gezeigt werden $(p<0,05)$. Unter den weiteren untersuchten Vitamin-D3-regulierten Genen zeigte lediglich noch GADD45 einen deutlich statistisch signifikanten Anstieg der Genexpression ( $p<0,01)$. CYP27B1 zeigte eine geringe statistisch signifikante Abnahme der Genexpression nach Stimulation mit 200 nM Vitamin D3 ( $<<0,05)$. Die übrigen untersuchten Gene zeigten nach Stimulation mit 200 nM keine statistisch signifikante Änderung der Genexpression (Abb.15).

Zusammenfassend lässt sich sagen, dass die Tumorzelllinien NCCIT und NTERA-2 VDR-, NCOR1-, NCOR2-, TRIP15-, GADD45-, MAPKAPK2- und CYP27B1-mRNA exprimieren. Des Weiteren zeigte sich nach jeweils 24 Stunden Stimulation mit Vitamin D3 (200nM) besonders in der NCCIT-Zelllinie eine statistisch signifikante Zunahme von VDR, NCOR1 und MAPKPK2 und eine statistisch signifikante Abnahme der Genexpression von NCOR2. In den NCCIT-Zelllinien wurde nach 200 nM Vitamin-D3-Stimualtion eine statistisch signifikante Zunahme von VDR und 
GADD45, sowie eine statistisch signifikante Abnahme der CYP27B1 Expression gezeigt.

Die restlichen untersuchten Vitamin-D3-regulierten Gene zeigten weder in den NCCIT noch in den NTERA-2-Zelllinien eine statistisch signifikante Änderung der Genexpression. Interessanterweise wurde das untersuchte Gen CYP24A1 in unstimulierten NTERA-2-Zellen nicht exprimiert, nach Stimulation mit Vitamin D3 kam es allerdings zu einer Expression von CYP24A1-mRNA. Bei den NCCIT-Zellen hingegen gab es weder bei unstimulierten noch bei stimulierten Verhältnissen eine Expression von CYP24A1 (Ergebnisse nicht dargestellt).

\subsection{Proliferation der TGCT-Zelllinien NCCIT und NTERA-2 nach Stimulation mit Vitamin D3}

Die TGCT-Zelllinien NCCIT und NTERA-2 wurden mit 50, 100 oder 200 nM Vitamin D3 stimuliert und die Proliferation nach 24 und 48h gemessen. Nach 24h zeigten die Tumorzellen der TGCT-Zelllinie NCCIT eine statistisch signifikante Abnahme $(p<0,05)$ der Proliferation um maximal $44 \%$ bei einer Konzentration von 200 nM Vitamin D3 (Abb.16A). Nach 48h Stimulation mit 200 nM Vitamin D3 zeigte sich eine Reduktion der Proliferation um maximal $13 \%$ (Abb.16B).

Das Proliferationsverhalten der TGCT-Zelllinie NTERA-2 nach 50, 100 oder 200 nM Vitamin-D3-Stimulation wurde ebenfalls mittels BrdU ELISA nach 24h und 48h untersucht. Nach 24h zeigten die Tumorzellen eine statistisch signifikante Abnahme der Proliferation um maximal 39\% bei einer Konzentration von 200 nM Vitamin D3 $(p<0,05)$ und um maximal 33\% bei einer Konzentration von 100nM Vitamin D3 $(p<0,05)$ (Abb.17A). Nach 48 h Stimulation mit $200 \mathrm{nM}$ Vitamin D3 zeigte sich eine Reduktion der Proliferation um maximal $9 \%$ (Abb.17B). 

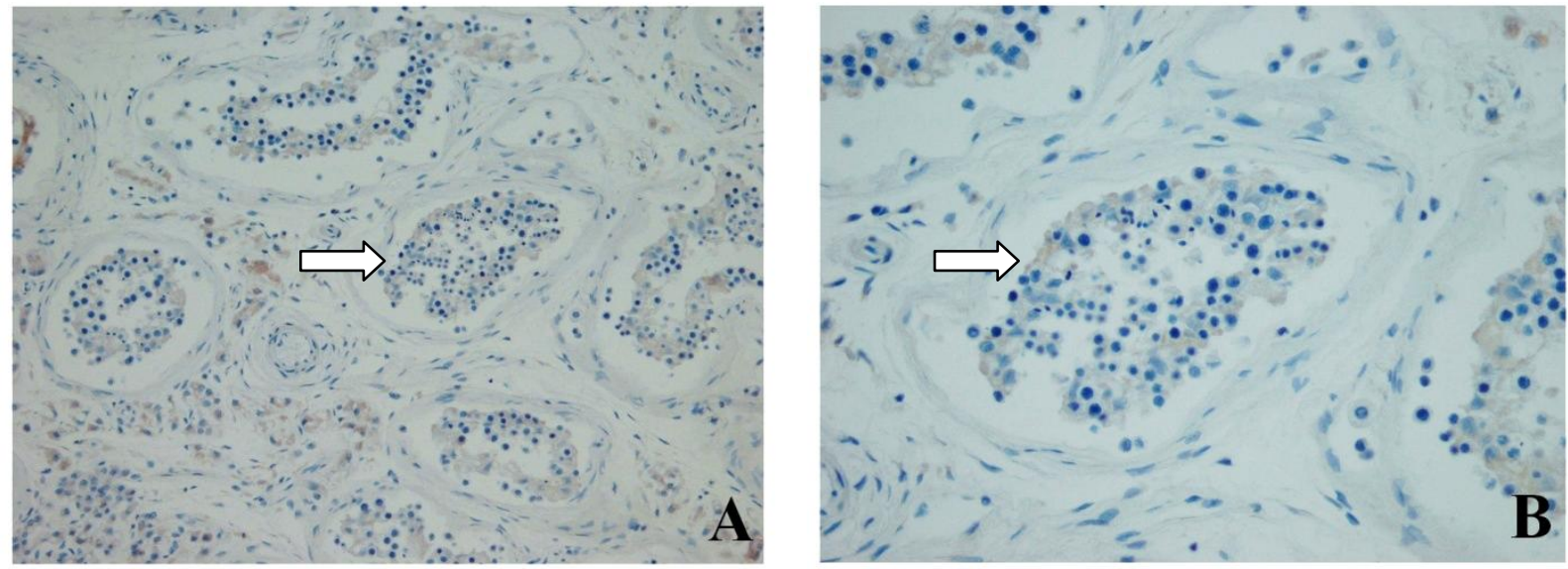

Abbildung 3. Expression von VDR in normalem Hodengewebe

Die Expression von VDR in normalem Hodengewebe wurde mittels Immunhistochemie untersucht. Das normale Hodengewebe mit den typischen Keimzellen $(\Rightarrow)$ zeigt keine Expression von VDR (A, Vergrößerung x100; B, Vergrößerung x200).
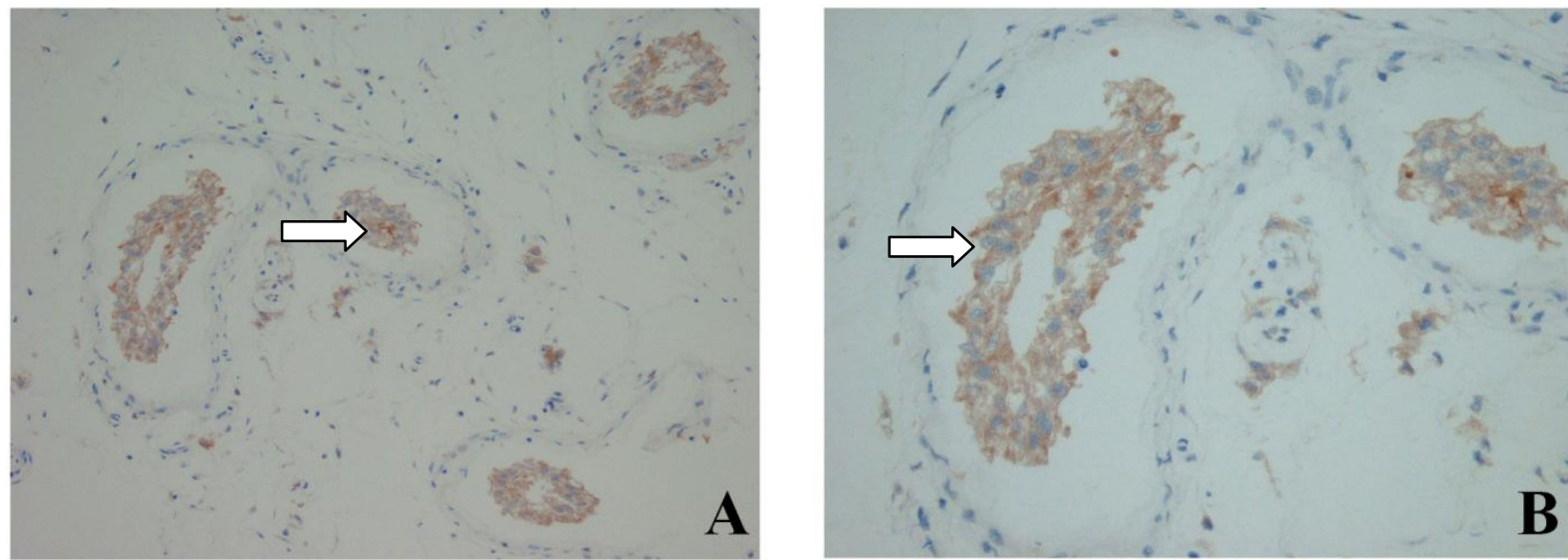

\section{Abbildung 4. Expression von VDR in IGCNU}

Die Expression von VDR in der nicht-invasiven Vorläuferläsion IGCNU wurde mittels Immunhistochemie untersucht. Die atypischen Keimzellen $(\Rightarrow)$ der IGCNU lassen eine geringe zytoplasmatische Expression von VDR erkennen (braune Signale). (A, Vergrößerung x100; B, Vergrößerung x200). 

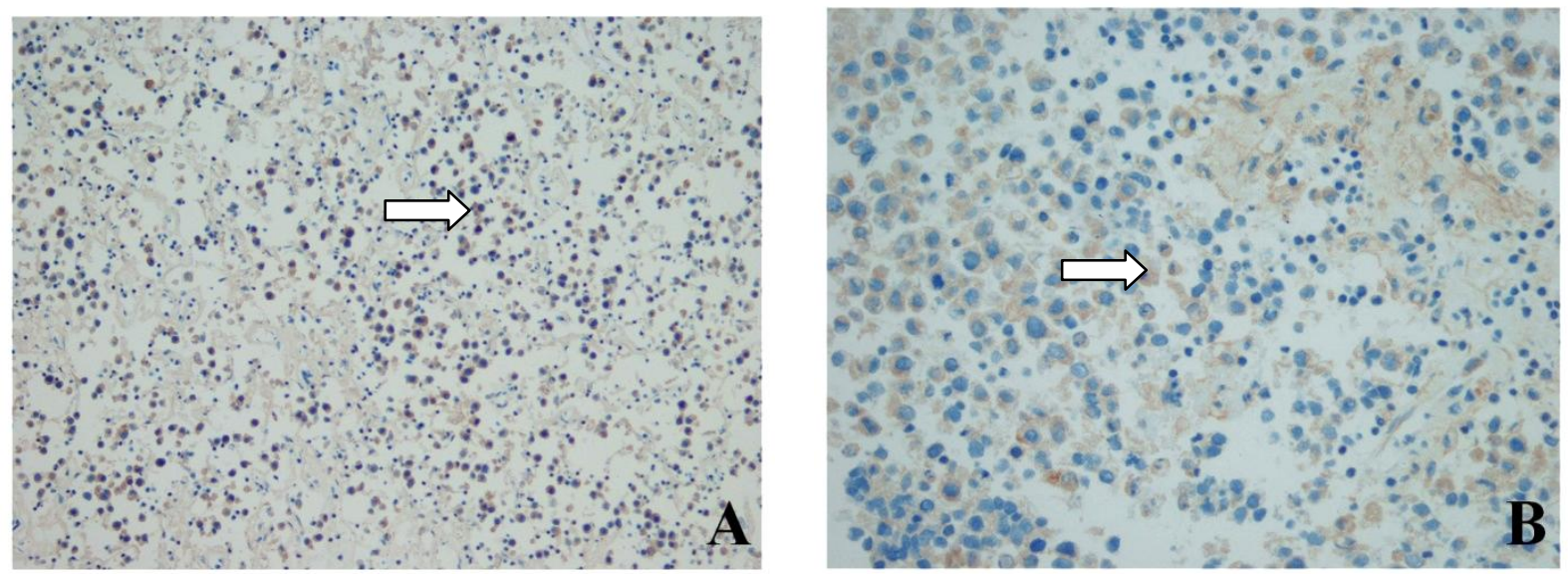

\section{Abbildung 5. Expression von VDR in Seminomen}

Die Expression von VDR in Seminomen wurde mittels Immunhistochemie untersucht. Die Tumorzellen der Seminome $(\Rightarrow)$ zeigen eine schwache zytoplasmatische Expression von VDR (braune Signale). (A, Vergrößerung x100; B, Vergrößerung x200).
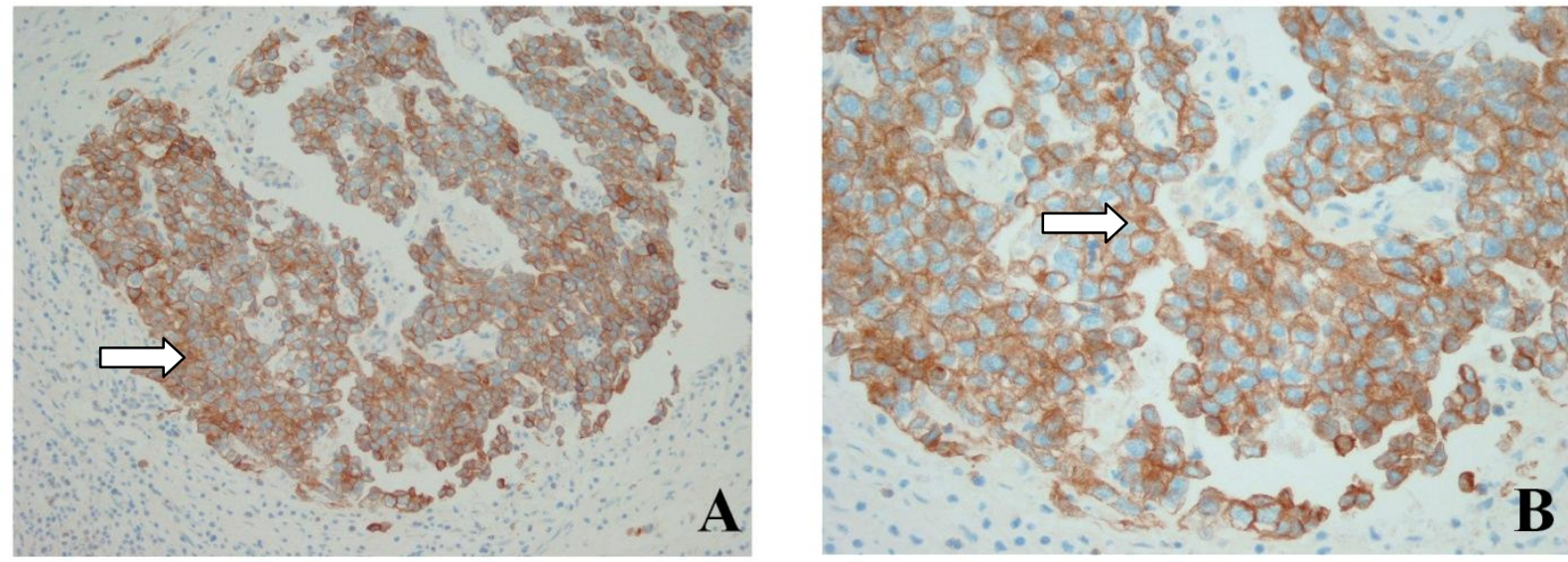

\section{Abbildung 6. Expression von VDR in embryonalen Karzinomen}

Die Expression von VDR in embryonalen Karzinomen wurde mittels Immunhistochemie untersucht. Die Tumorzellen $(\Rightarrow)$ der embryonalen Karzinome zeigen eine starke zytoplasmatische und teils nukleäre Expression von VDR (braune Signale).

(A, Vergrößerung x100; B, Vergrößerung x200). 

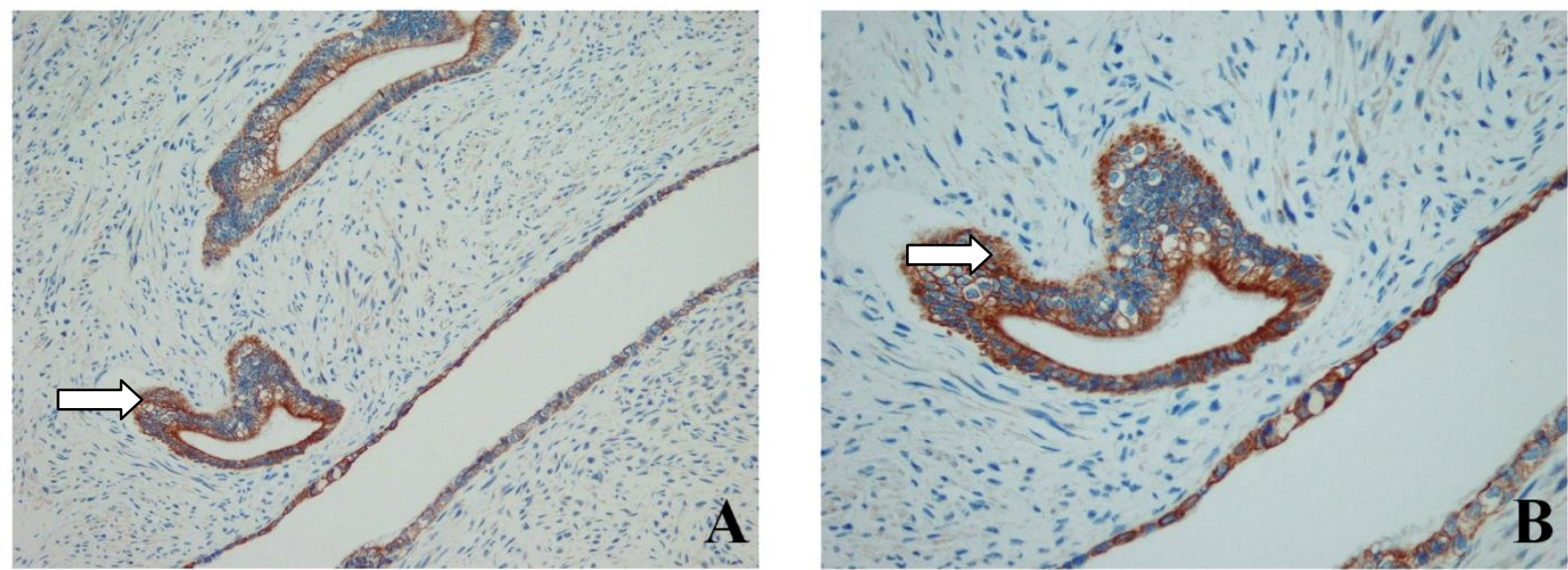

\section{Abbildung 7. Expression von VDR in Teratomen}

Die Expression von VDR in Teratomen wurde mittels Immunhistochemie untersucht. Die epithelialen Tumorzellen $(\Rightarrow)$ der Teratome zeigen eine starke zytoplasmatische und teils nukleäre Expression von VDR (braune Signale). (A, Vergrößerung x100; B, Vergrößerung x200).
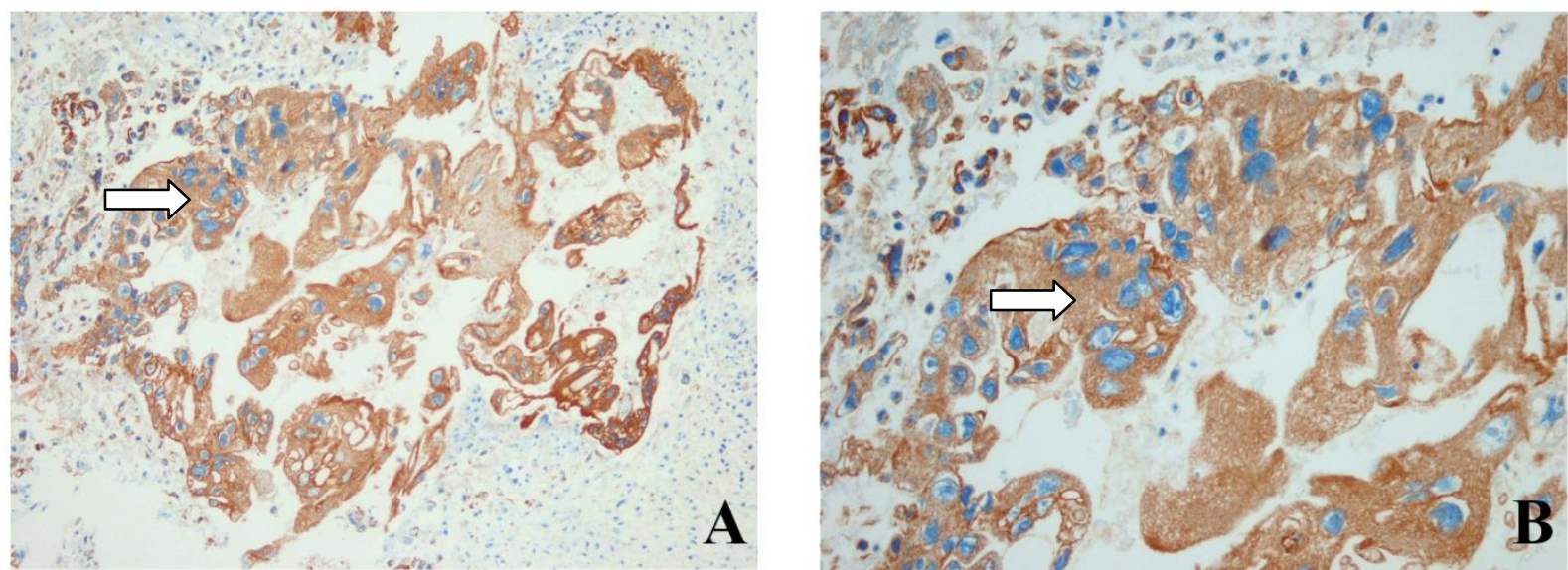

\section{Abbildung 8. Expression von VDR in Chorionkarzinom}

Die Expression von VDR in einem Chorionkarzinom wurde mittels Immunhistochemie untersucht. Die Tumorzellen $(\Rightarrow)$ des Chorionkarzinoms zeigen eine starke zytoplasmatische und teils nukleäre Expression von VDR (braune Signale). (A, Vergrößerung x100; B, Vergrößerung x200). 

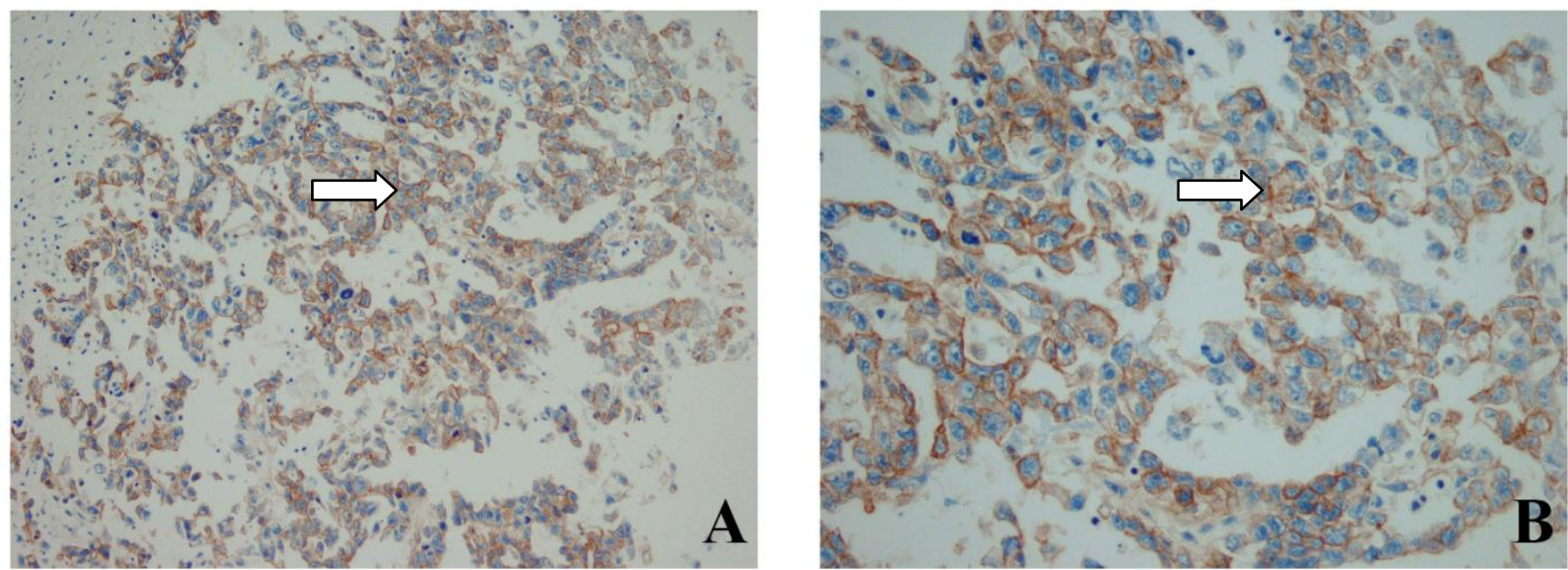

\section{Abbildung 9. Die Expression von VDR in Dottersacktumor}

Die Expression von VDR in einem Dottersacktumor wurde mittels Immunhistochemie untersucht. Die Tumorzellen $(\Rightarrow$ ) des Dottersacktumors zeigen eine starke zytoplasmatische und teils nukleäre Expression von VDR (braune Signale). (A, Vergrößerung x100; B, Vergrößerung x200).

\begin{tabular}{|c|c|c|c|}
\hline Tumorentität & Gruppe I & Gruppe II & Gruppe III \\
\hline Tumorfrei & 80 & 0 & 0 \\
\hline IGCNU & 0 & 37 & 0 \\
\hline Seminom & 0 & 57 & 0 \\
\hline Embryonales Carcinom & 0 & 1 & 12 \\
\hline Teratom & 0 & 0 & 8 \\
\hline Chorionkarzinom & 0 & 0 & 1 \\
\hline Dottersacktumor & 0 & 0 & 1 \\
\hline
\end{tabular}

Tabelle 3: Immunhistochemische Expression von VDR in TGCT 


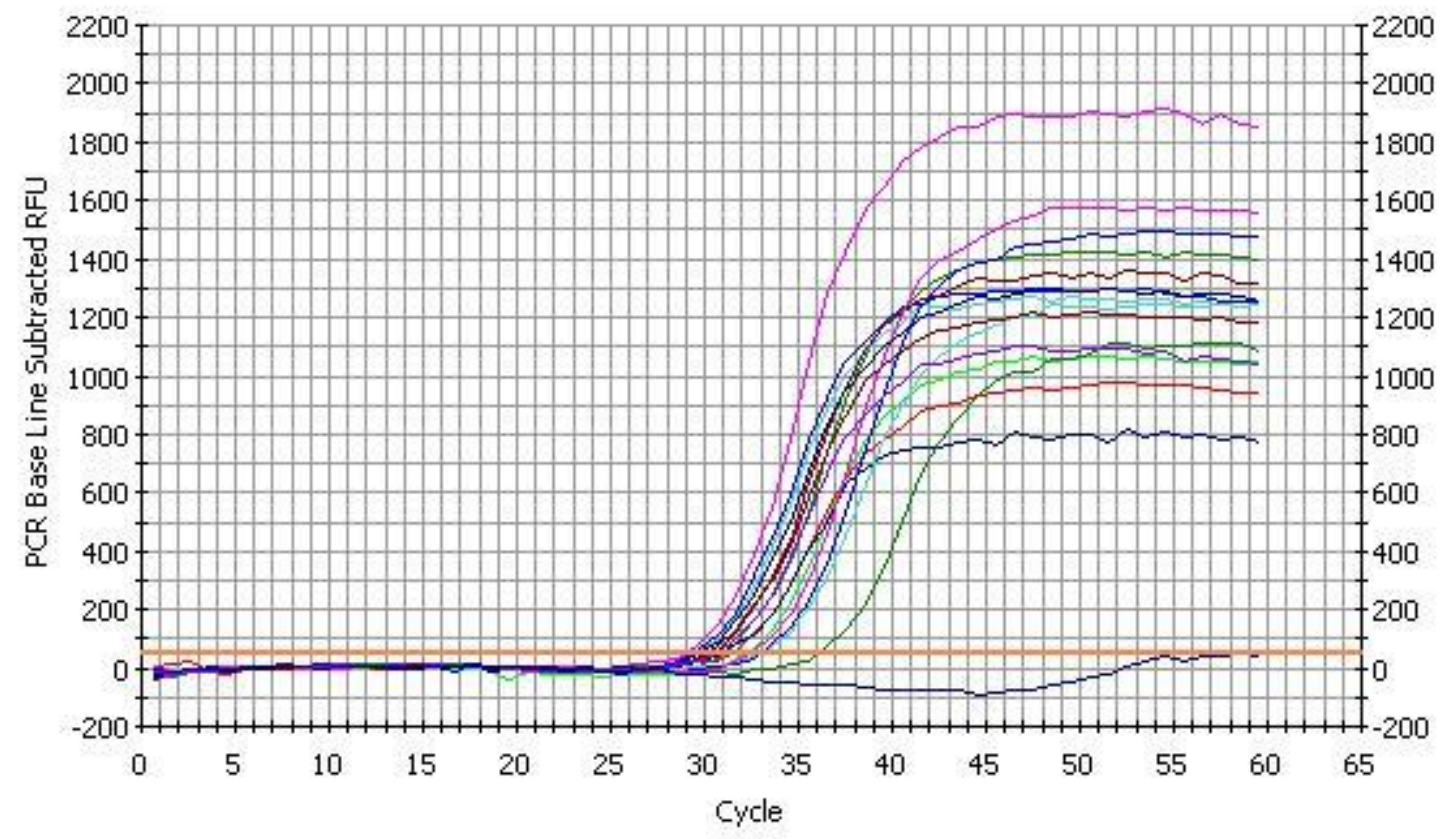

\section{Abbildung 10. Expression von VDR-mRNA in Seminomen}

Die Expression von VDR-mRNA in TGCT wurde mittels qRT-PCR untersucht. Seminome zeigen eine Expression von VDR-mRNA, die Grafik zeigt 15 repräsentative Gewebeproben von Seminomen.

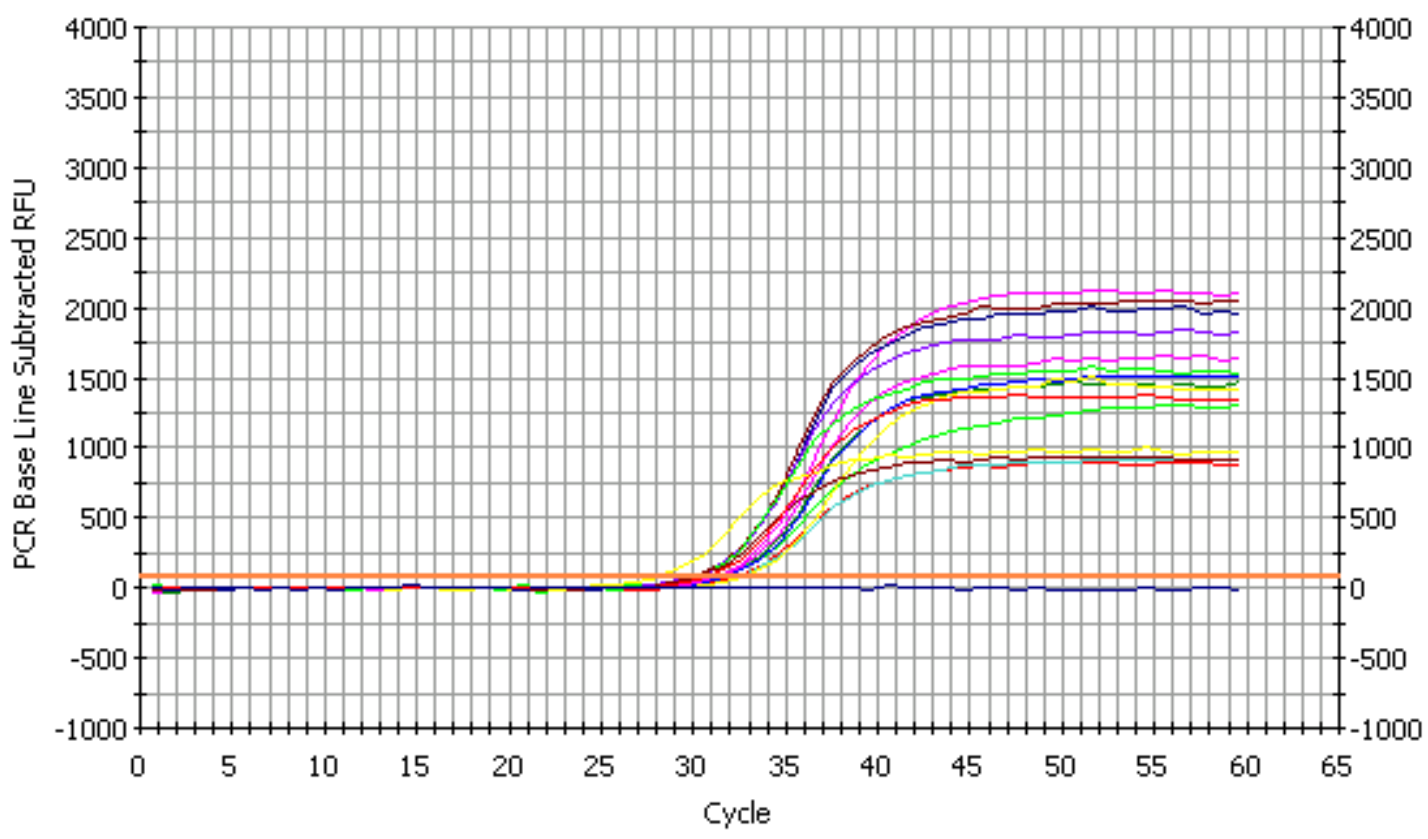

\section{Abbildung 11. Expression von VDR-mRNA in Nicht-Seminomen}

Die Expression von VDR mRNA in TGCT wurde mittels qRT-PCR untersucht. NichtSeminome zeigen eine Expression von VDR-mRNA, die Grafik zeigt 15 repräsentative Gewebeproben von Nicht-Seminomen. 


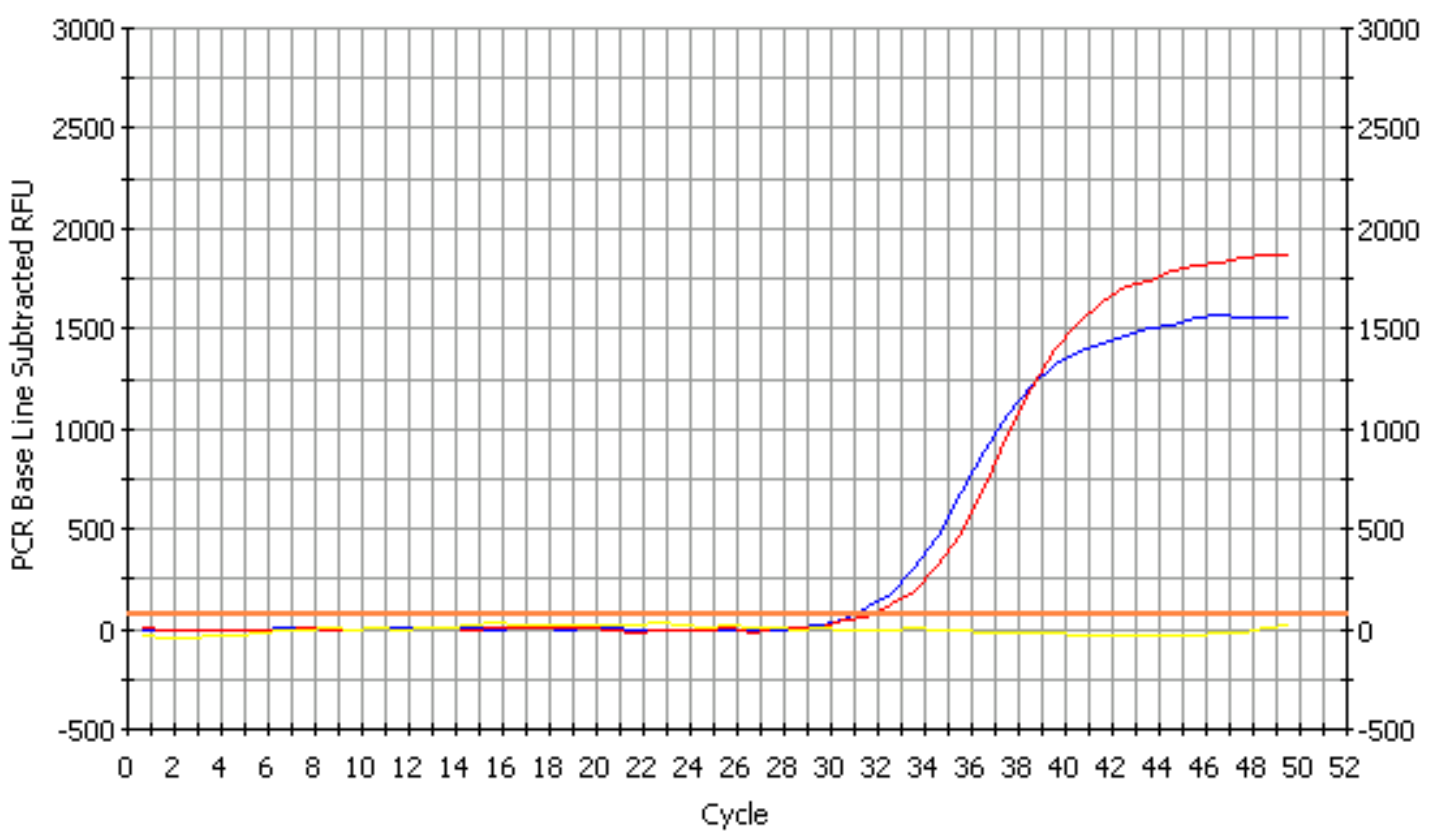

Abbildung 12. Expression von VDR-mRNA in TGCT-Zellinien NCCIT und NTERA-2

Die Expression von VDR-mRNA in TGCT-Zelllinien wurde mittels qRT-PCR untersucht. Die untersuchten TGCT-Zellinien NCCIT und NTERA-2 zeigen eine Expression von VDR mRNA.

$\sim 55 \mathrm{kDa}$

NTERA

NCCIT

\section{Abbildung 13. Expression von VDR in TGCT-Zelllinien}

Die Expression von VDR-Protein in TGCT-Zelllinien wurde mittels Western Blot untersucht. Die untersuchten TGCT-Zelllinien NTERA-2 und NCCIT exprimieren VDR Protein (55 kDa). 


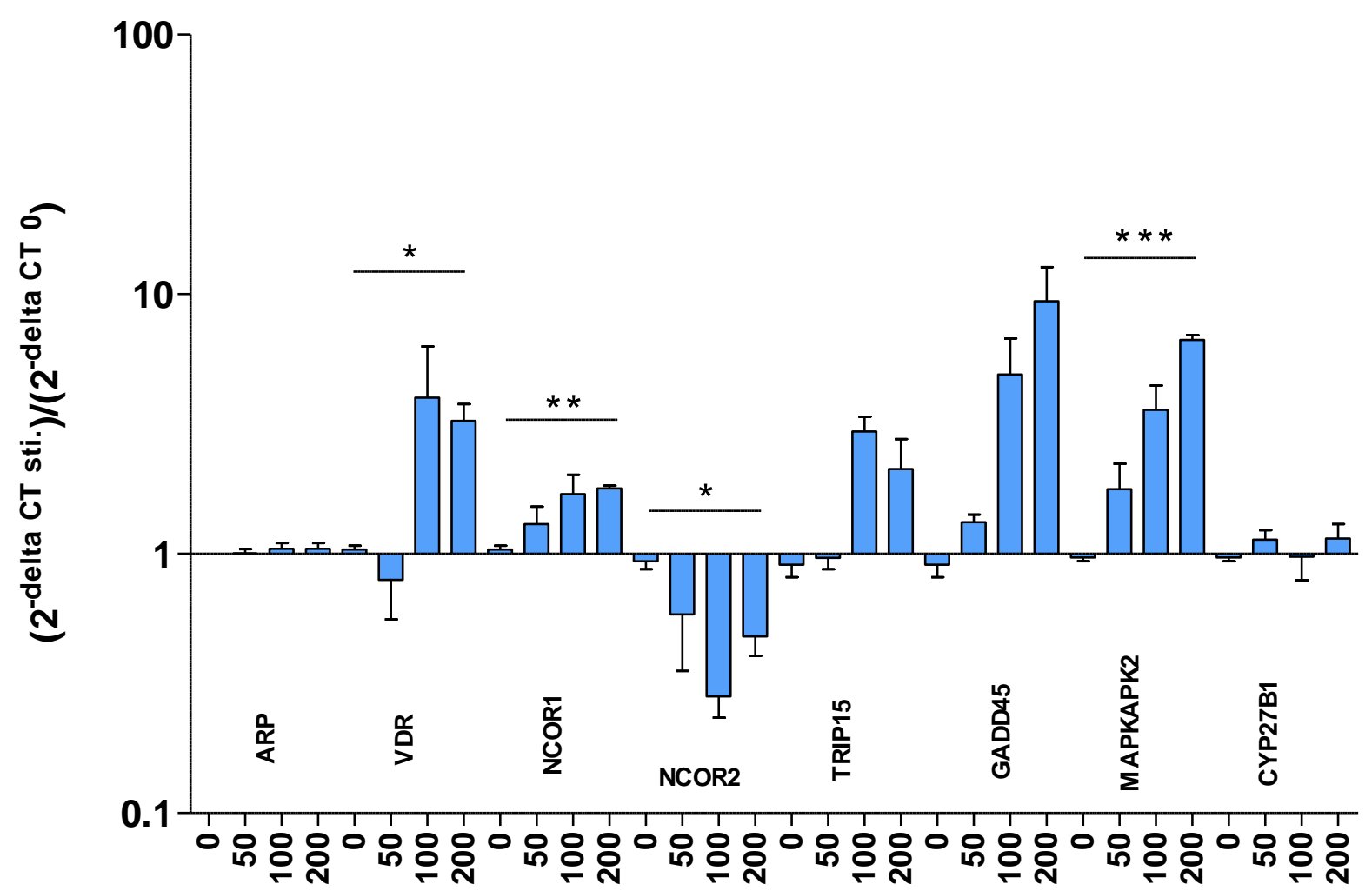

\section{Vitamin D 24h nM}

Abbildung 14. Expressionsprofil von VDR und Koregulatoren in der TGCT-Zelllinie NCCIT nach 50, 100 und $200 \mathrm{nM}$ Vitamin D3

Die Expression von VDR und Koregulatoren wurde mittels qRT-PCR in der TGCT-Zelllinie NCCIT untersucht. Die Tumorzelllinie NCCIT exprimiert VDR und Koregulatoren. Nach Stimulation mit 200 nM Vitamin D3 zeigt VDR eine geringe statistisch signifikante Zunahme der Genexpression. NCOR1 weist eine mäßig starke signifikante Zunahme nach Vitamin-D3Stimulation auf. NCOR2 zeigt eine geringe statistisch signifikante Abnahme der Genexpression. Bei MAPKAPK2 lässt sich eine starke statistisch signifikante Zunahme der Genexpression nach Stimulation mit Vitamin D3 nachweisen. Die restlichen Koregulatoren zeigen keine statistisch signifikante Veränderung der Genexpression. ${ }^{*} p<0,05$; ${ }^{* *} p<0,01$; ${ }^{* * *} p<0,001$. 


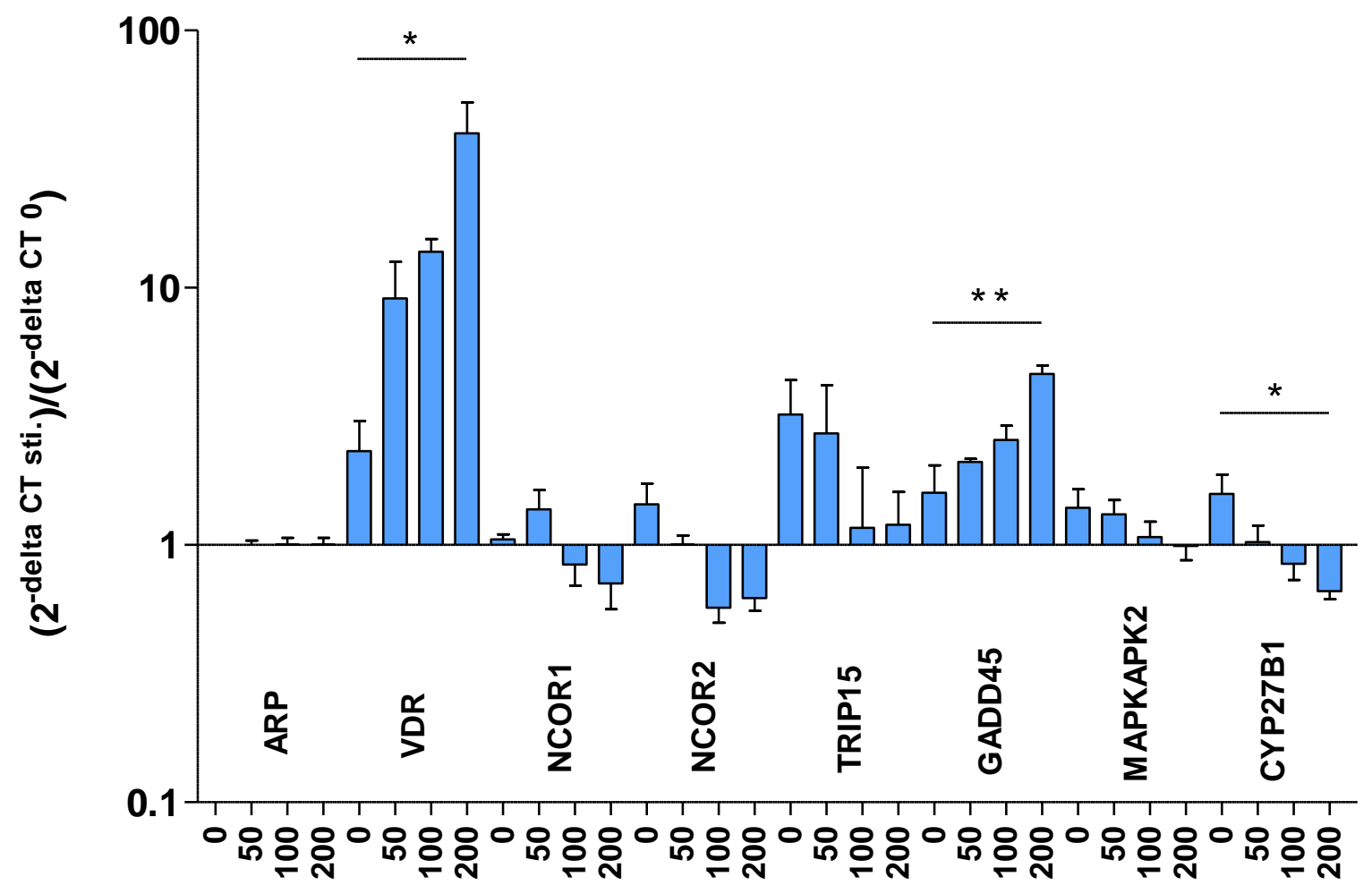

Vitamin D 24h nM

Abbildung 15. Expressionsprofil von VDR und Koregulatoren in der TGCT-Zelllinie NTERA-2 nach Stimulation mit 50, 100 und 200 nM Vitamin D3

Die Expression von VDR und Koregulatoren wurde mittels qRT-PCR in der TGCT-Zelllinie NTERA-2 untersucht. Die Tumorzelllinie exprimiert VDR und Koregulatoren. Nach Stimulation mit $200 \mathrm{nM}$ Vitamin D3 zeigt VDR eine geringe statistisch signifikante Zunahme und GADD45 eine deutliche statistisch signifikante Zunahme der Expression. CYP27B1 weist eine geringe statistisch signifikante Abnahme der Expression nach Stimulation mit Vitamin D3 auf. Die restlichen Koregulatoren zeigen keine Änderung der Expression nach Vitamin-D3-Stimulation. ${ }^{*} p<0,05 ;{ }^{* *} p<0,01 ;{ }^{* * *} p<0,001$. 

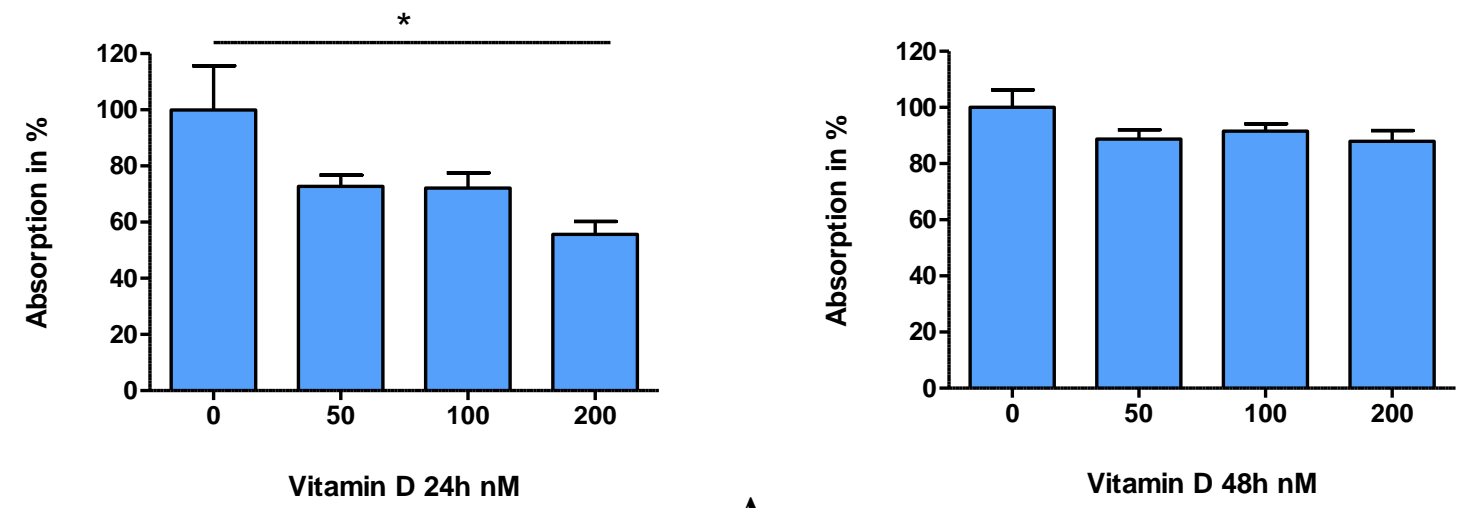

A

B

\section{Abbildung 16. Proliferation der TCGT-Zelllinie NCCIT nach Vitamin-D3-Stimulation}

Die Proliferation der TGCT-Zelllinie NCCIT nach Vitamin-D3-Stimulation (50, 100 oder 200 $\mathrm{nM}$ ) wurde mittels BrdU ELISA nach $24 \mathrm{~h}(\mathrm{~A})$ und $48 \mathrm{~h}$ (B) untersucht. Nach 24h zeigen die Tumorzellen eine geringe statistisch signifikante Abnahme der Proliferation um maximal $44 \%$ $(p=0,0208)$ bei einer Konzentration von $200 \mathrm{nM}$ Vitamin D3 (A). Nach $48 \mathrm{~h}$ Stimulation mit Vitamin D3 (200 nM) zeigt sich eine Reduktion der Proliferation um $13 \%$ (B). ${ }^{*} p<0,05$; ${ }^{* *} p<0,01 ;{ }^{* * *} p<0,001$.

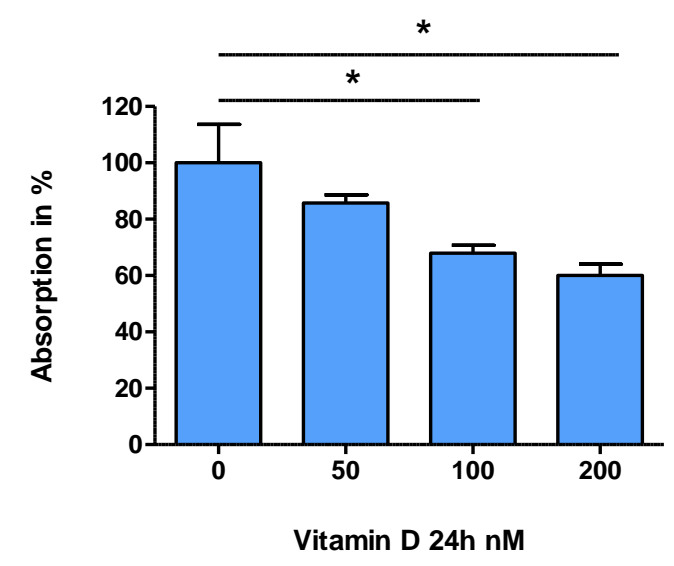

$\mathbf{A}$

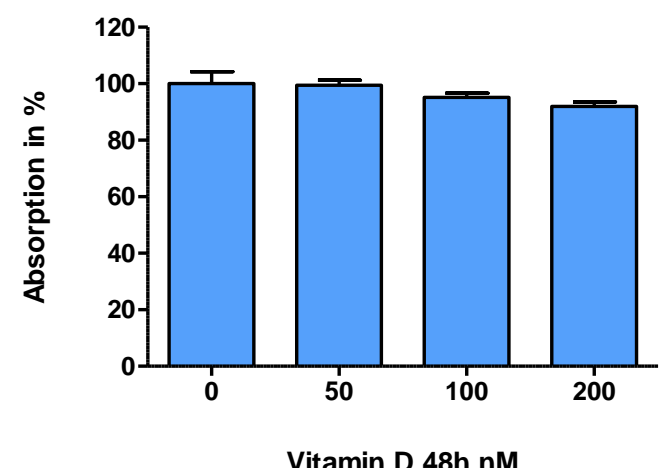

B

\section{Abbildung 17. Proliferation der TGCT-Zelllinie NTERA-2 nach Vitamin-D3-Stimulation}

Die Proliferation der TGCT-Zelllinie NTERA-2 nach Vitamin-D3-Stimulation (50, 100 oder $200 \mathrm{nM}$ ) wurde mittels BrdU ELISA nach $24 \mathrm{~h} \mathrm{(A)}$ und $48 \mathrm{~h}(\mathrm{~B})$ untersucht. Nach 24h zeigen die Tumorzellen eine statistisch signifikante Abnahme der Proliferation um maximal 39\% bei einer Konzentration von $200 \mathrm{nM}$ Vitamin D3 und um maximal 33\% bei einer Konzentration von $100 \mathrm{nM}(\mathrm{A})$. Nach $48 \mathrm{~h}$ Stimulation mit Vitamin D3 (200 nM) zeigt sich eine Reduktion der Proliferation um maximal $9 \%(B) .{ }^{*} p<0,05 ;{ }^{* *} p<0,01 ;{ }^{* *} p<0,001$ 


\section{Diskussion}

\subsection{Expression von VDR in Malignomen und TGCT}

IGCNU gelten in der aktuellen Literatur übereinstimmend als Vorläuferläsion invasiver Keimzellneoplasien (Roelofs et al. 2000). Epigenetische Veränderungen scheinen die Entstehung von IGCNU zu beeinflussen. Da in epidemiologischen Untersuchungen transkontinentale Unterschiede bezüglich der ansteigenden Zahl an Neuerkrankungen in Industrieländern beobachtet wurde (Papaioannou et al. 1975, Bokemeyer et al. 1992), scheinen exogene Faktoren, insbesondere Östrogen, eine entscheidende Rolle bei der Entstehung von IGCNU bzw. TGCT zu spielen (Skakkebaek et al. 2001). So könnte zum Beispiel die Differenzierung der Keimzellen gestört werden, wenn in der Frühschwangerschaft durch einen Östrogenüberschuss die Entwicklung der Gonaden negativ beeinflusst wird. Der daraus resultierende Differenzierungsstillstand führt zur Ausbildung von IGCNU. Die maligne Umwandlung der undifferenzierten Keimzellen vollzieht sich dann unter Hormoneinfluss und/oder anderer unbekannter Kofaktoren (Tamimi und Adham 2000, Skakkebaek et al. 2001). Für diese Theorien konnte allerdings in experimentellen/klinischen Studien noch kein Nachweis erbracht werden.

Neben epigenetischen Ursachen kommt es beim Übergang der nicht-invasiven IGCNU in invasive TGCT in über 90\% der Fälle zu strukturellen Chromosomenveränderungen von Chromosom 12. Dabei beobachtet man in etwa $80 \%$ ein Isochromosom 12, i(12p), wobei die Verdopplung des kurzen Armes von Chromosom 12 uniparenteral ist. Auch die übrigen Fälle der TGCT zeigen strukturelle Veränderungen von Chromosom 12, so dass diesem offenbar eine zentrale Rolle bei der Invasivität der TGCT zukommt. Aberrationen kommen aber auch in etwa 40 Prozent der TGCT auf dem langen Arm von Chromosom 12 vor, häufig in Form einer Deletion in den Regionen 12q13 und 12q22 (Delozier-Blanchet et al. 1985, Samaniego et al. 1990, Rodriguez et al. 1992). Der VDR gehört, wie die Retinoid-, Thyroid- und Östrogen-Hormon-Rezeptoren, in die Familie der Steroidhormonrezeptoren. Er ist ein Liganden-aktivierter Transkriptionsfaktor und wird interessanterweise auf Chromosom 12 kodiert (Hsieh et al. 1998, Michigami et al. 1999, Yasmin et al. 2005). 
Nachdem mehrere Forschungsgruppen das Vorhandensein des VDR in verschiedenen Malignomen bereits nachgewiesen haben (Skowronski et al. 1993, Friedrich et al. 1998, Cross et al. 2001, Mitschele et al. 2004, Khadzkou et al. 2006, Menezes et al. 2008) war es Gegenstand der hier vorliegenden Dissertationsschrift, TGCT auf die Expression und Funktion von VDR zu untersuchen.

Bis zum heutigen Zeitpunkt gibt es keine Studie, welche eine VDR-Expression in TGCT untersucht hat. Die in den beschriebenen Veröffentlichungen erlangten Erkenntnisse einer VDR Expression in Malignomen konnte erstmals mit den erzielten Ergebnissen dieser Arbeit auch für TGCT aufgezeigt werden. Dabei konnte in den durchgeführten immunhistochemischen Untersuchungen insbesondere in allen nichtseminomatösen TGCT eine VDR Expression nachgewiesen werden. Des Weiteren konnte in den TGCT-Zelllinien NCCIT und NTERA-2 neben VDR-Protein, auch eine VDR-mRNA Expression festgestellt werden. Die vor allem in nicht seminomatösen Keimzelltumoren dargestellte Expression von VDR legt eine Beteiligung des VitaminD3-Stoffwechsels in der Pathogenese von TGCT nahe.

$1 \alpha, 25(\mathrm{OH})_{2} \mathrm{D}_{3}$ ist die aktive Form des Vitamins $\mathrm{D} 3$ und entfaltet seine Wirkung über den Vitamin-D-Rezeptor (VDR) (Haussler et al. 1998). Nach intrazellulärer Bindung von $1 \alpha, 25(\mathrm{OH})_{2} \mathrm{D}_{3}$ an den VDR kommt es im Zellkern zu einer Heterodimerisation mit dem Retinoidsäurerezeptor (RXR). Das VDR/RXR-Heterodimer bindet an VDR response elements (VDREs) der DNA. Mit der Bindung des $1 \alpha, 25(\mathrm{OH})_{2} \mathrm{D}_{3} / \mathrm{VDR} / \mathrm{RXR}$-Komplexes an die VDREs ist es möglich, die Expression und Repression bestimmter Zielgene zu beeinflussen (Haussler et al. 1998). Neben dem physiologischen Vorkommen des VDR in verschiedenen Geweben des Menschen, wurde in den letzten Jahren zunehmend VDR-Expression in den verschiedensten Malignomen des Menschen beschrieben, die im folgenden aufgezeigt werden sollen. Khadzkou et al. (2006) beschrieben eine Expression von VDR und 1a-Hydroxylase in papillären Schilddrüsenkarzinomen. Außerdem exprimieren frühe und gut differenzierte Kolonkarzinome den VDR (Cross et al. 2001). Interessanterweise ging diese VDR-Expression offenbar in späten Stadien und schlecht differenzierten Kolonkarzinomen weitgehend verloren (Cross et al. 2001). Das unterstützt die von Khadzkou et al. (2006) gezeigten Ergebnisse und lässt Grund zur Annahme, dass der VDR in Verbindung mit 1 1 ,25(OH)2D3 einen fördernden Einfluss auf Differenzierung und Proliferation von Tumorzellen haben 
könnte. Des Weiteren wurde eine Expression von VDR in Prostatakarzinomen (Skowronski et al. 1993), Basalzellkarzinomen (Mitschele et al. 2004), verschiedenen Tumorentitäten von Mammakarzinomen (Friedrich et al. 1998) und in Tumoren der Lunge (Menezes et al. 2008) nachgewiesen. Diese Vielzahl unterschiedlicher Tumorarten, in denen der VDR exprimiert wird, spricht für seine Bedeutung auf Differenzierung und Proliferation und damit auch in der Pathogenese von Tumoren.

Darüberhinaus gibt es zwei interessante Beobachtungen, die mit einer Expression des VDR in TGCT in Verbindung stehen könnten.

(I) VDR wird auf Chromosom 12 codiert und typischerweise zeigen TGCT eine Deletion des langen Arms von Chromosom 12 (Delozier-Blanchet et al. 1985, Samaniego et al. 1990, Rodriguez et al. 1992). Dies könnte zusätzlich zu den epigenetischen Veränderungen, ein Hinweis auf mögliche genetische Aberationen von Onkogenen auf Chromosom 12 sein. Die beschriebenen Aberrationen auf chromosomaler Ebene scheinen Einfluss auf die Proliferationsenthemmung und Apoptosedefizienz sowie eine damit verbundene maligne Umwandlung von Keimzellen zu haben. Unterstützt wird diese These durch die Tatsache, dass neben denen am Zellzyklus beteiligten Genen, Onkoproteine und Gene welche für antiapoptotische Proteine kodieren, auf Chromosom 12 lokalisiert sind (Dmitrovsky et al. 1990, Strohmeyer et al. 1991, Sherr 1996, Houldsworth et al. 1997, Schmidt et al. 2001, Zafarana et al. 2002).

(II) Im Auftreten von TGCT sind geographische Unterschiede zu beobachten (10/100.000 Männer/Jahr in der Schweiz versus 0,6/100.000 Männer/Jahr in China), was die Rolle exogener Faktoren unterstreichen würde (Bokemeyer et al. 1992, Skakkebaek et al. 2001). Vitamin D3 kann in der Haut durch UV-Licht entstehen (Hollis 2005) und entfaltet seine Wirkung über Bindung an den VDR (Haussler et al. 1998). Eine erhöhte oder erniedrigte Expression könnte mit einer Exposition gegenüber UV-Licht in Verbindung stehen und mit der Pathogense von TGCT in Zusammenhang gebracht werden. 


\subsection{Regulation des Vitamin-D3-Polymorphismus in TGCT}

Nach der gewonnen Erkenntnis einer VDR Expression, insbesondere bei nicht seminomatösen Tumoren, wurden die nicht-seminomatösen Zelllinien NCCIT und NTERA-2 auf das Vorliegen von VDR und diverser Koregulatoren des Zellzyklus untersucht. Dazu wurden angezüchtete Zelllinien mit Vitamin D3 stimuliert und deren mRNA-Expression verschiedener Gene untersucht, die im Folgenden dargestellt werden sollen.

CYP27B1 und CYP24A1 sind zwei entscheidende Gene in der Regulation des Vitamin-D3-Stoffwechsels. Das Gen CYP24A1 kodiert für die 24-Hydroxylase welche die beiden Produkte $25(\mathrm{OH}) \mathrm{D}_{3}$ und $1,25(\mathrm{OH})_{2} \mathrm{D}_{3}$ in $24,25(\mathrm{OH})_{2} \mathrm{D}_{3}$ und $1,24,25(\mathrm{OH})_{2} \mathrm{D}_{3}$ durch Hydroxylierung an Position 24 umwandelt. Diese Umwandlung ist der limitierende Schritt im Katabolismus dieser beiden Stoffe. Darüber hinaus ist interessant zu beobachten, dass $1,25(\mathrm{OH})_{2} \mathrm{D}_{3}$ über CYP24A1 eine Produktion der weniger aktiven Metabolite $24,25(\mathrm{OH})_{2} \mathrm{D}_{3}$ und $1,24,25(\mathrm{OH})_{2} \mathrm{D}_{3}$ induziert. Das Gen CYP27B1 kodiert für die 1 $\alpha$-Hydroxylase in der Niere, welche für die Umwandlung von $25(\mathrm{OH}) \mathrm{D}_{3}$ zu $1,25(\mathrm{OH})_{2} \mathrm{D}_{3}$ verantwortlich ist (Haussler et al. 1998).

In der Tumorzellinie NTERA-2 konnte in dieser Arbeit erst nach Stimulation mit Vitamin D3 eine Expression von CYP24A1 verzeichnet werden. Vitamin D3 hatte in den Zellkulturversuchen allerdings keinen Einfluss auf die Proteinkonzentration von CYP24A1. In der Tumorzellinie NCCIT wird CYP24A1 nicht exprimiert, lediglich CYP27B1 zeigt eine Expression. Die Expression von CYP27B1 zeigte nach Stimulation mit 200nM Vitamin D3 in den durchgeführten Stimulationsversuchen eine statistisch signifikante Änderung der mRNA Konzentration.

Neben dem renalen Vorkommen der 1a-Hydroxylase ist diese auch in extrarenalem Gewebe zu finden. Unter anderem besteht so die Möglichkeit einer lokalen Umwandlung von $25(\mathrm{OH}) \mathrm{D}_{3} \mathrm{zu} 1,25(\mathrm{OH})_{2} \mathrm{D}_{3}$ in verschiedenen Geweben wie Kolon, Gehirn, Plazenta, Pankreas, Lymphknoten sowie der Haut. Interessanterweise ist eine erhöhte CYP27B1-Expression in Tumoren der Mamma (Townsend et al. 2005) und der Prostata (Schwartz et al. 1998) festzustellen. Auch in frühen Stadien von gut differenzierten Kolonkarzinomen wird eine erhöhte CYP27B1-Expression beobachtet, welche in schlecht differenzierten Stadien von Kolonkarzinomen allerdings wieder abnimmt (Bareis et al. 2001, Cross et al. 2001, Bises et al. 2004). Eine erhöhte 
Expression von CYP27B1 in Karzinomgewebe spricht für eine lokale Umwandlung von $25(\mathrm{OH}) \mathrm{D}_{3}$ zu $1,25(\mathrm{OH})_{2} \mathrm{D}_{3}$ und würde die Theorie einer chemopräventiven Rolle von $25(\mathrm{OH}) \mathrm{D}_{3}$ und $1,25(\mathrm{OH})_{2} \mathrm{D}_{3}$ in diesen Tumoren unterstützen (Deeb et al. 2007). Eine gezeigte erhöhte CYP24A1 mRNA Expression in Tumoren wirkt vermutlich über eine verminderte $1,25(\mathrm{OH})_{2} \mathrm{D}_{3}$ Konzentration dem antiproliferativen Effekt von $1,25(\mathrm{OH})_{2} \mathrm{D}_{3}$ entgegen (Friedrich et al. 2003, Cross et al. 2005). Eine von Cross et al. (2005) gezeigte erhöhte Expression von CYP24A1, bei einer gleichzeitigen Abnahme des Genproduktes von CYP27B1, in high-grade Kolonkarzinomen würde diese These untermauern (Cross et al. 2005). Während in Normalgeweben von Ovar, Lunge, Kolon und Mamma nur eine geringe Expression an CYP24A1 mRNA zu verzeichnen war, kam es in Tumorgewebe von Lunge, Ovar und Kolon zu einer erhöhten Expression von CYP24A1 mRNA. In Tumorgewebe der Mamma hingegen kam es zu einer Abnahme der Expression. Dies lässt vermuten, dass die $1,25(\mathrm{OH})_{2} \mathrm{D}_{3}$ Spiegel in diesen Fällen reduziert sein könnten (Albertson et al. 2000, Weiss et al. 2003, Cross et al. 2005, Anderson et al. 2006). Somit würde eine Suppression der CYP24A1 Expression und Aktivität für eine erfolgreiche Tumorprävention hilfreich sein. Dabei machen verschiedene Inhibitoren der 24Hydroxylase Tumorzellen sensitiver für $1,25(\mathrm{OH})_{2} \mathrm{D}_{3}$ und seine Metaboliten (Zhao et al. 1996, Ly et al. 1999, Peehl et al. 2002, Parise et al. 2006).

Das NCOR1-Gen kodiert für ein Protein, das eine ligandenunabhängige Unterdrückung der Transkription von Thyroidhormon- und Retinsäure-Rezeptoren vermittelt. Im Rahmen dessen sorgt es für eine Chromatin-Kondensation und für eine Unterdrückung bestimmter Transkriptionsfaktoren. Dabei ist es Teil eines Komplexes, bestehend aus Histondeacetylase und Transkriptionsfaktoren. NCOR1 ist somit ein entscheidendes Protein bei der Interaktion mit Thyroidhormon- und Retinsäure-Rezeptoren (Horlein et al. 1995). Die Ergebnisse dieser Arbeit zeigen eine statistisch signifikante Zunahme der NCOR1 Expression in der TGCT-Zelllinien NCCIT. Tzelepi et al. (2009) beschrieben den Zusammenhang einer Expression von NCOR1 und dem erkrankungsfreien Intervall bzw. dem Überleben bei Kolonkarzinomen. Dabei scheint die gestörte Regulation von Co-Regulatoren des VDR wie NCOR1 einen Beitrag zur Initiation und Progression von kolorektalen Karzinomen zu leisten (Tzelepi et al. 2009). Die Expression von NCOR1 in TGCT könnte damit eine Rolle für eine bessere Prognose bei Patienten mit TGCT spielen. 
NCOR2 ist ebenfalls in der transkriptionellen Regulation nukleärer Hormonrezeptoren involviert. Zum einen ist NCOR2 für eine Repression bestimmter nukleärer Hormonrezeptoren verantwortlich und zum anderen scheint NCOR2 Histondeacetylasen zu DNA Promotor Regionen zu rekrutieren. Histondeacetylasen führen zu einer Demethylierung an Histonproteinen und somit zu einer Repression der Transkription. Somit unterstützen sie nukleäre Hormonrezeptoren in der Inhibition von Zielgenen (Chen und Evans 1995, Sande und Privalsky 1996, Nagy et al. 1997).

Die in dieser Arbeit erzielten Ergebnisse zeigen eine NCOR2-Expression in malignen Keimzelltumoren des Hodens. Nach Stimulation mit Vitamin D3 kommt es hier zu einer statistisch signifikanten Abnahme der mRNA-Expression in TGCT-Zelllinien. Diese Tatsache lässt Grund zu der Annahme, dass NCOR2 regulatorischen Einfluss auf die Interaktion zwischen VDR/RXR haben könnte.

TRIP 15, auch CSN2 genannt, ist ein Protein welches als Bestandteil des COP9/signalosome Komplexes eingeschaltet ist und an der Regulation verschiedenster Zell-Signalwege sowie des Zellzyklus beteiligt ist. Daneben hat es als ligandenabhängiges Protein Einfluss auf Thyroidhormon- und Retinsäure-XRezeptoren (RXR) (Lee et al. 1995, Seeger et al. 1998, Schaefer et al. 1999). Der VDR gehört in die Gruppe der Thyroidhormonrezeptoren und fusioniert, nach Bindung mit Vitamin D3, mit einem RXR (Haussler et al. 1998). Dabei könnte die erhöhte Expression von VDR und TRIP 15 mRNA in den Tumorzelllinien NCCIT und NTERA-2 in Zusammenhang stehen. TRIP 15 wird in den beiden Tumorzellinien NCCIT und NTERA-2 exprimiert erfährt aber durch die Stimulation mit Vitamin D3 keine Zunahme der mRNA Expression. Ob das CSN2 Protein als Untereinheit des COP9/signalosome, Einfluss auf die Transkription des VDR hat wurde im Rahmen dieser Arbeit nicht untersucht. Die Ergebnisse könnten allerdings als Ansatz für weitere Untersuchungen genutzt werden. Des Weiteren scheint der COP9/signalosome Komplex mit seinen Untereinheiten eine Rolle in der Pathogenese verschiedenster Tumorerkrankungen zu spielen (Richardson und Zundel 2005). Welche Rolle der COP9/signalsome Komplex in TGCT spielen könnte ist bisher nicht aufgeklärt worden.

MAPKAPK2 ist ein Gen welches für das gleichnamige Protein kodiert und im p38 MAPK Signaltransduktionsweg eingeschaltet ist. Dabei wird MAPKAPK2 durch direkte Phosphorilierung der p38 MAP Kinase reguliert. Das Hitzeschockprotein 27 
(HSP27) ist dabei ein Substrat der MAPKAPK2 (Stokoe et al. 1992, Stokoe et al. 1993, Rouse et al. 1994).

Die TGCT-Zelllinien exprimieren MAPKAPK2. Nach Vitamin D3 Stimulation kam es interessanterweise bei der NCCIT-Zelllinie $\mathrm{zu}$ einer deutlichen statistisch signifikanten Zunahme der MAPKAPK2-mRNA Konzentration. Bei der NTERA-2Zelllinie hatte die Vitamin-D3-Stimulation einen signifikanten Einfluss auf die MAPKAPK2-mRNA-Konzentration. Kumar et al. (2010) zeigten die Rolle von MAPKAPK2 in Blasenkarzinomen (Kumar et al. 2010) und konnten somit die von Xu und Kollegen gezeigten Ergebnisse bestätigen, welche bereits 2006 die Rolle von MAPKAPK2 bei der Invasion von Prostatakarzinomen zeigten (Xu et al. 2006). Des Weiteren unterstrichen Kotlyarov und Kollegen (2002) die Bedeutung von MAPKAPK2 in der Metastasierung von Tumorzellen (Kotlyarov et al. 2002). Die MAPKAPK2-Expression in TGCT-Zelllinien könnte somit eine Rolle in der Pathogenese von TGCT spielen. Darüber hinaus wäre eine mögliche Expression von MAPKAPK2 in Metastasen von TGCT ein Ansatz für weitere Untersuchungen.

GADD45 ist durch die Aktivierung verschiedenster Gene an der Replikation der DNA, des G1-Zellzyklusarrest und durch die Unterdrückung von Protoonkogenen an antiproliferativen Effekten in Tumorzellen beteiligt. Es wirkt direkt proapototisch und hat Einfluss auf die DNA Reperatur $1,25(\mathrm{OH})_{2} \mathrm{D}_{3}$ führt in Kolonkarzinomen, Ovarialtumoren und Leukämiezellen zu einer Hochregulation von GADD45 (Fornace et al. 1992, Liebermann und Hoffman 1998, Takekawa und Saito 1998, Mita et al. 2002). Die TGCT-Zelllinien NCCIT und NTERA-2 exprimieren GADD45 und interessanterweise kommt es nach Stimulation mit 200nM Vitamin D3 zu einer statistisch signifikanten Hochregulation von GADD45 in der NTERA-2-Zelllinie. Tront et al. (2006) konnten zeigen, dass ein Verlust der GADD45-Expression in Tumorzellen von Mammakarzinomen die Tumorentstehung fördert. Es wurde vermutet, dass dies Ausdruck einer Apoptoseinhibition in Mammakarzinom Zellen sein könnte. Die geringe Expression von GADD45 in aggressiven histologischen Phänotypen würde diese These unterstützen (Tront et al. 2006). Diese Erkenntnisse könnten darauf hindeuten, dass $1,25(\mathrm{OH})_{2} \mathrm{D}_{3}$ die Fähigkeit besitzt über eine erhöhte Expression von GADD45 Einfluss auf Differenzierung und Wachstum von TGCT zu haben. 


\subsection{Proliferationsverhalten von TGCT-Zelllinien nach Vitamin-D3- Stimulation}

Insgesamt scheint die Pathogenese der IGCNU und der TGCT neben epigenetischen Faktoren auch mit einer Fehlentwicklung sowie einer mangelnden Funktion des Hodens, wie fehlerhafte Spermatogenese und Infertilität, in Zusammenhang zu stehen. Aufgrund dieser Zusammenhänge entwickelte sich in den letzten Jahren die Theorie des testikulären Dysgenesie-Syndroms (TDS, testicular dysgenesis syndrome)(Pike et al. 1986, Hoei-Hansen et al. 2003). Wie unter Punkt 1.1 beschrieben kann das TDS als eine Art testikuläre Grunderkrankung angesehen werden, in dem funktionelle Läsionen wie fehlerhafte Spermatogenese und Infertilität, neoplastische Läsionen wie Mikrolithiasis und Keimzellneoplasien sowie ontogenetische Läsionen wie Kryptorchismus und Hypospadie zusammengefasst werden (Skakkebaek et al. 2001, Hoei-Hansen et al. 2003). Vergleichende Beobachtungen an Patienten mit Intersexualsyndromen, bei denen sehr häufig Erkrankungen wie Hypospadie, Kryptorchismus einerseits und TGCT andererseits zu beobachten sind, zeigen einen Zusammenhang zum TDS (Aarskog 1970, Savage und Lowe 1990). Hoei-Hansen et al (2003) fanden heraus, dass neben einer signifikant gestörten Spermatogenese in Hodentumoren, interessanterweise auch in Gewebeproben des kontralateralen Hodens häufig Tubuli seminiferi mit Mikrokalzifikation, undifferenzierten Sertoli- Zellen, Sertoli- Zellknötchen und/oder IGCNU zu finden waren.

Exogene Faktoren, insbesondere Östrogen, scheinen eine entscheidende Rolle bei der Entstehung von IGCNU bzw. TGCT zu spielen (Skakkebaek et al. 2001). In wie weit Vitamin D3, als exogener Faktor, Einfluss in der Pathogenese maligner Keimzelltumoren haben könnte sollte in dieser Arbeit ebenfalls untersucht werden.

1,25-DihydroxyVitamin D3 $\left[1,25(\mathrm{OH})_{2} \mathrm{D}_{3}\right]$ als der aktive Metabolit von Vitamin D3 ist in wichtige regulatorische Prozesse involviert und beeinflusst dadurch eine vielfältige Reihe von physiologischen Vorgängen im menschlichen Körper (Deeb et al. 2007). Die Abwesenheit von $1,25(\mathrm{OH})_{2} \mathrm{D}_{3}$ ist mit Krankheitsbildern wie Rachitis, Osteomalazie und Skelett-Erkrankungen verbunden, welche sich durch fehlende Knochenmineralisierung auszeichnet. Des weiteren besitzt $1,25(\mathrm{OH})_{2} \mathrm{D}_{3}$ auch einen 
bedeutenden Effekt auf die Kalzium- und Phosphat-Homöostase (Dusso et al. 2005). Neben diesen bekannten klassischen Effekten kommt $1,25(\mathrm{OH})_{2} \mathrm{D}_{3}$ eine wichtige Rolle bei der Regulation der Zellproliferation und Differenzierung zu. So wurde bereits in den frühen 1980er Jahren die Anwesenheit des Vitamin-D-Rezeptor (VDR) in normalen und malignen Geweben nachgewiesen (Eisman et al. 1980). In einer Vielzahl von normalen und malignen Zelltypen konnten antiproliferative und prodifferenzierende Effekte von $1,25(\mathrm{OH})_{2} \mathrm{D}_{3}$ gezeigt werden (Abe et al. 1981, K. Colston et al. 1981). Interessanterweise hemmt $1,25(\mathrm{OH})_{2} \mathrm{D}_{3}$ das Zellwachstum von normalen Zellen und Tumorzellen durch Hemmung des Zellzyklus in der G1 zur SPhase (Verlinden et al. 1998, Q. Wang et al. 2000). Die Hemmung des Zellzyklus von $1,25(\mathrm{OH})_{2} \mathrm{D}_{3}$ ist auf eine Herunteregulation von Zellzyklus reguliernden Cycline und Cyclin abhängigen Kinasen zurückzuführen (Jensen et al. 2001, Li et al. 2004). In durchgeführten Studien an Plattenepithelkarzinomen, Prostatakarzinomen, Ovarialtumoren, Tumoren der Brust und der Lunge konnte ein signifikanter antitumoröser Effekt von 1,25(OH) ${ }_{2} \mathrm{D}_{3}$ und Vitamin-D3-Analoga aufzeigt werden ( $\mathrm{K}$. W. Colston et al. 1992, Getzenberg et al. 1997, Nakagawa et al. 2005, Zhang et al. 2005). Dabei haben $1,25(\mathrm{OH})_{2} \mathrm{D}_{3}$ und seine Derivate über den VDR Einfluss auf die Regulation von Proliferation, Apoptose und Angiogenese (Shabahang et al. 1993, M. Liu et al. 1996, Simboli-Campbell et al. 1996, Mantell et al. 2000, X. Wang und Studzinski 2001, Ylikomi et al. 2002).

Die untersuchten Tumorzellinien NCCIT und NTERA-2 zeigten jeweils nach Stimulation mit 200 nM Vitamin D3 für 24 Stunden eine statistisch signifikante Abnahme der Proliferation. Vitamin D3 scheint folglich einen antiproliferativen Effekt auch auf Tumorzellen des Hodens zu haben.

\subsection{Therapeutische Aspekte von Vitamin D3}

Die beschriebenen antiproliferativen Effekte eröffnen mögliche Perspektiven für eine potentielle pharmakologische Verwendung von $1,25(\mathrm{OH})_{2} \mathrm{D}_{3}$. Analysen in vitro und in vivo haben eine synergistische Wirkung von $1,25(\mathrm{OH})_{2} \mathrm{D}_{3}$ zu chemotherapeutischen Agenzien aufgezeigt (Fornace et al. 1992, Light et al. 1997, Moffatt et al. 1999). Dabei scheint Vitamin D3 die antikanzeröse Wirkung von Taxanen und DNA interkalierenden Substanzen aber auch für Platinanaloga zu potenzieren (Light et al. 
1997, Moffatt et al. 1999, Q. Wang et al. 2000, Hershberger et al. 2001, Hershberger et al. 2002). Eine Potenzierung wurde beobachtet, wenn $1,25(\mathrm{OH})_{2} \mathrm{D}_{3}$ während oder vor einer chemotherapeutischen Behandlung gegeben wurde. Eine Gabe nach Chemotherapie hingegen ergab keine potenzierende Wirkung (Light et al. 1997, Hershberger et al. 2001). McGuire et al. (2001) zeigten eine durch die Kombination von $1,25(\mathrm{OH})_{2} \mathrm{D}_{3}$ und Cisplatin vermittelte Tumorzell-Apoptose bei Plattenepithelkarzinomen in vitro. Obwohl einige Patienten auf die Therapie mit $1,25(\mathrm{OH})_{2} \mathrm{D}_{3}$ anzusprechen schienen, konnten keine größeren klinischen Studien durchgeführt werden, da $20 \%$ bis $30 \%$ der Patienten unter täglicher Applikation von $1,25(\mathrm{OH})_{2} \mathrm{D}_{3}$ hyperkalziämische Krisen entwickelten (Hansen et al. 2000, Masuda und Jones 2003). Es bleibt abzuwarten in wie weit die Wirkungen und Nebenwirkungen von $1,25(\mathrm{OH})_{2} \mathrm{D}_{3}$ und seiner Analoga optimiert werden und somit die antitumorösen Wirkungen in die Tumortherapie einfließen können.

Weiterhin wird vermutet, dass als Ursache eines TDS nicht etwa Mutationen sondern vielmehr epigenetische Modifikationen von CpG-Inseln und/oder Histonproteinen verschiedenster DNA-Regionen mit fortlaufender Über-/Unterexpression spezifischer Proteine als Ursache in Frage kommen. Diese Beeinflussung scheint die Differenzierung von Keimzellen zu verändern und so zur Entstehung von IGCNU beizutragen. Dabei ist die Acetylierung von Histonproteinen sowie die Methylierung von CpG-Inseln neben der Differenzierung maligner Keimzellen interessanterweise auch für die Differenzierung nicht-neoplastischer Keimzellen von Bedeutung (Gottlicher et al. 2001, Smiraglia et al. 2002).

Ein wesentliches Thema der hier vorliegenden Arbeit war die Frage, inwieweit Vitamin D3 und seine aktiven Metabolite auch in Hodentumoren sowie deren Zellinien antitumoröse Wirkungen entfalten können. In den Proliferationsbestimmungen dieser Arbeit konnte eine statistisch signifikante Abnahme der Proliferation bei den untersuchten Tumorzellinien NCCIT und NTERA2 dargestellt werden. Vitamin D3 besitzt also auch bei TGCT antiproliferative Fähigkeiten. Dabei würde in der Diagnostik von TGCT ein positiver VDR Rezeptorstatus für ein besseres Ansprechen von Vitamin D3 in Tumorzellen sprechen und einen möglichen antikanzerösen Effekt von Vitamin D3 auf Tumorzellen begünstigen. 


\section{$5 \quad$ Zusammenfassung}

Die malignen Keimzelltumoren des Hodens (testicular germ cell tumors, TGCT) sind die häufigsten soliden malignen Tumoren des Mannes zwischen dem 20. und 40. Lebensjahr. Die TGCT lassen sich klinisch-therapeutisch als auch histologisch in die zwei großen Gruppen der Seminome (55\%) und Nicht- Seminome (35\%) unterteilen. Vitamin D3 gehört in die Gruppe der fettlöslichen Vitamine und enfaltet physiologisch über seinen aktiven Metaboliten $1,25(\mathrm{OH})_{2} \mathrm{D}_{3}$ und die Bindung an den Vitamin-D3Rezeptor (VDR) in verschiedenen Organen spezifische Wirkungen. Der VDR gehört wie die Retinoid-, Thyroid- und Östrogen-Hormon-Rezeptoren in die Familie der Steroidhormonrezeptoren.

Neben den physiologischen Wirkungen von $1,25(\mathrm{OH})_{2} \mathrm{D}_{3}$ wurde in den letzten Jahren auch die Bedeutung des VDR in diversen Tumorentitäten des Menschen beschrieben. Die Ergebnisse dieser Arbeit zeigen erstmals eine Expression von VDR in TGCT. Neben dem VDR zeigen ebenfalls diverse an der Regulation des Zellzyklus beteiligte und im Vitamin-D3-Stoffwechsel involvierte Proteine eine deutliche Expression.

In den Stimulationsversuchen mit Vitamin D3 konnte insbesondere für den VDR eine statistisch signifikante Zunahme der mRNA-Expression verzeichnet werden. Von den untersuchten Vitamin-D3-regulierten Genen zeigten NCOR1, MAPKAPK2 und GADD45 eine statistisch signifikante Zunahme der Genexpression nach Stimulation mit Vitamin D3. NCOR2 und CYP27B1 hingegen wiesen eine statistisch signifikante Abnahme der Genexpression nach Stimulation mit Vitamin D3 auf. Die deutliche Abnahme der Proliferation nach Vitamin-D3-Stimulation deutet auf eine antiproliferative Wirkung in TGCT hin.

Zusammenfassend lässt sich sagen, dass TGCT VDR exprimieren und es unter Einfluss von Vitamin D3 zu einer Zunahme der VDR-Expression kommt. Des Weiteren führt die Behandlung von TGCT mit Vitamin D3 zu einer statistisch signifikanten Abnahme der Proliferation. Dies könnte in der Zukunft mögliche neue therapeutische Ansätze, insbesondere in der Kombination mit Cisplatinderivaten, eröffnen. 


\section{$6 \quad$ Literaturverzeichnis}

Aarskog D (1970): Clinical and cytogenetic studies in hypospadias. Acta Paediatr Scand Suppl 203, Suppl 203:201+

Abe E, Miyaura C, Sakagami H, Takeda M, Konno K, Yamazaki T, Yoshiki S,Suda T (1981): Differentiation of mouse myeloid leukemia cells induced by 1 alpha,25dihydroxyVitamin D3. Proc Natl Acad Sci USA $\underline{78}$, 4990-4994

Albertson DG, Ylstra B, Segraves R, Collins C, Dairkee SH, Kowbel D, Kuo WL, Gray JW,Pinkel D (2000): Quantitative mapping of amplicon structure by array CGH identifies CYP24 as a candidate oncogene. Nat Genet 25, 144-146

Anderson MG, Nakane M, Ruan X, Kroeger PE,Wu-Wong JR (2006): Expression of VDR and CYP24A1 mRNA in human tumors. Cancer Chemother Pharmacol 57, 234-240

Bareis P, Bises G, Bischof MG, Cross HS,Peterlik M (2001): 25-hydroxy-Vitamin D3 metabolism in human colon cancer cells during tumor progression. Biochem Biophys Res Commun 285, 1012-1017

Bises G, Kallay E, Weiland T, Wrba F, Wenzl E, Bonner E, Kriwanek S, Obrist P,Cross HS (2004): 25-hydroxyVitamin D3-1alpha-hydroxylase expression in normal and malignant human colon. J Histochem Cytochem $\underline{52}, 985-989$

Bokemeyer C, Harstrick A, Schoffski P, Schmoll HJ,Poliwoda H (1992): [Germ-cell tumors of the testis. The epidemiological and etiological aspects]. Dtsch Med Wochenschr 117, 1532-1537

Brenza HL,DeLuca HF (2000): Regulation of 25-hydroxyVitamin D3 1alphahydroxylase gene expression by parathyroid hormone and 1,25-

dihydroxyVitamin D3. Arch Biochem Biophys $\underline{381}$, 143-152

Chen JD,Evans RM (1995): A transcriptional co-repressor that interacts with nuclear hormone receptors. Nature $\underline{377}, 454-457$

Colston K, Colston MJ,Feldman D (1981): 1,25-dihydroxyVitamin D3 and malignant melanoma: the presence of receptors and inhibition of cell growth in culture. Endocrinology $\underline{108}$, 1083-1086

Colston KW, Chander SK, Mackay AG,Coombes RC (1992): Effects of synthetic Vitamin D3 analogues on breast cancer cell proliferation in vivo and in vitro. Biochem Pharmacol 44, 693-702

Conde I, Paniagua R, Fraile B, Ruiz A,Arenas MI (2004): Expression of Vitamin D3 receptor and retinoid receptors in human breast cancer: identification of potential heterodimeric receptors. Int J Oncol 25, 1183-1191

Cross HS, Bareis P, Hofer H, Bischof MG, Bajna E, Kriwanek S, Bonner E,Peterlik M (2001): 25-HydroxyVitamin D3(3)-1alpha-hydroxylase and Vitamin D3 receptor gene expression in human colonic mucosa is elevated during early cancerogenesis. Steroids $\underline{66}, 287-292$

Cross HS, Bises G, Lechner D, Manhardt T,Kallay E (2005): The Vitamin D3 endocrine system of the gut--its possible role in colorectal cancer prevention. $J$ Steroid Biochem Mol Biol 97, 121-128 
Deeb KK, Trump DL,Johnson CS (2007): Vitamin D3 signalling pathways in cancer: potential for anticancer therapeutics. Nat Rev Cancer $\underline{7}, 684-700$

Delozier-Blanchet CD, Engel E,Walt H (1985): Isochromosome 12p in malignant testicular tumors. Cancer Genet Cytogenet 15, 375-376

Dmitrovsky E, Murty VV, Moy D, Miller WH, Jr., Nanus D, Albino AP, Samaniego F, Bosl G,Chaganti RS (1990): Isochromosome 12p in non-seminoma cell lines: karyologic amplification of c-ki-ras2 without point-mutational activation. Oncogene $\underline{5}, 543-548$

Dusso AS, Brown AJ,Slatopolsky E (2005): Vitamin D3. Am J Physiol Renal Physiol 289, F8-28

Eisman JA, Macintyre I, Martin TJ, Frampton RJ,King RJ (1980): Normal and malignant breast tissue is a target organ for $1,25-(0 \mathrm{H}) 2$ Vitamin D3. Clin Endocrinol (Oxf) 13, 267-272

Ekbom A,Akre O (1998): Increasing incidence of testicular cancer--birth cohort effects. APMIS $\underline{106}, 225-229$; discussion 229-231

Fornace AJ, Jr., Jackman J, Hollander MC, Hoffman-Liebermann B,Liebermann DA (1992): Genotoxic-stress-response genes and growth-arrest genes. gadd, MyD, and other genes induced by treatments eliciting growth arrest. Ann N Y Acad Sci $\underline{663}, 139-153$

Friedrich M, Rafi L, Tilgen W, Schmidt W,Reichrath J (1998): Expression of 1,25dihydroxy Vitamin D3 receptor in breast carcinoma. J Histochem Cytochem 46, $1335-1337$

Friedrich M, Rafi L, Mitschele T, Tilgen W, Schmidt W, Reichrath J (2003): Analysis of the Vitamin D3 system in cervical carcinomas, breast cancer and ovarian cancer. Recent Results Cancer Res 164, 239-246

Getzenberg RH, Light BW, Lapco PE, Konety BR, Nangia AK, Acierno JS, Dhir R, Shurin Z, Day RS, Trump DL (1997): Vitamin D3 inhibition of prostate adenocarcinoma growth and metastasis in the Dunning rat prostate model system. Urology $\underline{50}$, 999-1006

Gottlicher M, Minucci S, Zhu P, Kramer OH, Schimpf A, Giavara S, Sleeman JP, Lo Coco F, Nervi C, Pelicci PG (2001): Valproic acid defines a novel class of HDAC inhibitors inducing differentiation of transformed cells. EMBO J $\underline{20}$, 6969-6978

Gray A, Guillou L, Zufferey J, Rey F, Kurt AM, Jichlinski P, Leisinger HJ,Benhattar J (1998): Persistence of parvovirus B19 DNA in testis of patients with testicular germ cell tumours. J Gen Virol 79 (Pt 3), 573-579

Haag P, Hanhart N,Müller M: Hodentumoren; in: Gynäkologie und Urologie für Studium und Praxis. Müller M; 3.Auflage; Medizinische Verlags- und Informationsdienste; Breisach 2007/08; 366-370

Hansen CM, Hamberg KJ, Binderup E,Binderup L (2000): Seocalcitol (EB 1089): a Vitamin D3 analogue of anti-cancer potential. Background, design, synthesis, pre-clinical and clinical evaluation. Curr Pharm Des $\underline{6}$, 803-828

Haussler MR, Whitfield GK, Haussler CA, Hsieh JC, Thompson PD, Selznick SH, Dominguez CE,Jurutka PW (1998): The nuclear Vitamin D3 receptor: biological and molecular regulatory properties revealed. J Bone Miner Res $\underline{13}$, 325-349 
Herbst H, Sauter M,Mueller-Lantzsch N (1996): Expression of human endogenous retrovirus $\mathrm{K}$ elements in germ cell and trophoblastic tumors. Am J Pathol $\underline{149}$, 1727-1735

Hershberger PA, Yu WD, Modzelewski RA, Rueger RM, Johnson CS,Trump DL (2001): Calcitriol (1,25-dihydroxycholecalciferol) enhances paclitaxel antitumor activity in vitro and in vivo and accelerates paclitaxel-induced apoptosis. Clin Cancer Res $\underline{7}$, 1043-1051

Hershberger PA, McGuire TF, Yu WD, Zuhowski EG, Schellens JH, Egorin MJ, Trump DL,Johnson CS (2002): Cisplatin potentiates 1,25-dihydroxyVitamin D3-induced apoptosis in association with increased mitogen-activated protein kinase kinase kinase 1 (MEKK-1) expression. Mol Cancer Ther 1 , 821-829

Hewison M, Zehnder D, Bland R,Stewart PM (2000): 1alpha-Hydroxylase and the action of Vitamin D3. J Mol Endocrinol 25, 141-148

Hoei-Hansen CE, Holm M, Rajpert-De Meyts E,Skakkebaek NE (2003): Histological evidence of testicular dysgenesis in contralateral biopsies from 218 patients with testicular germ cell cancer. J Pathol 200, 370-374

Hollis BW (2005): Circulating 25-hydroxyVitamin D3 levels indicative of Vitamin D3 sufficiency: implications for establishing a new effective dietary intake recommendation for Vitamin D3. J Nutr 135, 317-322

Horlein AJ, Naar AM, Heinzel T, Torchia J, Gloss B, Kurokawa R, Ryan A, Kamei Y, Soderstrom M, Glass CK (1995): Ligand-independent repression by the thyroid hormone receptor mediated by a nuclear receptor co-repressor. Nature 377, 397-404

Houldsworth J, Reuter V, Bosl GJ,Chaganti RS (1997): Aberrant expression of cyclin $\mathrm{D} 2$ is an early event in human male germ cell tumorigenesis. Cell Growth Differ $\underline{8}, 293-299$

Hsieh JC, Shimizu Y, Minoshima S, Shimizu N, Haussler CA, Jurutka PW,Haussler MR (1998): Novel nuclear localization signal between the two DNA-binding zinc fingers in the human Vitamin D3 receptor. J Cell Biochem $\underline{70}, 94-109$

Jacobsen R, Bostofte E, Engholm G, Hansen J, Skakkebaek NE, Moller H (2000): Fertility and offspring sex ratio of men who develop testicular cancer: a record linkage study. Hum Reprod $\underline{15}$, 1958-1961

Jensen SS, Madsen MW, Lukas J, Binderup L,Bartek J (2001): Inhibitory effects of 1alpha,25-dihydroxyVitamin D3 on the G(1)-S phase-controlling machinery. Mol Endocrinol 15, 1370-1380

Khadzkou K, Buchwald P, Westin G, Dralle H, Akerstrom G,Hellman P (2006): 25hydroxyVitamin D3 1alpha-hydroxylase and Vitamin D3 receptor expression in papillary thyroid carcinoma. J Histochem Cytochem 54, 355-361

Kotlyarov A, Yannoni Y, Fritz S, Laass K, Telliez JB, Pitman D, Lin LL,Gaestel M (2002): Distinct cellular functions of MK2. Mol Cell Biol 22, 4827-4835

Krege S, Beyer J, Souchon R, Albers P, Albrecht W, Algaba F, Bamberg M, Bodrogi I, Bokemeyer C, Cavallin-Stahl E (2008a): European consensus conference on diagnosis and treatment of germ cell cancer: a report of the second meeting of the European Germ Cell Cancer Consensus Group (EGCCCG): part II. Eur Urol $\underline{53}, 497-513$

Krege S, Beyer J, Souchon R, Albers P, Albrecht W, Algaba F, Bamberg M, Bodrogi I, Bokemeyer C, Cavallin-Stahl E (2008b): European consensus conference 
on diagnosis and treatment of germ cell cancer: a report of the second meeting of the European Germ Cell Cancer Consensus group (EGCCCG): part I. Eur Urol $\underline{53}, 478-496$

Kumar B, Koul S, Petersen J, Khandrika L, Hwa JS, Meacham RB, Wilson S,Koul HK (2010): p38 mitogen-activated protein kinase-driven MAPKAPK2 regulates invasion of bladder cancer by modulation of MMP-2 and MMP-9 activity. Cancer Res $\underline{70}$, 832-841

Lee JW, Choi HS, Gyuris J, Brent R,Moore DD (1995): Two classes of proteins dependent on either the presence or absence of thyroid hormone for interaction with the thyroid hormone receptor. Mol Endocrinol $\underline{9}$, 243-254

Li P, Li C, Zhao X, Zhang X, Nicosia SV,Bai W (2004): p27(Kip1) stabilization and $\mathrm{G}(1)$ arrest by 1,25 -dihydroxyVitamin $\mathrm{D}(3)$ in ovarian cancer cells mediated through down-regulation of cyclin E/cyclin-dependent kinase 2 and Skp1Cullin-F-box protein/Skp2 ubiquitin ligase. J Biol Chem 279, 25260-25267

Liebermann DA,Hoffman B (1998): MyD genes in negative growth control. Oncogene $17,3319-3329$

Light BW, Yu WD, McElwain MC, Russell DM, Trump DL,Johnson CS (1997): Potentiation of cisplatin antitumor activity using a Vitamin D3 analogue in a murine squamous cell carcinoma model system. Cancer Res $\underline{57}$, 3759-3764

Liu M, Lee MH, Cohen M, Bommakanti M,Freedman LP (1996): Transcriptional activation of the Cdk inhibitor p21 by Vitamin D3 leads to the induced differentiation of the myelomonocytic cell line U937. Genes Dev $\underline{10}, 142-153$

Liu W, Tretiakova M, Kong J, Turkyilmaz M, Li YC,Krausz T (2006): Expression of Vitamin D3 receptor in kidney tumors. Hum Pathol 37, 1268-1278

Livak KJ,Schmittgen TD (2001): Analysis of relative gene expression data using realtime quantitative PCR and the 2(-Delta Delta C(T)) Method. Methods. 25, $402-$ 408

Ly LH, Zhao XY, Holloway L,Feldman D (1999): Liarozole acts synergistically with 1alpha,25-dihydroxyVitamin D3 to inhibit growth of DU 145 human prostate cancer cells by blocking 24-hydroxylase activity. Endocrinology 140, 20712076

Mantell DJ, Owens PE, Bundred NJ, Mawer EB,Canfield AE (2000): 1 alpha,25dihydroxyVitamin $\mathrm{D}(3)$ inhibits angiogenesis in vitro and in vivo. Circ Res $\underline{87}$, 214-220

Masuda S,Jones G (2003): Vitamin D3 analogs--drug design based on proteins involved in Vitamin D3 signal transduction. Curr Drug Targets Immune Endocr Metabol Disord $\underline{3}, 43-66$

McGuire TF, Trump DL,Johnson CS (2001): Vitamin D(3)-induced apoptosis of murine squamous cell carcinoma cells. Selective induction of caspasedependent MEK cleavage and up-regulation of MEKK-1. J Biol Chem $\underline{276}$, 26365-26373

Menezes RJ, Cheney RT, Husain A, Tretiakova M, Loewen G, Johnson CS, Jayaprakash V, Moysich KB, Salgia R, Reid ME (2008): Vitamin D3 receptor expression in normal, premalignant, and malignant human lung tissue. Cancer Epidemiol Biomarkers Prev 17, 1104-1110

Michigami T, Suga A, Yamazaki M, Shimizu C, Cai G, Okada S,Ozono K (1999): Identification of amino acid sequence in the hinge region of human Vitamin D3 
receptor that transfers a cytosolic protein to the nucleus. J Biol Chem $\underline{274}$, 33531-33538

Mikuz G: Männliche Geschlechtsorgane; in: Pathologie. Böcker W; Denk H; Heitz, P $\mathrm{U}$; Moch H; 4.Auflage; Elsevier GmbH; München, Jena 2008; 900-908

Mita H, Tsutsui J, Takekawa M, Witten EA,Saito H (2002): Regulation of MTK1/MEKK4 kinase activity by its $\mathrm{N}$-terminal autoinhibitory domain and GADD45 binding. Mol Cell Biol 22, 4544-4555

Mitschele T, Diesel B, Friedrich M, Meineke V, Maas RM, Gartner BC, Kamradt J, Meese E, Tilgen W,Reichrath J (2004): Analysis of the Vitamin D3 system in basal cell carcinomas (BCCs). Lab Invest $\underline{84}$, 693-702

Moffatt KA, Johannes WU,Miller GJ (1999): 1Alpha,25dihydroxyVitamin D3 and platinum drugs act synergistically to inhibit the growth of prostate cancer cell lines. Clin Cancer Res $\underline{5}, 695-703$

Nagy L, Kao HY, Chakravarti D, Lin RJ, Hassig CA, Ayer DE, Schreiber SL,Evans RM (1997): Nuclear receptor repression mediated by a complex containing SMRT, mSin3A, and histone deacetylase. Cell $\underline{89}$, 373-380

Nakagawa K, Kawaura A, Kato S, Takeda E,Okano T (2005): 1 alpha,25DihydroxyVitamin $\mathrm{D}(3)$ is a preventive factor in the metastasis of lung cancer. Carcinogenesis 26, 429-440

Papaioannou VE, McBurney MW, Gardner RL,Evans MJ (1975): Fate of teratocarcinoma cells injected into early mouse embryos. Nature $\underline{258}, 70-73$

Parise RA, Egorin MJ, Kanterewicz B, Taimi M, Petkovich M, Lew AM, Chuang SS, Nichols M, El-Hefnawy T,Hershberger PA (2006): CYP24, the enzyme that catabolizes the antiproliferative agent Vitamin D3, is increased in lung cancer. Int J Cancer 119, 1819-1828

Peehl DM, Seto E, Hsu JY,Feldman D (2002): Preclinical activity of ketoconazole in combination with calcitriol or the Vitamin D3 analogue EB 1089 in prostate cancer cells. J Urol $\underline{168}, 1583-1588$

Pike MC, Chilvers C,Peckham MJ (1986): Effect of age at orchidopexy on risk of testicular cancer. Lancet 1986, 1, 1246-1248

Richardson KS,Zundel W (2005): The emerging role of the COP9 signalosome in cancer. Mol Cancer Res $\underline{3}$, 645-653

Richter WO,Eckardstein Av: Vitaminstoffwechsel; in: Klinische Pathophysiologie. Siegenthaler W, Blum H E; Georg Thieme Verlag; Stuttgart 2006; 232-235

Riede UN, Böhm N,Böcking A: Männliches Genitalsystem; in: Allgemeine und spezielle Pathologie. Riede U-N, Werner M und Schäfer H-E; 5., komplett überarbeitete Auflage; Georg Thieme Verlag; Stuttgart 2004; 920-926

Rodriguez E, Mathew S, Reuter V, Ilson DH, Bosl GJ,Chaganti RS (1992): Cytogenetic analysis of 124 prospectively ascertained male germ cell tumors. Cancer Res $\underline{52}$, 2285-2291

Roelofs H, Mostert MC, Pompe K, Zafarana G, van Oorschot M, van Gurp RJ, Gillis AJ, Stoop H, Beverloo B, Oosterhuis JW (2000): Restricted 12p amplification and RAS mutation in human germ cell tumors of the adult testis. Am J Pathol 157, 1155-1166

Rouse J, Cohen P, Trigon S, Morange M, Alonso-Llamazares A, Zamanillo D, Hunt T,Nebreda AR (1994): A novel kinase cascade triggered by stress and heat shock that stimulates MAPKAP kinase-2 and phosphorylation of the small heat shock proteins. Cell $\underline{78}, 1027-1037$ 
Samaniego F, Rodriguez E, Houldsworth J, Murty VV, Ladanyi M, Lele KP, Chen QG, Dmitrovsky E, Geller NL, Reuter V (1990): Cytogenetic and molecular analysis of human male germ cell tumors: chromosome 12 abnormalities and gene amplification. Genes Chromosomes Cancer 1, 289-300

Sande S,Privalsky ML (1996): Identification of TRACs (T3 receptor-associating cofactors), a family of cofactors that associate with, and modulate the activity of, nuclear hormone receptors. Mol Endocrinol 10, 813-825

Savage MO,Lowe DG (1990): Gonadal neoplasia and abnormal sexual differentiation. Clin Endocrinol (Oxf) 32, 519-533

Schaefer L, Beermann ML,Miller JB (1999): Coding sequence, genomic organization, chromosomal localization, and expression pattern of the signalosome component Cops2: the mouse homologue of Drosophila alien. Genomics $\underline{56}$, 310-316

Schmidt BA, Rose A, Steinhoff C, Strohmeyer T, Hartmann M,Ackermann R (2001): Up-regulation of cyclin-dependent kinase 4/cyclin D2 expression but downregulation of cyclin-dependent kinase 2 /cyclin $E$ in testicular germ cell tumors. Cancer Res 61, 4214-4221

Schwartz GG, Whitlatch LW, Chen TC, Lokeshwar BL,Holick MF (1998): Human prostate cells synthesize 1,25-dihydroxyVitamin D3 from 25-hydroxyVitamin D3. Cancer Epidemiol Biomarkers Prev ㄱ, 391-395

Seeger M, Kraft R, Ferrell K, Bech-Otschir D, Dumdey R, Schade R, Gordon C, Naumann M,Dubiel W (1998): A novel protein complex involved in signal transduction possessing similarities to $26 \mathrm{~S}$ proteasome subunits. FASEB J $\underline{12}$, 469-478

Shabahang M, Buras RR, Davoodi F, Schumaker LM, Nauta RJ,Evans SR (1993): 1,25-DihydroxyVitamin D3 receptor as a marker of human colon carcinoma cell line differentiation and growth inhibition. Cancer Res $\underline{53}, 3712-3718$

Sherr CJ (1996): Cancer cell cycles. Science 274, 1672-1677

Simboli-Campbell M, Narvaez CJ, Tenniswood M,Welsh J (1996): 1,25DihydroxyVitamin D3 induces morphological and biochemical markers of apoptosis in MCF-7 breast cancer cells. J Steroid Biochem Mol Biol 모, 367376

Skakkebaek NE, Rajpert-De Meyts E,Main KM (2001): Testicular dysgenesis syndrome: an increasingly common developmental disorder with environmental aspects. Hum Reprod 16, 972-978

Skowronski RJ, Peehl DM,Feldman D (1993): Vitamin D3 and prostate cancer: 1,25 dihydroxyVitamin D3 receptors and actions in human prostate cancer cell lines. Endocrinology 132, 1952-1960

Smiraglia DJ, Szymanska J, Kraggerud SM, Lothe RA, Peltomaki P,Plass C (2002): Distinct epigenetic phenotypes in seminomatous and nonseminomatous testicular germ cell tumors. Oncogene 21, 3909-3916

Stokoe D, Campbell DG, Nakielny S, Hidaka H, Leevers SJ, Marshall C,Cohen P (1992): MAPKAP kinase-2; a novel protein kinase activated by mitogenactivated protein kinase. EMBO J 11, 3985-3994

Stokoe D, Caudwell B, Cohen PT, Cohen P (1993): The substrate specificity and structure of mitogen-activated protein (MAP) kinase-activated protein kinase2. Biochem J 296 (Pt 3), 843-849 
Strohmeyer T, Reissmann P, Cordon-Cardo C, Hartmann M, Ackermann R,Slamon D (1991): Correlation between retinoblastoma gene expression and differentiation in human testicular tumors. Proc Natl Acad Sci USA $\underline{88}, 6662$ 6666

Takekawa M,Saito H (1998): A family of stress-inducible GADD45-like proteins mediate activation of the stress-responsive MTK1/MEKK4 MAPKKK. Cell 95 , $521-530$

Takeyama K, Kitanaka S, Sato T, Kobori M, Yanagisawa J,Kato S (1997): 25HydroxyVitamin D3 1alpha-hydroxylase and Vitamin D3 synthesis. Science 277, 1827-1830

Tamimi R,Adham HO: Testicular cancer; in: Textbook of cancer epidemiology. Adham HO, Hunter D, Trichopoulos D; Oxford University Press; Oxford 2000; 429-445

Townsend K, Banwell CM, Guy M, Colston KW, Mansi JL, Stewart PM, Campbell MJ,Hewison M (2005): Autocrine metabolism of Vitamin D3 in normal and malignant breast tissue. Clin Cancer Res 11, 3579-3586

Tront JS, Hoffman B,Liebermann DA (2006): Gadd45a suppresses Ras-driven mammary tumorigenesis by activation of c-Jun NH2-terminal kinase and p38 stress signaling resulting in apoptosis and senescence. Cancer Res $\underline{66}$, 84488454

Tzelepi V, Grivas P, Kefalopoulou Z, Kalofonos H, Varakis JN,Sotiropoulou-Bonikou G (2009): Expression of estrogen receptor co-regulators NCoR and PELP1 in epithelial cells and myofibroblasts of colorectal carcinomas: cytoplasmic translocation of NCoR in epithelial cells correlates with better [corrected] prognosis. Virchows Arch 454, 41-53

Verlinden L, Verstuyf A, Convents R, Marcelis S, Van Camp M,Bouillon R (1998): Action of 1,25(OH)2D3 on the cell cycle genes, cyclin D1, p21 and p27 in MCF-7 cells. Mol Cell Endocrinol 142, 57-65

Wang Q, Yang W, Uytingco MS, Christakos S,Wieder R (2000): 1,25DihydroxyVitamin D3 and all-trans-retinoic acid sensitize breast cancer cells to chemotherapy-induced cell death. Cancer Res 60, 2040-2048

Wang X,Studzinski GP (2001): Activation of extracellular signal-regulated kinases (ERKs) defines the first phase of 1,25-dihydroxyVitamin D3-induced differentiation of HL60 cells. J Cell Biochem $\underline{80}$, 471-482

Weiss MM, Snijders AM, Kuipers EJ, Ylstra B, Pinkel D, Meuwissen SG, van Diest PJ, Albertson DG,Meijer GA (2003): Determination of amplicon boundaries at 20 13.2 in tissue samples of human gastric adenocarcinomas by highresolution microarray comparative genomic hybridization. J Pathol $\underline{200}, 320$ 326

Xu L, Chen S,Bergan RC (2006): MAPKAPK2 and HSP27 are downstream effectors of p38 MAP kinase-mediated matrix metalloproteinase type 2 activation and cell invasion in human prostate cancer. Oncogene 25, 2987-2998

Yasmin R, Williams RM, Xu M,Noy N (2005): Nuclear import of the retinoid X receptor, the Vitamin D3 receptor, and their mutual heterodimer. J Biol Chem. $\underline{280}, 40152-40160$

Ylikomi T, Laaksi I, Lou YR, Martikainen P, Miettinen S, Pennanen P, Purmonen S, Syvala $\mathrm{H}$, Vienonen A,Tuohimaa $P$ (2002): Antiproliferative action of Vitamin D3. Vitam Horm $\underline{64}, 357-406$ 
Zafarana G, Gillis AJ, van Gurp RJ, Olsson PG, Elstrodt F, Stoop H, Millan JL, Oosterhuis JW, Looijenga LH (2002): Coamplification of DAD-R, SOX5, and EKI1 in human testicular seminomas, with specific overexpression of DAD-R, correlates with reduced levels of apoptosis and earlier clinical manifestation. Cancer Res 62, 1822-1831

Zehnder D, Bland R, Williams MC, McNinch RW, Howie AJ, Stewart PM,Hewison M (2001): Extrarenal expression of 25-hydroxyVitamin D(3)-1 alpha-hydroxylase. $\mathrm{J}$ Clin Endocrinol Metab 86, 888-894

Zhang X, Jiang F, Li P, Li C, Ma Q, Nicosia SV,Bai W (2005): Growth suppression of ovarian cancer xenografts in nude mice by Vitamin D3 analogue EB1089. Clin Cancer Res 11, 323-328

Zhao J, Tan BK, Marcelis S, Verstuyf A,Bouillon R (1996): Enhancement of antiproliferative activity of 1alpha,25-dihydroxyVitamin D3 (analogs) by cytochrome P450 enzyme inhibitors is compound- and cell-type specific. J Steroid Biochem Mol Biol 프, 197-202 


\section{Abbildungsverzeichnis}

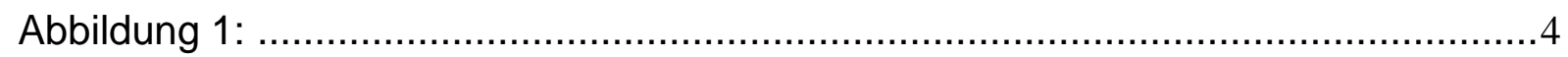

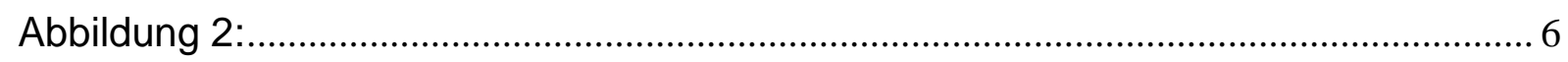

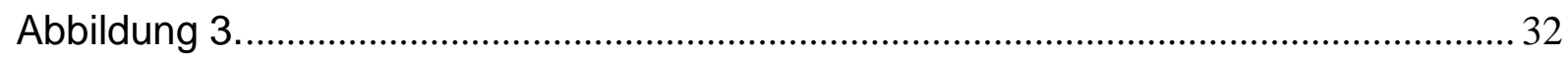

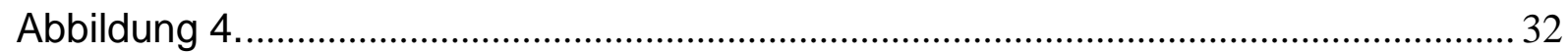

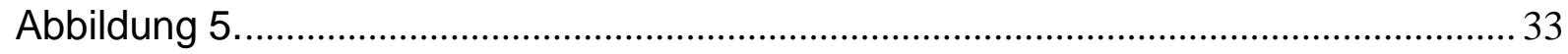

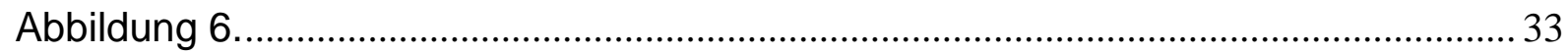

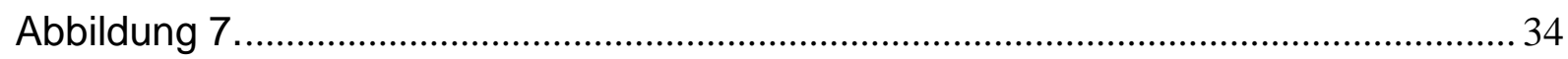

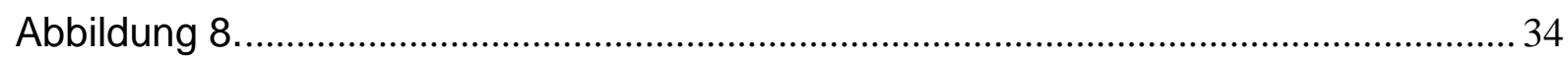

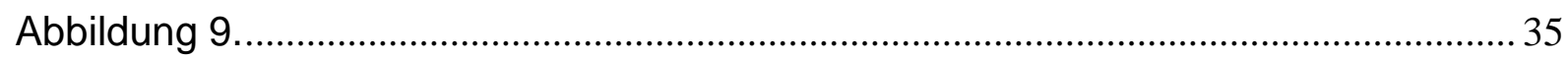

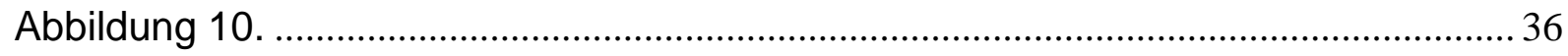

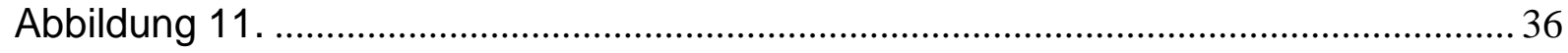

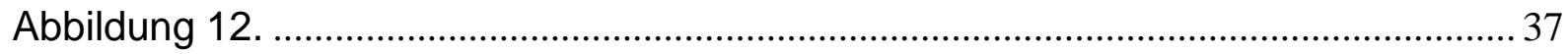

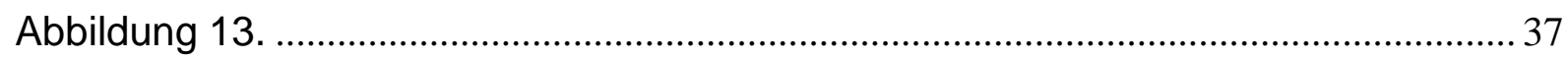

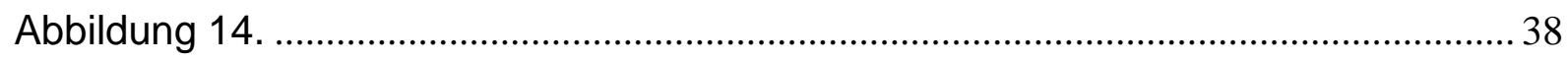

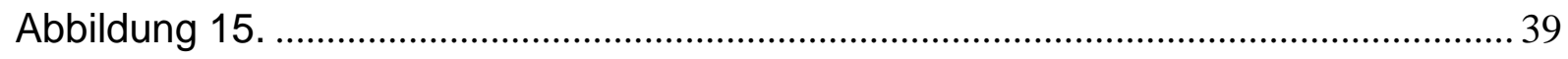

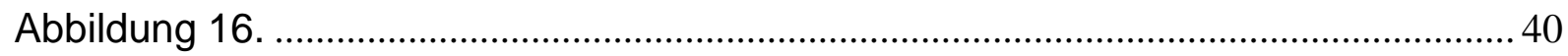

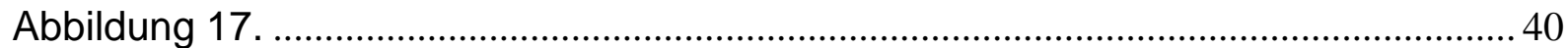

\section{Tabellenverzeichnis}

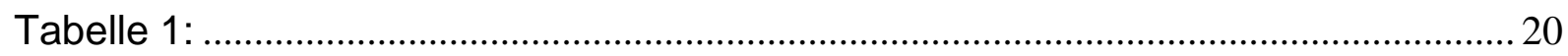

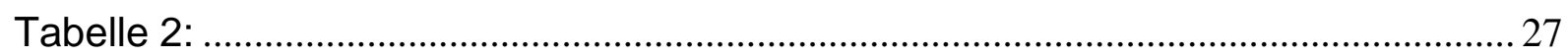

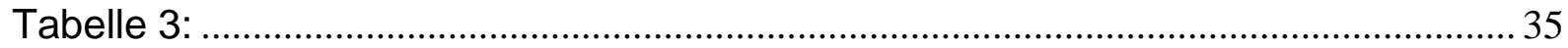




\section{Danksagung:}

Herrn PD Dr. Stefan Schweyer möchte ich für die Überlassung des Themas dieser Arbeit und für die jederzeit geduldige Unterstützung bei wissenschaftlichen Fragestellungen ganz herzlich danken. Sein Engagement sowie das Interesse an meinen Fortschritten trugen maßgeblich zum Gelingen dieser Arbeit bei.

Herrn Prof. H.-J. Radzun möchte ich für die Bereitstellung des Arbeitsplatzes sowie aller nötigen Materialien danken.

Bei den Mitarbeitern des Zentrums Pathologie möchte ich mich besonders bei Anke Klages bedanken, die mir bei allen durchgeführten Untersuchungen dieser Arbeit immer mit Rat und Tat beiseite stand.

Ebenfalls bedanken möchte ich mich bei Frau Kerl, Frau Putzer, Frau Jüneman, Frau Ulbricht und Herrn Kleinhans, welche mir immer wieder hilfreiche Ratschläge bei der Durchführung meiner Laborarbeiten gegeben haben. 


\section{Lebenslauf:}

Ich wurde am 13. April 1983 als erster Sohn von Michael Bremmer und Brigitte Bremmer, geb. Zickgraf, in Ludwigshafen am Rhein geboren.

Die ersten 20 Lebensjahre wuchs ich in meiner Geburtsstadt Ludwigshafen auf. Im Jahre 1989 wurde ich eingeschult und verbrachte die ersten vier Schuljahre meiner schulischen Ausbildung an der Wilhelm Leuschner Grundschule. Meine schulische Weiterbildung setzte ich in den Jahren 1993 bis 2002 am Theodor-Heuss Gymnasium Ludwigshafen fort. Als erste Fremdsprache belegte ich Latein bis einschließlich zur 10. Klasse und bestand erfolgreich das Latinum. Als zweite Fremdsprache belegte ich ab der 7.Klasse bis einschließlich der 13. Klasse Englisch und als dritte Fremdsprache ab der 9. Klasse bis einschließlich der 10. Klasse Französisch. 2002 legte ich an dieser Schule das Abitur mit den Leistungsfächern Biologie, Englisch und Musik ab.

Von April 2002 bis Januar 2003 leistete ich meinen Zivildienst beim Arbeiter Samariter Bund Ludwigshafen ab und machte im Rahmen meines Zivildienstes eine Ausbildung zum Rettungssanitäter.

Zum Sommersemester 2003 nahm ich dann das Studium der Humanmedizin an der Georg-August-Universität Göttingen auf. Im August 2005 legte ich die ärztliche Vorprüfung ab.

Im Sommer 2005 arbeitete ich als studentische Hilfskraft im Zentrum Anatomie in den Fächern Histologie und makroskopische Anatomie unter Prof. Herken.

Im Februar 2006 begann ich in der Abteilung Pathologie von Herrn Prof. Dr. med. H.J. Radzun unter der Leitung von Herrn PD. Dr. S. Schweyer die experimentellen Arbeiten zu der hier vorliegenden Dissertation, die ich Ende 2008 abschloss.

Im November 2009 absolvierte ich erfolgreich den zweiten Abschnitt der ärztlichen Prüfung. 